\title{
ANÁLISE DE CORRESPONDÊNCIA NA IDENTIFICAÇÃO DOS FATORES DE RISCO ASSOCIADOS À DIARRÉIA E À PERFORMANCE DE LEITÕES NA FASE DE LACTAÇÃO
}

\author{
WALDOMIRO BARIONI JÚNIOR \\ Bacharel em Estatística
}

Orientador: Prof. Dr. IRINEU UMBERTO PACKER

Dissertação apresentada à Escola Superior de Agricultura "Luiz de Queiroz ", da Universidade de São Paulo, para obtenção do título de Mestre em Agronomia, Área de Concentração em " Estatística e Experimentação Agronômica ".

P I R A C I C A B A

Estado de São Paulo - Brasil

Abril - 1995 
CATALOGAÇÃO NA PUBLICAÇÃO

DIVISÃO DE BIBLIOTECA E DOCUMENTAÇÃO - CAMPUS "LUIZ DE QUEIROZ"/USP

Barioni Júnior, Waldomiro

Análise de correspondência na identificação dos fatores de risco associados à diarréia e à performance de leitões na fase de lactação. Piracicaba, 1995.

97 p. ilus.

Diss.(Mestre) - ESALQ

Bibliografia.

1. Diarréia em suíno - Fator de risco 2. Leitão em lactação - Doença - Análise Estatística 3. SAS I. Escola Superior de Agricultura Luiz de Queiroz, Piracicaba, SP 


\title{
ANÁLISE DE CORRESPONDÊNCIA NA IDENTIFICAÇ̃̃O DOS FATORES DE RISCO ASSOCIADOS À DIARRÉIA E À PERFORMANCE DE LEITÕES NA FASE DE LACTAÇÃO
}

\author{
WALDOMIRO BARIONI JÚNIOR
}

Aprovado em: 25/05/95

Comissão Julgadora:

TITULARES:

Prof. Dr. Irineu Umberto Packer

ESALQ

Profa. Dra. Clarice G. B. Demétrio

ESALQ

Profa. Dra. Regina Célia Carvalho P. Moran

Prof. Dr. IRINEU UNBBERTO PACKER Orientador 
Aos Meus Pais,

Waldomiro e Lairde,

ofereço.

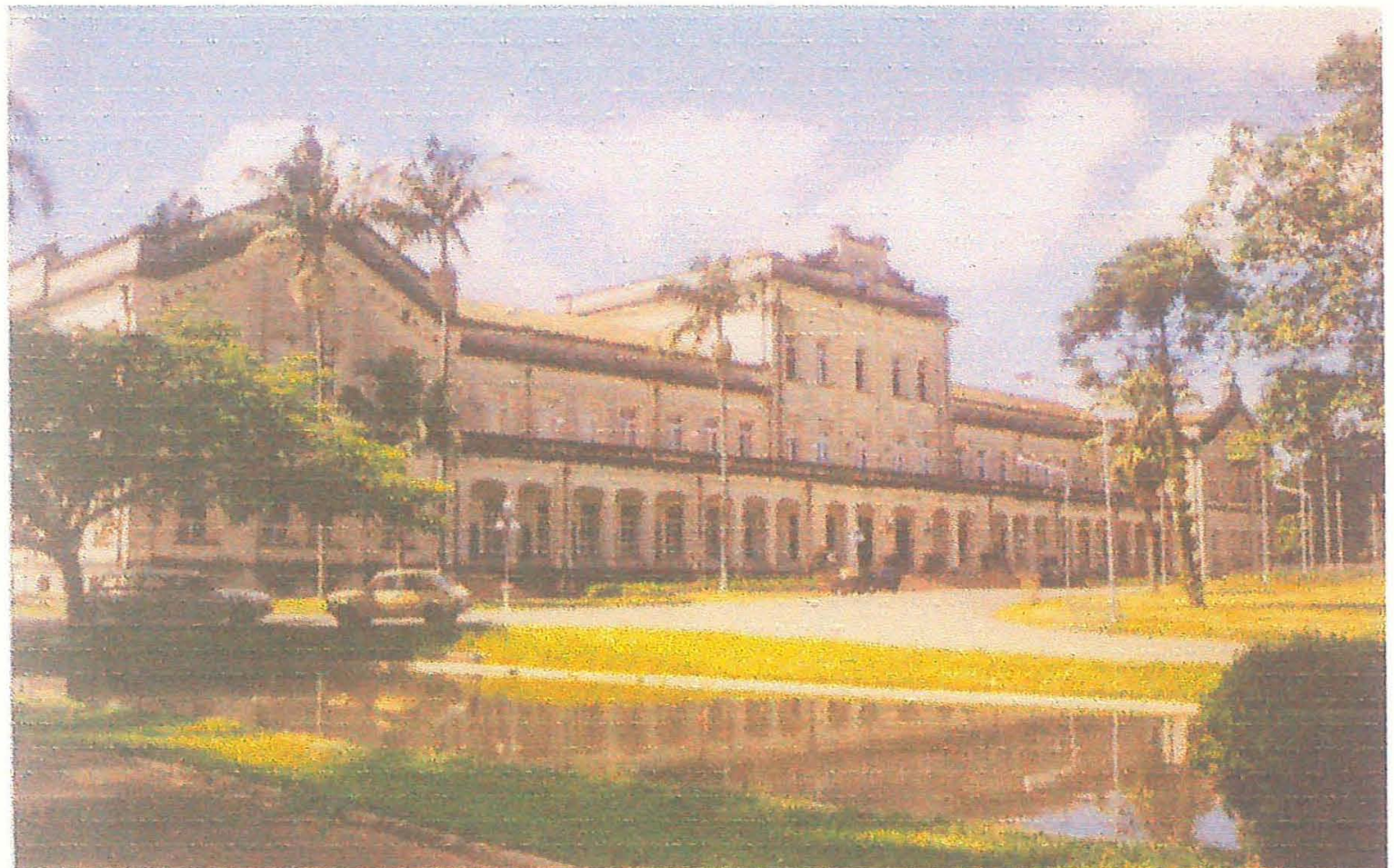

ESALQ 1992-1995.

À minha esposa Roseli,

e ao nosso filho Álvaro Bruno, dedico. 


\section{Agradecimentos}

A DEUS, por estar sempre presente $e$ permitir-me a realização de mais esta missão.

Expresso aqui meus agradecimentos a todos aqueles que de algum modo colaboraram para a realização deste trabalho, em especial:

Ao Prof. Dr. Umberto Irineu Packer, pela orientação, motivação e amizade durante este trabalho.

Aos membros da banca examinadora: Profa. Dra. Regina Célia Carvalho Pinto Moran, (IMECCI-UNICAMP2), Profa. Dra. Clarice Garcia Borges Demétrio, (DME3-ESALQ $\left.Q^{4}-U S P^{5}\right)$, Prof. Dr. Cássio Roberto Mello Godoy, (DME ${ }^{3}$ ESALQ4-USP5) e Pesquisador Dr. Jurij Sobestiansky (CNPSA ${ }^{6}-E M B R A P A^{7}$ ).

Aos Amigos: Ms. Maria Teresa Villalobos Aguayo, Consultora em Estatística da Comissão de Pesquisa da FCM ${ }^{8}-U N I C A M P$, pela sua presteza em auxiliar-me nos momentos de dúvidas e principalmente, no desenvolvimento do Capítulo de Análise de Correspondência.

Prof. Ms. Luis Maria Salvarrey Rebolo, Prof. Ms. João Gil de Luna e Prof. Luiz Gino Farina de Oliveira, Pesquisador Ms. Cicero Moticcelli, Prof. Ms. João Batista e a Turma de 1.992 do Mestrado em Estatística e Experimentação Agronômica da ESALQ-USP.

Aos funcionários, Professores e colaboradores: Profa. Dra. Maria Cristina Stolff Nogueira, Prof. Ms. Gabriel Sarries, Bel. Luciene Brajão e aos estagiários: Fábio A. Carlet, Rafael Daudt e Carlos Rogério S. de Almeida e aos colegas: Carlos José Farbiarz e a aluna Renata Totti. 
iii.

EMBRAPA, como Instituição responsável pelo financiamento e apoio durante a minha permanência nesta Universidade e ao CNPSA, nas pessoas de meus Superiores, em especial à Jerônimo Antônio Fávero, (Chefe do CNPSA) e Claudio Bellaver, (Chefe Adjunto Técnico), pela atenção e reconhecimento as minhas solicitações de prorrogação, sem o que não seria possivel concluir este trabalho.

Ao CNPSA: Aos Pesquisadores: Ms. Nelson Mores e Dr. Jurij Sobestiansky por me possibilitarem estabelecer o primeiro contacto com o problema. Aos Técnicos Especializados: Armando Lopes do Amaral e Vicente Sangoi pela presteza e colaboração. Ao Prof. Dr. Rui Augusto Perestrelo Vieira (IPPAA ${ }^{9}$ - LISBOA/PO) que, naquela oportunidade, como Consultor do CNPSA apresentou-me o método, incentivando-me a estudar o assunto.

Enfim, a todos os meus amigos e colaboradores do CNPSA.

Aos meus pais, irmãs, aos meus sogros e aos meus cunhados que sempre, de algum modo, com a atenção e o carinho que dedicaram à Roseli e ao Álvaro Bruno, tentaram suprir minha ausência, durante estes três últimos anos.

À minha querida esposa Roseli, que muitas vezes, nestes três anos, suportou todos os momentos dificeis, desta fase de nossas vidas, sem se lamentar.

À familia Cella, que me recebeu com atenção, fornecendo todo o apoio desde o inicio deste trabalho.

1. Instituto de Matemática e Estatística e Ciências da Computação - IMECC

2. Universidade Estatual de Campinas - UNICAMP

3. Departamento de Matemática e Estatística - DME

4. Escola Superior de Agricultura "Luiz de Queroz" - ESALQ

5. Universidade de São Paulo - USP

6. Centro Nacional de Pesquisa de Suinos e Aves - CNPSA

7. Empresa Brasileira de Pesquisa Agropecuária - EMBRAPA

8. Faculdade de Ciências Médicas - FCM

9. Instituto de Proteção da Produção Agro-Alimentar - IPPAA 


\section{SUMÁRIO}

Página

RESUMO vi

SUMMARY vii

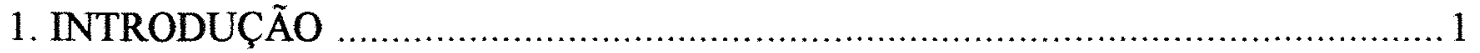

2. REVISÃO DA LITERATURA

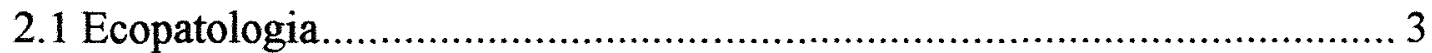

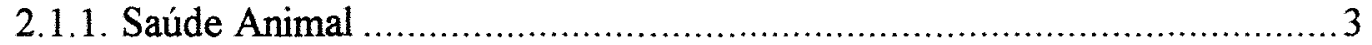

2.1.2. Sistema de Produção de Suínos ......................................................... 4

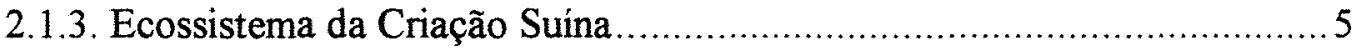

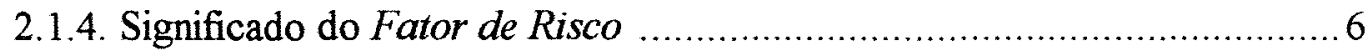

2.1.5. Importância de Estudos Ecopatólógicos .......................................... 7

2.1.6. Sequência no Desenvolvimento de Estudos Ecopatológicos ....................9

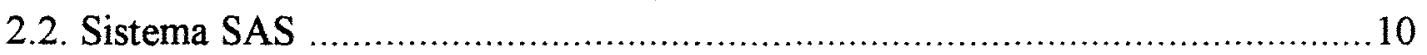

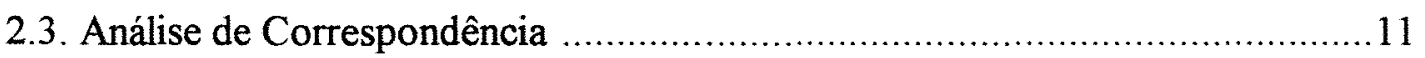

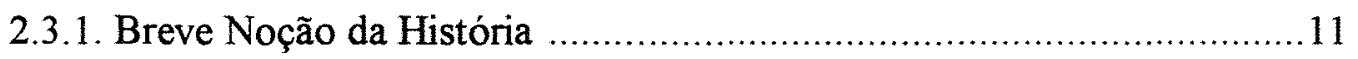

2.3.2. Objetivo da Análise de Correspondência ............................................11

2.3.3. Fundamentos Teórico e Algébrico do Método......................................12

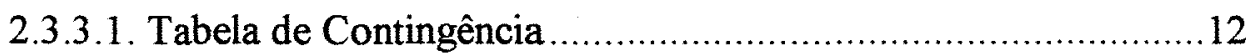

2.3.3.2. Matriz de Freqüências Relativas ..........................................13

2.3.3.3. Perfil Linha e Perfil Coluna ................................................... 14

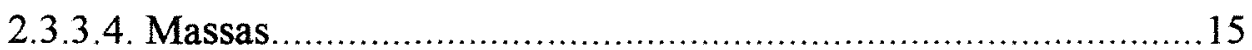

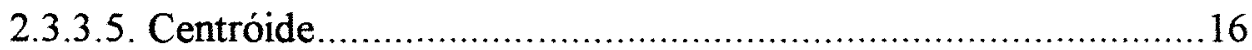

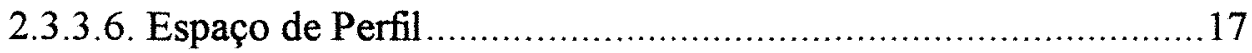

2.3.3.7. Estatística $\chi^{2}$, Distância $\chi^{2}$ e Inércia........................................

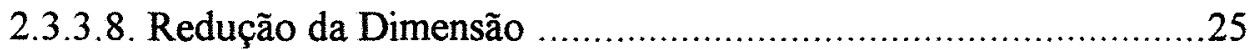

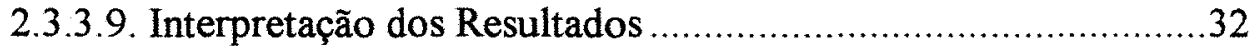

2.3.3.10. Reconstrução da Tabela de Contingência ................................37

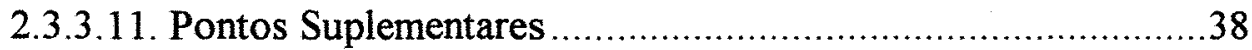

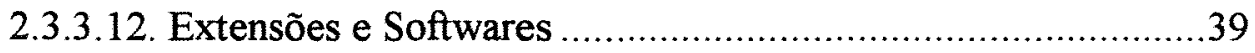




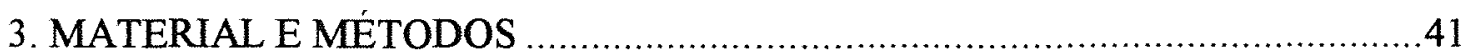

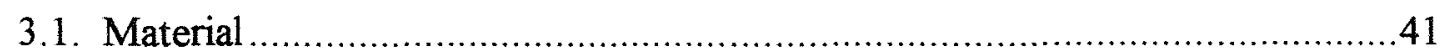

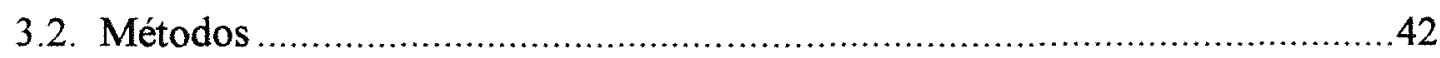

3.2.1. Realização da Coleta de Dados no Sistema de Produção ……...............42

3.2.2. Dados Recolhidos deste o Parto até o Desmame …...............................43

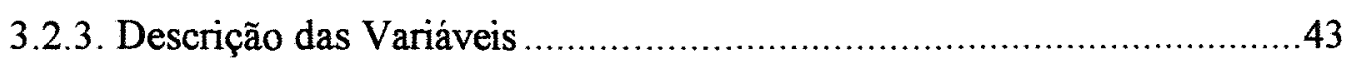

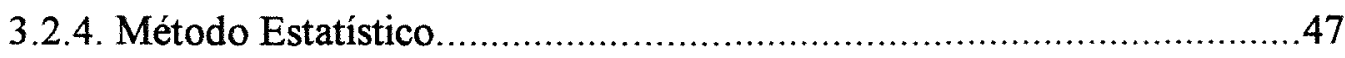

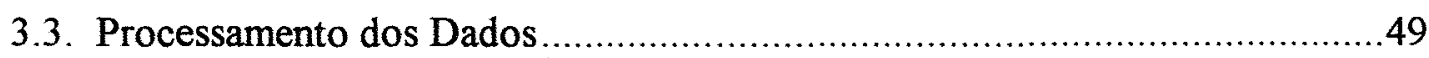

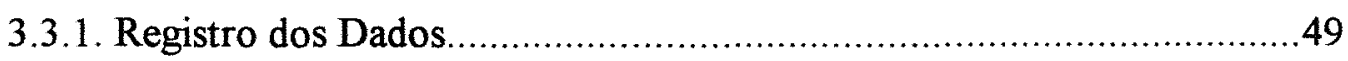

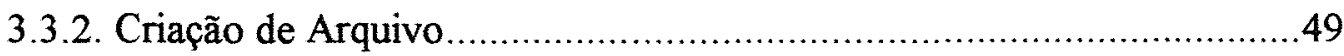

3.3.3. Geração de Variáveis a partir das Variáveis Originais ..........................50

3.3.3.1. Arquivo Resultante após Geração de Variáveis .......................57

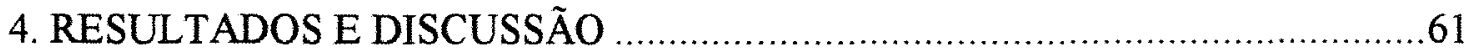

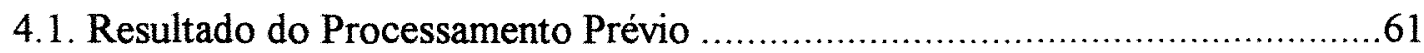

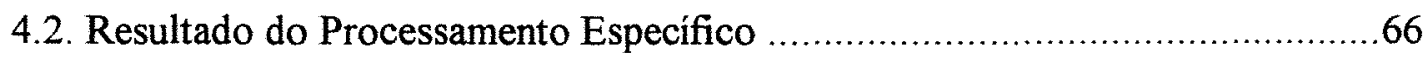

4.2.1. Análise de Correspondência para "DIARREIA" ..................................66

4.2.1.1. Interpretação do Mapa para "DIARREIA" ................................69

4.2.2. Análise de Correspondência para "GPM35" ......................................71

4.2.2.1. Interpretação do Mapa para "GPM35" ...................................74

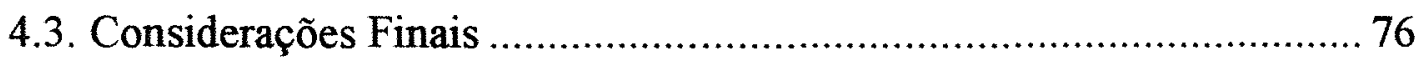

5. CONCLUSÕES

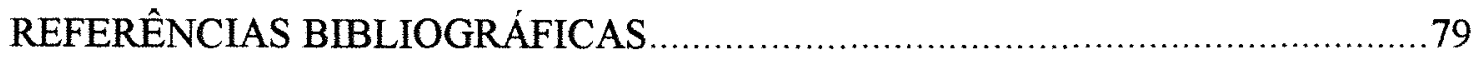

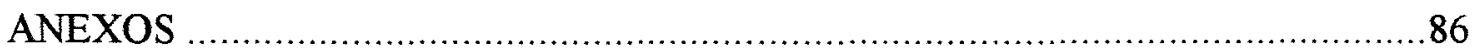

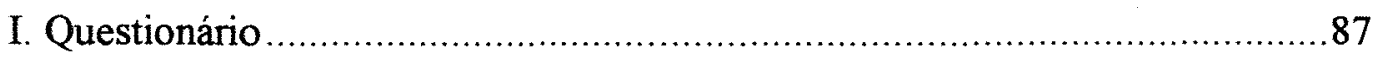

I I. Programa de Análise de Correspondência para "DIARREIA" .......................94

I I I. Programa de Análise de Correspondência para "GPM35" ............................96 


\title{
ANÁLISE DE CORRESPONDÊNCIA NA IDENTIFICAÇÃO DOS FATORES DE RISCO ASSOCIADOS À DIARRÉIA E À PERFORMANCE DE LEITÕES NA FASE DE LACTAÇÃO
}

\author{
Autor: WALDOMIRO BARIONI JÚNIOR \\ Orientador: PROF. DR. IRINEU UMBERTO PACKER
}

\section{RESUMO}

$\mathrm{Na}$ suinocultura intensiva brasileira, as doenças são consideradas como as grandes responsáveis pela baixa performance e perda de animais. Estudos ecopatológicos iniciados em 1988 por pesquisadores do Centro Nacional de Pesquisa de Suínos e Aves - EMBRAPA, evidenciaram uma elevada prevalência de diarréia e uma acentuada morbidade em leitões lactentes. Reconhecendo a etiologia multifatorial desta síndrome, procurou-se adaptar no presente trabalho a metodologia desenvolvida na França para a identificação dos fatores de risco para esta patologia.

Os dados foram coletados mediante a aplicação de um questionário em 85 granjas de suínos, selecionadas ao acaso, situadas na região Oeste de Santa Catarina e no Sudoeste do Paraná. O questionário continha variáveis que caracterizavam o ecossistema de leitões na fase de lactação.

Devido ao caráter qualitativo de muitas das informações a análise estatística dos dados foi fundamentada na Análise de Correspondência, técnica especifica para dados categorizados, usando o sistema SAS (Statistical Analysis Sistem). A análise identificou 8 fatores de risco mais importantes associados com a diarréia e também os 12 mais importantes que afetam o ganho de peso dos leitões. Esses resultados eram facilmente interpretados na forma de mapas.

Os mapas indicaram que: a prática do vazio sanitário acima de 5 dias, a presença do escamoteador com área disponível para os leitões com pelo menos $0,70 \mathrm{~m}^{2} \mathrm{e}$ a manutenção dos animais a uma temperatura menor que $28^{\circ} \mathrm{C}$ são alguns fatores que podem previnir a diarréia na granja e consequentemente melhorar o ganho de peso dos animais.

Com base nestes indicadores, poderão implementar-se programas preventivos visando a melhoria da performance e do estado sanitário dos animais, reduzindo o uso de medicamentos. 


\title{
IDENTIFICATION OF RISK FACTORS ASSOCIATED WITH DIARRHEA AND GROWTH OF NURSING PIGS WITH THE USE OF THE ANALYSIS OF CORRESPONDENCE
}

\author{
Author: WALDOMIRO BARIONI JUNIOR \\ Adviser: Prof. Dr. IRINEU UMBERTO PACKER
}

\section{SUMMARY}

In the Brazilian pig production, diseases are considered yet the great reason of reduced performance and loss of animals. Pathological studies carried by Brazilian Agricultural Research Company (EMBRAPA) since 1988, showed high prevalence of diarrhea and high morbidity in nursing piglets. Considering the several etiological causes of this syndrome this study was conducted in order to adapt one methodology developed in France with the objective of identifying some of the risk factors associated with that pathology.

Data was collected through a survey in 85 Brazilian pig farms in the States of Santa Catarina and Parana and they were related to management, nutrition, health care, facilities and environmental conditions. Since most variables were categorized, it was employed a Analysis of Correspondence, using the SAS system (Statistical Analysis Sistem). This analysis identified the eight most important risk factors related to diarrhea and also the twelve most important factors related to weight gain in piglets. These results were easily interpreted through the use of maps. Therefore, it was indicated that some of the factors that can prevent diarrhea and increase weight gain are: use of at least a 5d-period of empty farrowing house between groups; use of a creep area of at least $0.70 \mathrm{~m}^{2}$ and keep the animals at a temperature lower than $28^{\circ} \mathrm{C}$.

On the basis of these indicators, new management programs can be stabilished in order to improve performance and health status of animals, reducing the use of medication. 


\section{INTRODUÇÃO}

A suinocultura brasileira teve um enorme avanço nas últimas décadas evoluindo de uma criação extensiva, com suínos de baixa produtividade, para sistemas de produção tecnificados, com animais geneticamente superiores e mais exigentes quanto ao manejo, nutrição e meio ambiente.

A produção intensiva envolve sistemas de produção nos quais cada aspecto da vida animal, incluindo a disponibilidade de recursos, é determinado pelo homem, do qual o animal se torna praticamente dependente. Ela tem por objetivo obter dos animais a máxima produtividade de que são potencial e intrinsicamente capazes e consequentemente uma boa lucratividade com base na produtividade e redução de custos de produção.

Hoje as doenças são ainda a maior causa de perda da produção e lucros em rebanhos de suínos. Calcula-se que $75 \%$ ou mais das perdas econômicas em uma criação intensiva de suínos estejam relacionadas com doenças multifatoriais

Diante do cenário exposto, o conceito de doença multifatorial, definido como alguns complexos patológicos que afetam os suínos criados sob condições intensivas, é amplamente aceito.

A complexidade na inter-relação das variáveis de um sistema de produção, pode ser analisada através de estudos ecopatológicos, os quais visam identificar, no final de uma avaliação metódica e detalhada nos rebanhos de suínos, as circunstâncias mais importantes associadas ao fenômeno patológico; circunstâncias estas denominadas de fatores de risco.

No Brasil, o Centro Nacional de Pesquisa de Suínos e Aves CNPSA/EMBRAPA, é pioneiro no desenvolvimento de pesquisas na área de ecopatologia em suínos. Nestes estudos, iniciados em 1988 direcionados aos problemas entéricos de leitões lactentes e na desmama MORES et al. (1988), constataram que as 
perdas por mortalidade em leitões latentes podem atingir até $30 \%$, além da baixa performance e custos com medicamentos.

A importância econômica dos estudos ecopatológicos pode ser exemplificada por um trabalho realizado em Portugal, no qual a prevalência de infecções urinárias em fêmeas suínas em produção foi reduzida de $49 \%$ para $9 \%$ somente mediante correção dos fatores de risco. Deve-se ressaltar que neste estudo PERESTRELO et al., (1991) não utilizaram medidas medicamentosa como meio de controle.

Como os estudos ecopatológicos são caracterizados por um grande número de informações, tornando-os ainda mais complexos, faz com que, a presença da estatística, nestes estudos, seja fundamental. À aplicação adequada de seus métodos e técnicas, na análise dos dados, poderão facilitar a interpretação dos resultados, descrevendo-os de forma simples, coerente e comunicável. Nesta etapa, visando ainda minimizar o tempo de análise e a confiabilidade dos resultados é indispensável o uso de recursos computacionais e softwares especializados para resgistrar, manipular e análisar os dados.

O presente trabalho tem por objetivo adaptar a metodologia desenvolvida na França para identificação de fatores de risco associados à diarréia e à performance de leitões lactentes em criações intensivas da Região Sul Brasileira bem como verificar se a utilização do sistema SAS é conveniente neste tipo de estudo. 


\section{REVISÃO DA LITERATURA}

\subsection{Ecopatologia}

A ecopatologia é uma área da epidemiologia que estuda as doenças através da análise exaustiva do meio-ambiente, bem como dos agentes infecciosos envolvidos, cujos dados são observados e registrados nas próprias criações. Este procedimento é denominado de Estudo Observacional Nestes casos, os fenômenos patológicos surgem espontaneamente, sem nenhum artificio e independem da vontade do homem, diferindo dos estudos experimentais tradicionais, onde a maior parte das variáveis são previamente fixadas, como por exemplo: o inóculo, a dose, a densidade da baia e entre outros

Atraves de estudos ecopatológicos pode-se levantar as circunstâncias mais importantes associadas a um determinado problema patológico e verificar se a alteração simultânea de várias delas possibilita condições propicias ao seu desaparecimento. Desta forma é possível controlar determinados problemas de saúde animal agindo sobre as condições em que os animais são criados.

\subsubsection{Saúde Animal}

A saúde animal é um estado que reflete a harmonia de uma série de fatores que agem de forma inter-relacionada. Esses fatores indissociáveis são de origem genética, nutricional, zootécnica, ecológica, patológica, humana, social e econômica (VIEIRA, 1989), passando por características vitais inerentes ao animal até a presença da menor quantidade de estímulos causadores de estresse. 
O homem, pressionado por causas econômicas e sociais, passou a usar sistemas de produção que promoveram a instauração de uma saúde artificial, opondo-se à saúde natural dos animais em criações extensivas independentes e pouco perturbada pela ação humana (TUFFERY, 1986). Neste contexto, uma concepção dinâmica de doença propõe a existência de um desequilibrio entre o organismo e as condições em que os animais são mantidos o qual tem como consequência alterações em processos fisiológicos tornando os patológicos ou disfuncionais. Desta forma o termo doença tem um significado mais amplo do que uma simples condição causada por microorganismo.

No que concerne à doença, o produtor de suínos procura explicar determinados problemas sanitários através da simples presença de um vírus ou de uma bactéria, evitando "aceitar" que a ocorrência de determinadas patologias estão relacionadas com o ecossistema do suíno, isto é, às condições em que os animais são mantidos. Assim sendo, em muitas situações o produtor procura na utilização de antibióticos a solução para várias situações patológicas. Neste ponto, o papel da Veterinária Preventiva é fundamental, pois galgada em conhecimetos científicos consegue determinar as inter-relações das variáveis causais que compõe o problema e atuando sobre eles prevení-lo.

\subsubsection{Sistema de Produção de Suínos}

De acordo com GOMES et al. (1992) os sistemas de produção de suínos podem ser classificados em: confinado de alta tecnologia e eficiência, confinado tradicional de baixo custo e/ou baixa tecnologia, criação ao ar livre e extensivo. Estes sistemas por sua vez, segundo o tipo de produção podem ser de ciclo completo, ou no caso em que envolve apenas uma determinada fase do ciclo de produção, em produção de leitões, produção de terminados ou produção de reprodutores. 
A FIGURA 1 apresenta as fases de um sistema de produção de suínos de ciclo completo.

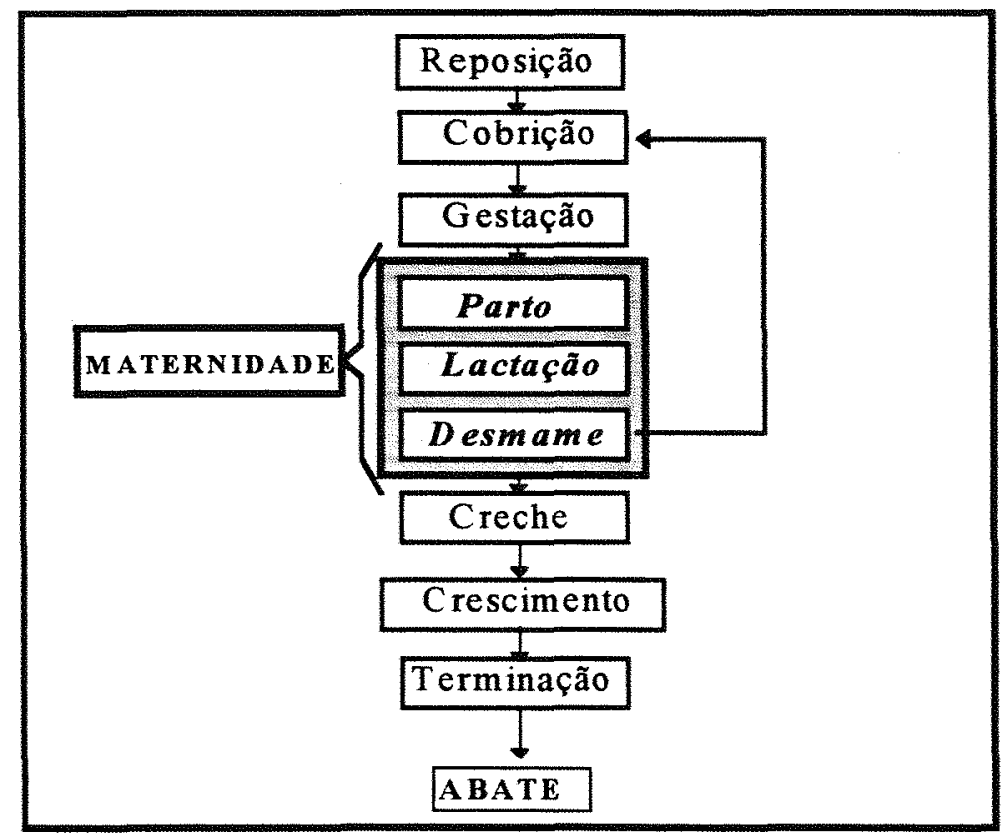

FIGURA 1. Sistema de ciclo completo de produção de suínos.

\subsubsection{Ecossistema do Suíno}

A definição do ecossistema suíno comporta duas variáveis resultantes: performance e sanidade e seis grandes familias de variáveis causais, as quais são: produtor, instalação, animais, alimentação e água, contaminantes e manejo do rebanho.

A organização e o nível de harmonia entre os componentes do ecossistema de suíno é expresso pelo estatus de saúde do sistema e consequentemente pelos resultados de performance.

Em um sistema de produção de suínos o proprietário desempenha o papel mais importante, uma vez que é ele responsável pela maneira com que o sistema é conduzido tanto nos aspectos financeiros de produção bem como pela compatibilização entre disponibilidades de recursos de ordem humana, genética, sanitária e física. 
A representação do ecossistema do suíno num sistema de produção otimizado é esquematizado utilizando-se a imagem de um hexágono regular (FIGURA 2) para ilustrar as relações entre as famílias de variáveis causais, estas também chamandas de variáveis de entrada (MADEC, 1986).

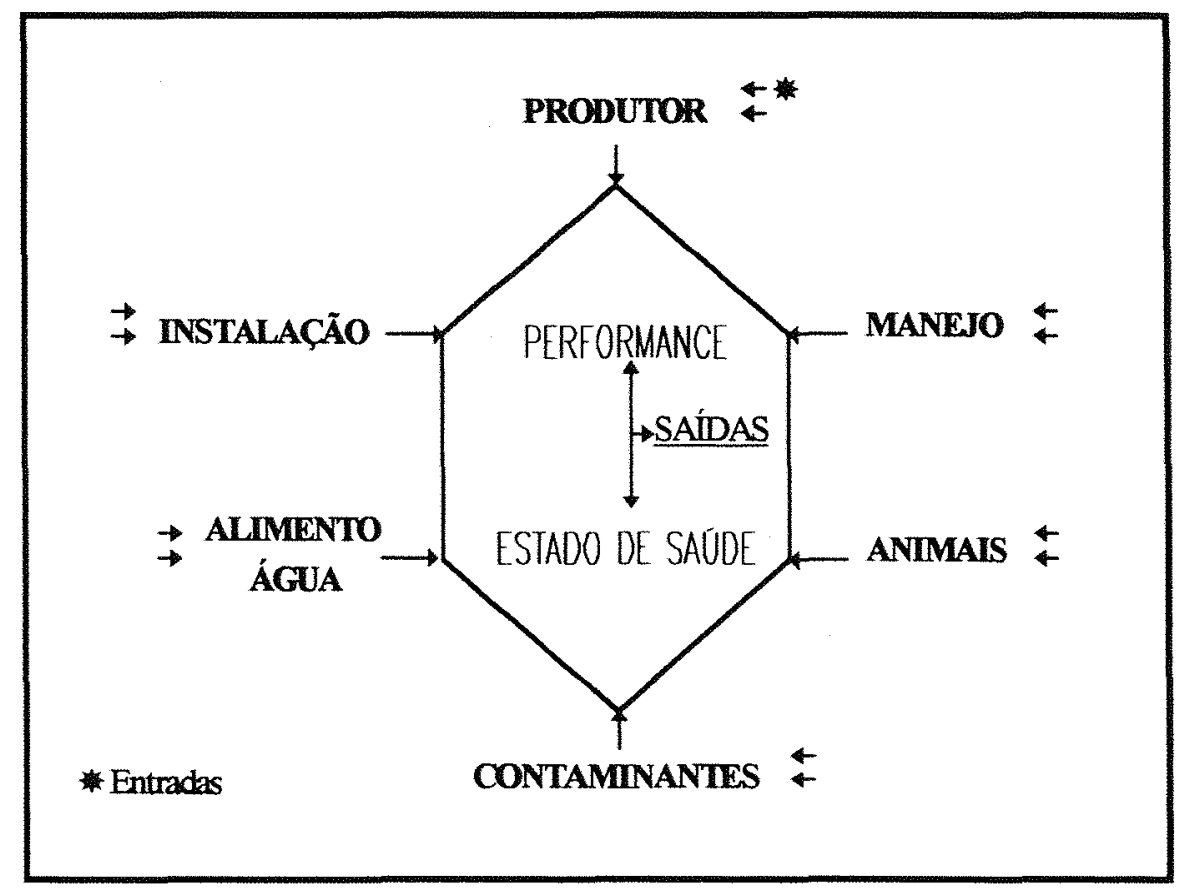

FIGURA 2. Representação do ecossistema do suíno em produção intensiva.

\subsubsection{Significado do Fator de Risco}

O fator de risco é uma característica de um indivíduo ou das condições em que ele é mantido a qual, uma vez presente em um sitema de produção aumenta a probabilidade do aparecimento e desenvolvimento de determinados problemas patológicos.

Para GRUNDY (1973), o fator de risco deve preceder a doença e deve estar associado ao processo mórbido, sendo um fator epidemiologicamente manipulável.

Por outro lado, JENICEK \& CLEROUX (1982), o termo fator de risco deve ser reservado a todos os fatores, exógenos ou endógenos, que podem ser controlados ou cujo efeito é controlável por intervenção clínica, epidemiológica ou 
mesmo não médica. Trata-se, portanto, de um elemento passivel da ação sanitária, sendo um indicador seguro para delinear programas sanitários.

\subsubsection{Importância de Estudos Ecopatológicos}

Com a intensificação da produção de suínos no Brasil, os problemas sanitários têm sido uma preocupação constante de produtores e técnicos, tanto pela perda de animais e gastos com medicamentos, como pela redução nos índices técnicos.

Atualmente, uma observação atenta e dinâmica das criações intensivas de suínos, permite estabelecer uma classificação geral dos problemas patológicos que ali se desenvolvem (MADEC \& JOSSE, 1983). Assim baseando-se em dados de campo e experimentais a maior parte das doenças dos suínos podem ser classificadas em duas grandes categorias:

a) DOENÇAS MONOFATORIAIS - doenças causadas de maneira exclusiva por um agente etiológico específico, com alta contagiosidade, conhecidas como doenças epizoóticas (ex: Peste Suína Clássica e Doença de Aujeszky);

b) DOENÇAS MULTIFATORIAS - ou doenças de etiologia complexa, são doenças que encontram, em certos rebanhos, condições favoráveis à sua eclosão, conhecidas como doenças enzoóticas. Exemplos dessas doenças são: os problemas entéricos da desmama, diarréia branca dos leitões lactentes, problemas urinários e problemas respiratórios da engorda. Essas doenças multifatoriais sofrem ou não a infuência de agentes microbianos, mas estes não exercem seu efeito patogênico, sem que as condições do meio ambiente e do manejo sejam propícias.

Dentre os problemas sanitários que afetam os leitões lactentes e na desmama, as diarréias são as mais freqüentes. Com relação aos leitões lactentes, a maior mortalidade ocorre na primeira semana de vida e as causas mais freqüentes são os esmagamentos e a inanição (MADEC et al. 1984). Os leitões mais fracos (com menos de 1000 gramas ao nascimento) representam $2 / 3$ das perdas nesta fase. Ainda, MADEC et al. (1984), verificaram que temperaturas ambientais baixas com ausência ou inadequação de um sistema de aquecimento para os leitões, reduz a ingestão de colostro, tendo como consequência uma diminuição da imunidade dos leitões contra agentes infecciosos. 
Os problemas digestivos do leitão, após a primeira semana de vida, são comuns nas criações da Região Sul Brasileira. Estudos de campo apontam que a Escherichia coli (E. coli), Isospora suis e o Rotavírus são os principais agentes infecciosos envolvidos (BARCELLOS et al., 1983; SOBESTIANSKY, 1987 e WENTZ, 1987). Entretando, vários fatores como o estresse, ambiente, qualidade da água, nutrição, deficiência de ferro e susceptibilidade genética podem infuenciar na ocorrência da diarréia.

Estas variáveis podem ser analisadas conjuntamente através de metodologia adequada (MADEC et al., 1982), já que possuem efeitos interativos.

Os distúrbios digestivos do leitão na desmama, também têm aumentado drasticamente nos últimos anos. Estes problemas se manifestam clinicamente sob a forma de diarréia ou doença do edema. Estudos experimentais e epidemiológicos mostraram que alguns sorotipos de $\underline{E}$. coli são incriminados como agente afetor. Porém, estas amostras de $\underline{E}$. coli são encontradas tanto em rebanhos com problemas, como em

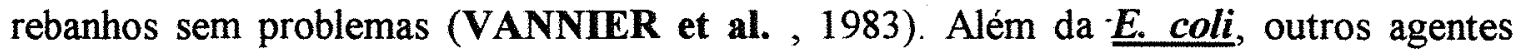
infecciosos, incluindo-se várias bactérias, vírus e protozoários, podem participar no quadro patológico da síndroma da diarréia pós-desmame (TZIPORI et al. , 1980). Além disso, o regime dietético influencia a ocorrência dos problemas da desmama (LECCE, 1983 e MORES, 1987).

As medidas quimioterápicas usadas no controle dos problemas entéricos dos leitões lactentes e na desmama, além dos custos elevados geram resultados irregulares e temporariamente satisfatórios. Então, o controle dessas doenças multifatoriais pode se basear no reconhecimento profundo do meio em que os animais são criados. Estudos ecopatológicos, nas nossas criações, no sentido de identificar os fatores de risco, podem melhorar a performance dos animais, sem o uso de medicamentos, proporcionando-lhes condições adequadas de criação, pela correção dos fatores de risco previamente estabelecidos.

Em trabalhos experimentais, geralmente as variáveis de um sistema de produção, são estudadas duas a duas, isto é, dando um enfoque monofatorial (análise estatística univariada), como por exemplo: diarréia pós desmame versus influência nutricional (PROHASZKA \& BARON, 1980; MORES, 1987). No entanto, num rebanho as influências das variáveis sobre os animais são complexas e acima de tudo, atuam ao mesmo tempo com efeito acumulativo (VANNIER et al., 1983). 
Os estudos ecopatológicos devem ser conduzidos nas próprias criações, pois uma granja é composta por seis grupos de variáveis, inter-relacionados, os quais são: animal, nutrição, instalação, manejo, microbismo e o próprio produtor; caracterizando o ecossistema suíno (TILLON, 1980).

\subsubsection{Sequência no Desenvolvimento de Estudos Ecopatológicos}

A complexa interação entre as variáveis de uma granja de um sistema de produção intensivo pode ser avaliada mediante estudos ecopatológicos (MADEC \& JOSSE, 1984).

Os passos gerais no desenvolvimento de estudos ecopatológicos, segundo MADEC \& TILLON (1986), são:

1) estudos preliminares, com o objetivo de se obterem melhores conhecimentos sobre a doença quanto a suas manifestação no campo, métodos de diagnóstico laboratoriais e, principalmente, estudos de campo sobre o meio ambiente ao qual o suíno é submetido;

2) elaboração de um protocolo para coleta de dados referente ao problema patológico específico, o qual deve ser tão exaustivo quanto possível e ter objetividade. Esta etapa, demanda muito trabalho e tempo até se chegar a um questionário simplificado, que contenha o máximo de informação das principais variáveis;

3) aplicação do questionário, esta fase de coleta de dados requer a ajuda de pessoas treinadas. Uma mesma questão tem que ser sempre similarmente interpretada (fidedignidade). Para evitar interpretação duvidosa as questões devem ser simples e quantificar o fenômeno tanto quanto possível;

4) a análise estatística dos dados coletados, visando à pesquisa dos fatores de risco. Nesta etapa, não se podem confundir variáveis explicativas com consecutivas, para não cometer o erro de explicar a ocorrência de uma doença pelos seus próprios sintomas, a análise estatística, referente a este passo, é baseada no método estatístico denominado: Análise de Correspondência. 
5) Validação dos resultados através da correção das variáveis, identificadas como fatores de risco, e acompanhamento dos índices técnicos das criações.

\subsection{Sistema SAS}

O SAS é um sistema de softwares integrados que permite um controle completo sobre o acesso, à manipulação, à análise e à apresentação de dados. O sistema foi desenvolvido originalmente nos EUA em 1966 (MENDES, 1984).

Hoje o sistema é reconhecido mundialmente com aplicações em diversas áreas do conhecimento, o que exige de seus criadores uma preocupação contínua na geração de novos softwares e no aprimoramento do sistema. O sucesso do SAS foi tão grande que seus criadores fundaram o Instituto SAS. Este Instituto é uma companhia privada que dedica-se ao suporte e desenvolvimento destes softwares e prestação de serviço ao sistema (SCHLOTZHAUER \& LITTELL, 1987). O SAS é util para qualquer tipo de dados. A sigla SAS significa "Statistical Analysis Sistem".

O software SAS BASICO (SAS/BASE) é o alicerce do Sistema SAS. Nos mais de 20 produtos do sistema SAS incluem-se:

- SAS/AF,

- SAS/GRAPH,

- SAS/IML,

- SAS/OR,

- SAS/FSP,

- SAS/STAT e

- OUTROS.

O SAS pode ser usado tanto em computadores de grande porte como em microcomputadores (PCs), sendo compatível com os ambientes: DOS, Windows, Unix e outros. Os procedimentos que compõem o software estatístico (SAS/STAT) do sistema SAS são de fácil acesso e através deles é possivel executar desde uma simples estatística descritiva até técnicas multivariada complexas (SAS, 1987). 


\subsection{Análise de Correspondência}

\subsubsection{Breve Noção da História}

A preocupação com análise exploratória de dados categórizados, particularmente para tabelas de contingência, pelo que se encontra na literatura, teve início em 1933 com RICHARDSON e KUDER; a partir daí, vários autores tais como HIRSHFIELD, 1935; FISHER, 1940; GUTTMAN, 1941; BURT, 1950; HAYASHI, 1950, e entre outros, escreveram de forma independente trabalhos referentes ao assunto com diferentes denominações como: Optimal scalling, Reciprocal averages, Optimal scoring, Homogeneity analysis, Dual scaling, Scalogram analysis.

$\mathrm{O}$ assunto foi retomado na década de 60 , por intermédio de um grupo Francês, liderado pelo pesquisador JEAN-PAUL BENZÉCRI, que definiu um método mostrando suas propriedades algébricas e geométricas. Este método foi denominado de "Analyse Factorialle des Correspondences", e mais tarde, apenas de "Analyse des Correspondences". A partir deste ponto, uma extensa quantidade de literatura sobre o tema vem sendo gerada.

Hoje o método esta difundido pelo mundo todo, com aplicações em diversas áreas de pesquisa tais como: sociologia, ecologia, paleontologia, arqueologia, geologia, educação, medicina, lingüística, pesquisa de mercado, ciências agrárias, estudos religiosos, arte, música, epidemiologia e outras, mediante grupos interdisciplinares em universidades e/ou unidades de pesquisa.

\subsubsection{Objetivo da Análise de Correspondência}

A Análise de Correspondência é um método gráfico de análise de dados, tendo como objetivo estudar as relações existentes entre as categorias de linhas e colunas e as semelhanças entre linhas ou entre colunas de uma Tabela de Contingência através da representação simultânea das categorias (linhas e colunas) sobre um gráfico, em "dimensão reduzida", na forma de pontos facilitando, assim, a interpretação da tabela. 
A Análise de Correspondência (AC) pode ser considerada como um caso particular da Análise de Componente Principal (ACP), por ambas buscarem o mesmo objetivo: "Redução de Dimensão"; o que as difencia é o tipo de matriz de dados a ser analisada, e por conseqüência, a métrica utilizada.

\subsubsection{Fundamentos Teórico e Algébrico do Método}

A intenção deste item é propiciar, através de alguns conceitos básicos, as etapas para se chegar aos resultados da Análise de Correspondência. Além disso, procurar-se-á enfatizar um pouco da estrutura geométrica e da terminologia envolvida no método, partindo-se de um conjunto de dados na forma de uma tabela de contingência.

Tomou-se como base as seguinte publicações: MARDIA, 1979; MANDEL，1982; GREENACRE，1984; GREENACRE，1987；JUDEZ，1988; CALLEGARI-JACQUES， 1991; ANDERSEN，1991; BENZÉCRI，1992; VILLALOBOS-AGUAYO, 1993; KRZANOWSKI, 1993 e GREENACRE, 1993.

\subsubsection{Tabela de Contingência}

Seja $\mathbf{N}$ uma tabela de contingência, com $\mathbf{I}$ categorias de linhas e $\mathbf{J}$ categorias de colunas, contendo elementos não negativos, de modo que, a soma de cada linha ou coluna seja não nula. A tabela é a seguinte:

TABELA 1. Tabela de Contingência

\begin{tabular}{|c|c|c|c|c|c|c|}
\hline $\mathbf{A} \backslash \mathbf{B}$ & 1 & $\cdots$ & $\mathbf{j}$ & $\ldots$ & $\mathrm{J}$ & $\begin{array}{l}\text { TOTAL } \\
\text { LINHA }\end{array}$ \\
\hline 1 & $\mathrm{n}_{11}$ & $\cdots$ & $\overline{n_{1 \mathbf{j}}}$ & $\cdots$ & $\overline{n_{1 J}}$ & $\mathrm{n}_{1}$ \\
\hline$\vdots$ & $0^{\circ}$ & & $\vdots$ & & $\vdots$ & $\vdots$ \\
\hline i & $\mathbf{n}_{\mathbf{i} 1}$ & $\cdots$ & $\mathbf{n}_{\mathbf{i j}}$ & $\ldots$ & $\mathbf{n}_{\mathbf{i} \mathbf{J}}$ & $\mathbf{n}_{\mathbf{i}}$ \\
\hline$\vdots$ & $\vdots$ & & $\vdots$ & & $\vdots$ & $\vdots$ \\
\hline I & $\mathrm{n}_{11}$ & $\ldots$ & $\mathbf{n}_{. \mathbf{j}}$ & $\ldots$ & $\mathrm{n}_{\mathrm{IJ}}$ & $\mathrm{n}_{\mathrm{I}}$ \\
\hline $\begin{array}{l}\text { TOTAL } \\
\text { COLUNA }\end{array}$ & $\mathrm{n}_{1}$ & $\cdots$ & $\mathbf{n}, \mathbf{j}$ & $\ldots$ & $\mathrm{n}_{J}$ & $\mathrm{n}$ \\
\hline
\end{tabular}


onde:

$\boldsymbol{n}_{i j}$ é o número de freqüências observadas pela interseção da i-ésima categoria da variável $\mathbf{A}$ com a j-ésima categoria da variável $\mathbf{B}$;

$n_{i}=\sum_{j} n_{i j}$ é o total de freqüências observadas na i-ésima categoria de $\mathbf{A}$; $\boldsymbol{n}_{. j}=\sum_{i} n_{i j}$ é o total de freqüências observadas na j-ésima categoria de $\mathbf{B}$; $\boldsymbol{n}=\sum_{i j} \boldsymbol{n}_{\boldsymbol{i j}}$ é o total geral de freqüências observadas; $\mathbf{N}=\left[\boldsymbol{n}_{\boldsymbol{i j}}\right]_{\mathbf{I x} \mathbf{J}}$ é uma matriz de freqüências absolutas.

\subsubsection{Matriz de Freqüências Relativas}

A matriz $\mathbf{N}$ pode transformar-se em uma matriz de freqüências relativas, expressa por:

$$
\mathbf{P}=(1 / \mathrm{n}) \mathbf{N}
$$

sendo também conhecida como Matriz de Correspondência. Cada linha ou coluna da matriz $\mathbf{P}$ pode ser visto como um vetor de proporções representados na TABELA 2.

TABELA 2. Freqüências relativas

\begin{tabular}{c|ccccc|c}
$\mathbf{A} \backslash \mathbf{B}$ & 1 & $\cdots$ & $\mathbf{j}$ & $\cdots$ & $\mathrm{J}$ & $\begin{array}{c}\text { TOTAL } \\
\text { LINHA }\end{array}$ \\
\hline 1 & $\mathrm{p}_{11}$ & $\cdots$ & $\mathbf{p}_{1 \mathbf{j}}$ & $\cdots$ & $\mathrm{p}_{1 \mathrm{~J}}$ & $\mathrm{p}_{1 .}$ \\
$\vdots$ & $\vdots$ & & $\vdots$ & & $\vdots$ & $\vdots$ \\
$\mathbf{i}$ & $\mathbf{p}_{\mathbf{i} 1}$ & $\cdots$ & $\mathbf{p}_{\mathbf{i j}}$ & $\cdots$ & $\mathbf{p}_{\mathrm{iJ}}$ & $\mathbf{p}_{\mathbf{i} .}$ \\
$\vdots$ & $\vdots$ & & $\vdots$ & & $\vdots$ & $\vdots$ \\
$\mathrm{I}$ & $\mathrm{p}_{\mathrm{II}}$ & $\cdots$ & $\mathbf{p}_{. \mathbf{j}}$ & $\cdots$ & $\mathrm{p}_{\mathrm{IJ}}$ & $\mathrm{p}_{\mathrm{I}}$ \\
\hline TOTAL & $\mathrm{p}_{.1}$ & $\cdots$ & $\mathbf{p . j}$ & $\cdots$ & $\mathrm{p}_{\mathrm{J}}$ & 1
\end{tabular}


A TABELA 2 fornece as seguintes relações:

$p_{i j}=n_{i j} / n ; \quad p_{i .}=\Sigma_{j} p_{i j}=\Sigma_{j} n_{i j} / n ; \quad p_{\cdot j}=\Sigma_{i} p_{i j}=\Sigma_{i} n_{i j} / n$

Então, definem-se os seguintes vetores:

r: vetor de frequiências relativas de linhas;

$\mathbf{r}=\left(p_{1 .}, p_{2}, \ldots, p_{i}, \ldots, p_{I .}\right)^{T}=\mathbf{P 1}^{\prime} \in \mathbf{R}^{I}$

c: vetor de freqüências relativas de colunas;

$$
\mathbf{c}=\left(p_{.1}, p_{.2}, \ldots, p_{. j}, \ldots, p_{. J}\right)^{T}=\mathbf{P}^{\prime} 1 \in \mathbf{R}^{\mathrm{J}}
$$

Definem-se, também, as matrizes diagonais de freqüências relativas de cada linha e de cada coluna por:

$$
\mathbf{D}_{\mathbf{r}}=\operatorname{diag}(\mathbf{r})=\left[\begin{array}{lll}
p_{1 .} & & 0 \\
& \ddots & \\
0 & & p_{I .}
\end{array}\right] ; \mathbf{D}_{\mathbf{c}}=\operatorname{diag}(\mathbf{c})=\left[\begin{array}{lll}
p_{.1} & & 0 \\
& \ddots & \\
0 & & p_{J}
\end{array}\right]
$$

\subsubsection{Perfil Linha e Perfil Coluna}

Em função da matriz de correspondência "P", define-se o i-ésimo perfil linha como o vetor:

$$
a_{\mathrm{i}}=\left(p_{i 1} / p_{i}, p_{i 2} / p_{i}, \ldots, p_{i j} / p_{i}, \ldots, p_{i J} / p_{i .}\right)^{T} ; \mathrm{i}=1, \ldots, \mathrm{I}
$$

onde cada vetor $\boldsymbol{a}_{\mathbf{i}}(\mathrm{i}=1, \cdots, \mathrm{I})$ representa uma distribuição multinomial, condicionada à i-ésima categoria da variável "A". 
Então, a Matriz de perfis linha é dada por:

$$
\mathbf{R}=\mathbf{D}_{\mathbf{r}}^{-1} \mathbf{P}=\left[a_{I}|\cdots| a_{I}\right]^{T}
$$

Analogamente, o j-ésimo perfil coluna será:

$b_{\mathrm{j}}=(p 1 j / p . j, p 2 j / p . j, \ldots, p i j / p . j, \ldots, p I j / p . j)^{T} ; \mathrm{j}=1, \ldots, \mathrm{J}$

Logo, a Matriz de perfis coluna é dada por:

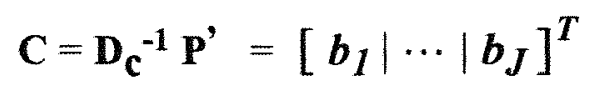

Note:

a) Os perfis (linha ou coluna) pertencem a uma "Lei de formação", onde a soma dos elementos de cada perfil (linha ou coluna) é igual a 1 (distribuição de probabilidade), isto é: $R_{1_{J}}=\mathbf{1}_{\mathbf{I}}$ e $\mathbf{C} \mathbf{1}_{\mathbf{I}}=\mathbf{1}_{\mathbf{J}}\left(\mathbf{1}_{\mathbf{I}}\right.$ e $\mathbf{1}_{\mathbf{J}}$ são vetores unitários);

b) Cada perfil (linha ou coluna) é afetado por um peso $\left(p_{i}: \mathrm{i}=1, \ldots, \mathrm{I}\right.$ ou $\left.p_{\cdot j}: \mathrm{j}=1, \ldots, \mathrm{J}\right)$, proporcional aos respectivos totais de linha ou de coluna dos dados originais. Posteriormente estes pesos serão denominados de massas.

\subsubsection{Massas}

Definem-se massas de linha ou de coluna de tabela de contingência por:

- Massa da i-ésima linha:

$$
r_{i}=p_{i .}=n_{i .} / n ; \mathrm{i}=1, \ldots, \mathrm{I}
$$

Então, o vetor de massa das linhas é representado por:

$$
r=\left(r_{1}, r_{2}, \ldots, r_{i}, \ldots, r_{I}\right)^{T}
$$


- Massa da j-ésima coluna:

$$
c_{j}=p_{. j}=n . j / n ; j=1, \ldots, \mathrm{J}
$$

Logo, o vetor de massas das colunas é representado por:

$$
c=\left(c_{1}, c_{2}, \ldots, c_{j}, \ldots, c_{J}\right)^{T}
$$

Note: Os vetores de massas $\boldsymbol{r}$ e $\boldsymbol{c}$ são as marginais coluna e linha, respectivamente, da Matriz de Correspondência "P". Nota-se também a presença da lei de formação (distribuição de probabilidade) por ter-se $r^{\prime} 1=c^{\prime} 1=1\left(\Sigma_{i} r_{i}=\Sigma_{j} c_{j}=1\right)$.

\subsubsection{Centróide}

O centróide (linha ou coluna) de uma tabela de contingência indica geometricamente a posição média dos perfis (linha ou coluna), como se fosse o centro de gravidade ou o ponto de equilíbrio da matriz de dados.

Como cada perfil (linha ou coluna) está associado a uma massa ( $\boldsymbol{r}_{\boldsymbol{i}}$ ou $c_{j}$ ), define-se como centróide (linha ou coluna) a média ponderada dos perfis (linha ou colunạ). Então:

- Centróide dos perfis linha;

$$
\operatorname{Centróide}_{(r)}=\Sigma_{i} r_{i} a_{i}=\mathrm{R}^{\prime} r=c
$$

- Centróide dos perfis coluna;

$$
\operatorname{Centróide}_{(\boldsymbol{c})}=\Sigma_{j} c_{j} b_{j}=\mathrm{C}^{\prime} c=\boldsymbol{r}
$$

Note: $\mathrm{O}$ Centróide dos perfis linha é o vetor de massa das colunas.

o Centróide dos perfis coluna é o vetor de massa das linhas. 


\subsubsection{Espaço de Perfil}

O conceito de perfil é fundamental na Análise de Correspondência.

\section{a) Espaço dos perfis linha}

Cada perfil linha $a_{\mathbf{i}}(\mathrm{i}=1, \ldots, \mathrm{I})$ define um ponto em $\mathbf{R}^{\mathbf{J}}$, logo, neste espaço acomoda-se uma nuvem de pontos representando os I perfis linha. $O$ fato de os elementos de cada perfil linha somarem 1 "lei de formação", significa que a nuvem está restrita numa região, num subespaço de dimensão $\mathbf{J}-1$ do espaço das colunas $\left(R^{\mathbf{J}}\right)$, conhecida como: "Simplex". Este simplex ou Espaço dos perfis linha está limitado por segmentos de retas que unem os vértices unitários $\left(\mathbf{e}_{\mathbf{1}}, \mathbf{e}_{2}, \ldots, \mathbf{e}_{\mathbf{J}}\right)$ sobre os $\mathbf{J}$ eixos perpendiculares, que representam as categorias de coluna. O sistema de coordenadas gerado dentro do simplex é definido como: "Sistema de coordenadas baricêntricas".

É fácil entender o aspecto geométrico mencionado anteriormente imaginando um caso especial, onde os perfis linha têm 3 elementos, então o simplex é simplesmente um triângulo fechado pelos segmentos de retas que unem os 3 vértices unitários $\left(\mathbf{e}_{1}, \mathbf{e}_{2}, \mathbf{e}_{3}\right)$ sobre os 3 eixos perpendiculares, representando as categorias de coluna $\left(\mathbf{c}_{1}, \mathbf{c}_{2}, \mathbf{c}_{3}\right)$. A FIGURA 3, denota este caso especial do "Sistema de coordenadas baricêntricas", conhecido como "Sistema de coordenadas triangulares". Entretanto, utilizando um gráfico trilinear (BATSCHELET, 1984), representado pela FIGURA 4, podem-se plotar as posições dos perfis linha diretamente no "Sistema de Coordenadas Triangulares", sem passar pelo sistema básico de eixos do espaço tridimensional.

Este procedimento pode ser exemplificado, adotando-se o i-ésimo perfil linha $a_{\mathrm{i}}=(0.50,0.20,0.30)^{T}$ e o centróide linha $c=(0.16,0.36,0.48)^{T}$. 


\section{b) Espaço dos perfis coluna}

A interpretação do espaço dos perfis coluna é feita de forma simétrica ao descrito anteriormente, porém utilizando-se a matriz transposta $\left(\mathbf{P}^{T}\right)$.

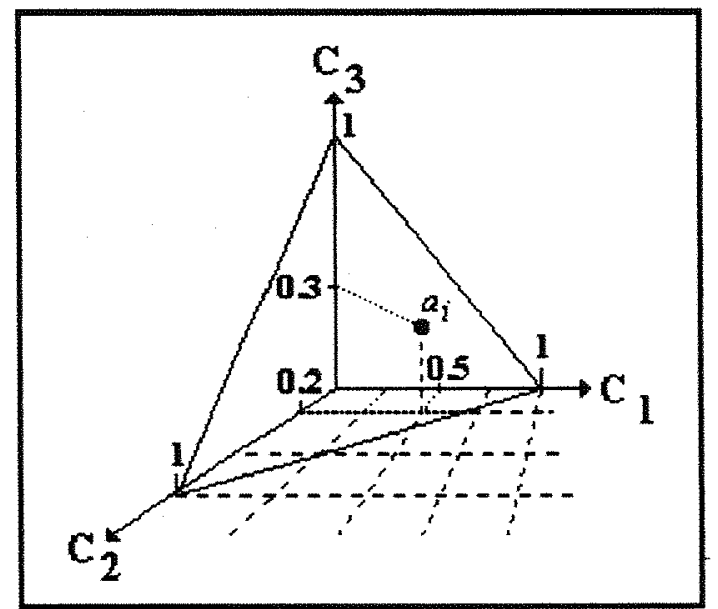

FIGURA 3. Sistema de coordenadas baricêntricas representando a posição do i-ésimo perfil linha $\left(a_{i}\right)$ e os vértices unitários $\left(\mathrm{e}_{1}, \mathrm{e}_{2}, \mathrm{e}_{3}\right)$ no espaço tridimensional.

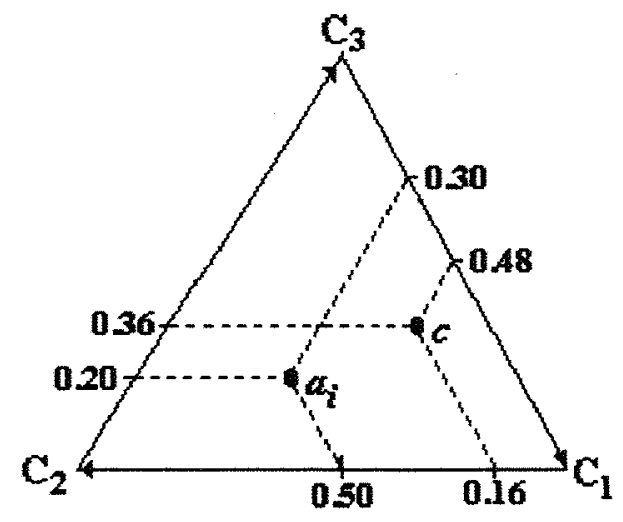

FIGURA 4. Sistema de coordenadas triangulares exibindo o i-ésimo perfil linha $\left(a_{\mathbf{i}}\right)$ e o centróide linha $(c)$ num gráfico trilinear. 


\subsubsection{Estatística $\chi^{2}$, Distância $\chi^{2}$ e Inércia}

A Estatistica $\chi^{2}$ é fundamental para se entender a Distância $\chi^{2}$ e a Inércia, termos frequentemente usados na Análise de Correspondência.

Quando o interesse é testar a hipótese de independência entre linhas e colunas $\left(\boldsymbol{p}_{\boldsymbol{i} j}=\boldsymbol{p}_{\boldsymbol{i} .} \boldsymbol{p}_{\mathrm{j}} \boldsymbol{j}\right.$, onde $\mathrm{i}=1, \ldots, \mathrm{I}$ e $\left.\mathrm{j}=1, \ldots, \mathrm{J}\right)$, que é equivalente a hipótese de homogeneidade entre linhas $\left(\boldsymbol{p}_{1 j} / \boldsymbol{p}_{1 .}=\boldsymbol{p}_{2 j} \boldsymbol{p}_{2 .}=\ldots=\boldsymbol{p}_{I j} \boldsymbol{p}_{\boldsymbol{I}_{\mathrm{o}}}\right.$, onde $\left.\mathrm{j}=1, \ldots, \mathrm{J}\right)$ de uma tabela de contingência recorre-se, na maioria das vezes, à Estatística $\chi^{2}$ de Pearson expressa pela fórmula a seguir:

$$
\begin{aligned}
& \chi^{2}=\sum_{i j} \frac{\left(n_{i j}-e_{i j}\right)^{2}}{e_{i j}} \\
& =\sum_{i j} \frac{\left(n_{i j}-n_{i \cdot{ }^{n} \cdot j} / n\right)^{2}}{n_{i \cdot{ }^{n} \cdot j} / n} \\
& =\sum_{i j} \frac{\left(n p_{i j}-n p_{i, p} . j\right)^{2}}{n p_{i .} p \cdot j} \\
& =\sum_{i j} \frac{\left[n\left(p_{i j}-p i . p \cdot j\right)\right]^{2}}{n p_{i . p} p_{j}} \\
& =\sum_{i j} n^{2} \frac{\left(p_{i j}-p_{i . p . j}\right)^{2}}{n p_{i . p . j}} \\
& =n \sum_{i j} \frac{\left(p_{i j}-p_{i .} p_{. j}\right)^{2}}{p_{i .} p_{. j}}, \text { com (I-1)(J-1) g.1., }
\end{aligned}
$$

onde: $\boldsymbol{e}_{\boldsymbol{i} \boldsymbol{j}} \equiv \boldsymbol{n}_{\boldsymbol{i} . \boldsymbol{n} \boldsymbol{j}} / \boldsymbol{n}$ é o valor "esperado" na cela $(\boldsymbol{i}, \boldsymbol{j})$ da matriz baseada sobre as marginais linhas e colunas, $\boldsymbol{n}_{\boldsymbol{i}}$ e $\boldsymbol{n}_{\boldsymbol{j}} \boldsymbol{j}$ respectivamente.

Logo, a Inércia Total de uma tabela de contingência é a Estatistica $\chi^{2}$ dividida pelo total geral $(n)$, que é dada por:

$$
\operatorname{Inércia}_{\{\text {Total }\}}=\sum_{i j} \frac{\left(p_{i j}-r_{i} c_{j}\right)^{2}}{r_{i} c_{j}}=\frac{\chi^{2}}{n}
$$


20.

Dividindo o numerador e denominador por $\boldsymbol{p}_{i .}{ }^{2}$, em (17), tem-se:

$$
\begin{aligned}
\chi^{2} & =n \sum_{i j} \frac{\left(p_{i j} / p_{i .}-p_{i .} p_{. j} / p_{i .}\right)^{2}}{p_{i .} p_{. j} /\left(p_{. j}\right)^{2}} \\
& =n \sum_{i j} p_{i .}\left(p_{i j} / p_{i .}-p_{. j}\right)^{2} / p_{. j} \\
& =n \sum_{i} p_{i .} \sum_{j}\left(p_{i j} / p_{i .}-p_{. j}\right)^{2} / p_{. j}
\end{aligned}
$$

Logo, define-se a Inércia Total dos perfis linha como:

$$
\operatorname{In}_{\{\boldsymbol{I}\}}=\frac{\chi \boldsymbol{Z}}{\boldsymbol{n}}=\sum_{i} p_{i .} \sum_{j}\left(p_{i j} / p_{i .}-p_{. j}\right)^{2} / p_{. j}
$$

Analogamente, dividindo numerador e denominador por $p_{. j}{ }^{2}$, em (17), tem-se a Inércia Total dos perfis coluna, dada por:

$$
\operatorname{In}_{\{\boldsymbol{J}\}}=\frac{\chi \boldsymbol{2}}{\boldsymbol{n}}=\Sigma_{j} p_{. j} \Sigma_{i}\left(p_{i j} / p_{. j}-p_{i}\right)^{2} / p_{i}
$$

Relações: Inércia $\{$ Total $\}=\operatorname{In}\left\{I_{\}}=\operatorname{In}\{\boldsymbol{J}\}=\frac{\chi^{2}}{n}\right.$

A diferença ao quadrado da expressão: $\sum_{j} 1 / p_{. j}\left(p_{i j} / p_{i}-p_{. j}\right)^{2}$, em (20), representa a distância entre o i-ésimo perfil linha $\left(a_{\mathbf{i}}\right)$ e o perfil linha médio (Centróide $\{\mathbf{c}\}$ ), Note que para cada termo da diferença ao quadrado, existe um fator extra $\left(p_{. j}: j=1, \ldots, J\right)$ que pondera estas diferenças. Por esta razão, em Análise de Correspondência não se define a distância dos perfis linha ao centróide pela Métrica Euclidiana Clássica, mas sim, pela Métrica Euclidiana Ponderada. 
Desta forma, fica definida a distancia $\chi^{2}$, entre os perfis linha e o centróide (c), como sendo a distância euclidiana ponderada por $\mathrm{D}^{-1}$, que é representada pela seguinte expressão:

$$
D^{2} \chi_{c}^{\left\{a_{i}, c\right\}=\left(a_{i}-c\right)^{T} \mathbf{D}_{\mathbf{c}^{-1}}\left(a_{\mathrm{i}}-c\right)=\left(\mathbf{R}-c^{\prime} 1\right)^{T} \mathbf{D}_{\mathbf{c}^{-1}}\left(\mathbf{R}-c^{\prime} \mathbf{1}\right)}
$$

De modo análogo, a distância $\chi^{2}$, entre os perfis coluna e o centróide (r), na métrica $\mathbf{D}_{\mathbf{r}^{-1}}$, é dada por:

$$
D^{2} 2_{r}^{\left\{b_{\mathrm{j}}, r\right\}=\left(b_{\mathrm{j}}-r\right)^{T} \mathbf{D}_{\mathbf{r}}^{-1}\left(b_{\mathrm{j}}-r\right)=\left(\mathrm{C}-\boldsymbol{r}^{\prime} \mathbf{1}\right)^{T} \mathbf{D}_{\mathbf{r}^{-1}}\left(\mathbf{C}-r^{\prime} \mathbf{1}\right)}
$$

Note: A Distância $\chi^{2}$ e Inércia são conseqüências da Estatistica $\chi^{2}$.

\section{Interpretacão geométrica}

- Estatística $\chi^{2}$

Sob a hipótese de homogeneidade pode ser interpretada geometricamente como sendo a diferença dos perfis (linha ou coluna) aos seus respectivos centróides ( $c$ ou $\boldsymbol{r}$ ).

\section{- Inércia}

A inércia total (linha ou coluna) decompõe a estatística qui-quadrado, além disso, é a soma ponderada das Distância $\chi^{2}$ dos pontos (linha ou coluna) em relação ao seus respectivos centróides ( $c$ ou $r$ ). 
GREENACRE (1993), interpreta o conceito de inércia total de linha de forma espetacular, usando uma seqüência de quatro pequenas matrizes de dados, cada uma com 5 linhas e 3 colunas, ilustrada pela figura 5 .

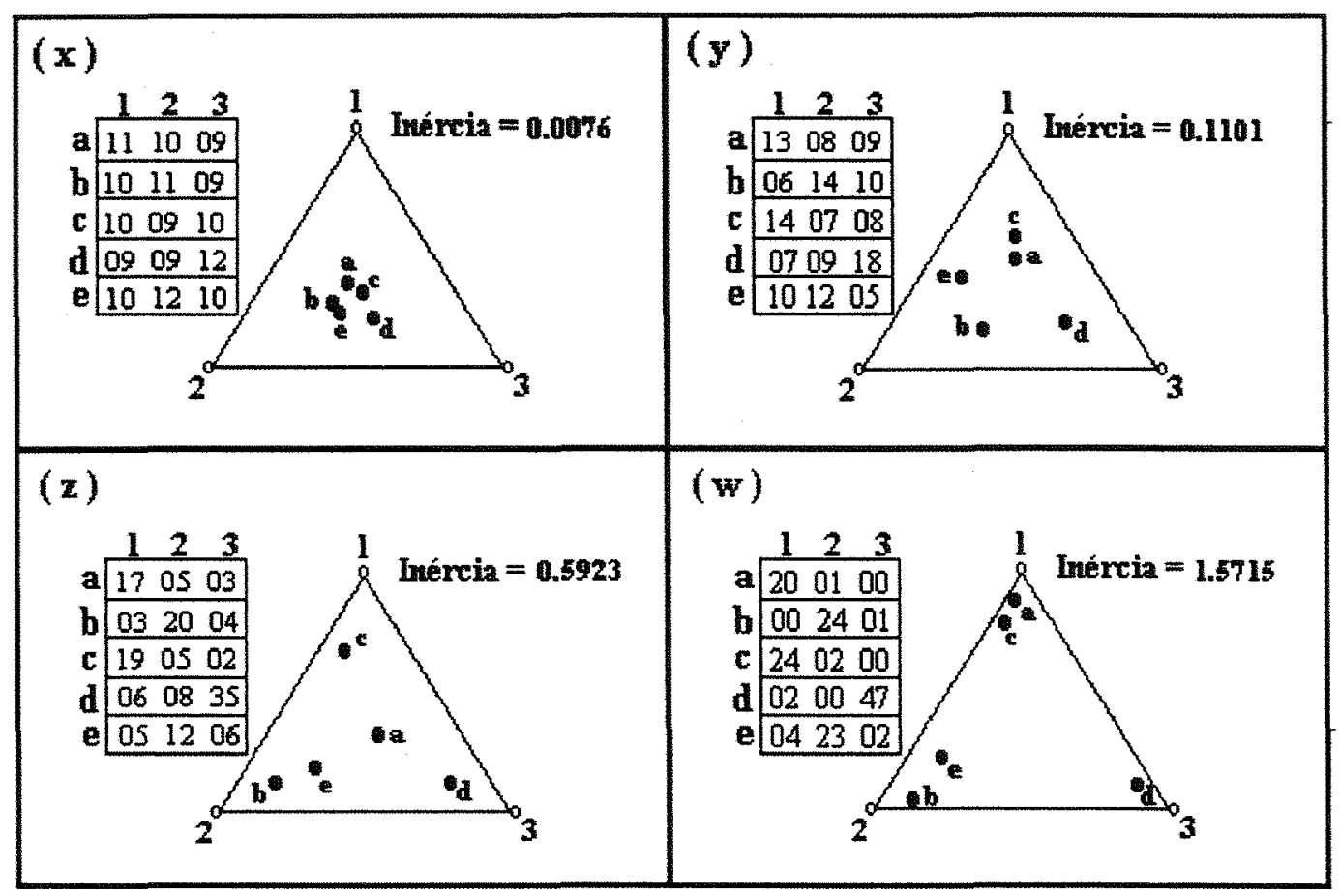

FIGURA 5. Exibição dos perfis linha e da inércia total num sistema de coordenadas triangulares para as respectivas matrizes de dados $(\mathbf{x}, \mathbf{y}, \mathbf{z} \mathbf{e} \mathbf{w})$.

Observe que as inércias totais apontadas em $\mathbf{x}, \mathbf{y}, \mathbf{z}$ e $\mathbf{w}$ estão numa forma ascendente, começando de uma pequena inércia, perto de zero, e chegando a uma alta inércia, superior a 1.5. Neste caso, o máximo que a inércia total poderia atingir seria 2 , isto é, igual ao dimensionamento do problema. Este máximo poderia ser alcançado se todos os perfis se encontrassem exatamente sobre os vértices do espaço de perfil. A inércia zero poderia ser alcançada se todos os perfis fossem idênticos e se encontrassem sobre o mesmo ponto.

Então, pode-se interpretar uma inércia alta como uma associação (ou correlação) altamente significativa entre linhas e colunas, sendo representada geometricamente pela ampla dispersão dos pontos no espaço de perfis. Portanto, a inércia é absolutamente uma medida de dispersão, isto é, similar ao papel da variância. 


\section{- Distância $\chi^{2}$}

As métricas $\chi^{2}, \mathbf{D}_{\mathbf{c}}{ }^{-1}$ e $\mathbf{D}_{\mathbf{r}^{-1}}$ no espaço dos perfis linha e coluna respectivamente, têm a característica de deformar o espaço num sentido "elástico". Então, os perfis, o centróide e os vértices unitários para os respectivos espaços também serão afetados, conseqüentemente, receberão novas coordenadas.

Isto pode ser ilustrado utilizando os dados da seção 2.3.3.6., referente ao caso especial do "Sistema de Coordenadas Triangulares", no qual é possivel visualizar a deformação sofrida pelo espaço dos perfis linha, acarretada pela sua correspondente métrica $\mathbf{D}_{\mathbf{c}} \mathbf{c}^{-1}$. Nesta métrica as novas coordenadas do perfil linha $\boldsymbol{a}_{\boldsymbol{i}}=$ $(0.50,0.20,0.30)^{T}$ e do centróide linha $c=(0.16,0.36,0.48)^{T}$ serão, respectivamente:

$$
\begin{aligned}
& \tilde{a}_{i}=\mathbf{D}_{\mathbf{c}}^{-1 / 2} a_{i}=\left[\frac{1}{\sqrt{\mathbf{0 . 1 6}}}(0.50), \frac{1}{\sqrt{\mathbf{0 . 3 6}}}(0.20), \frac{1}{\sqrt{\mathbf{0 . 4 8}}}(0.30)\right]=(1.25,0.33,0.43) \mathrm{e} \\
& c=\mathbf{D}_{\mathbf{c}}^{-1 / 2} \boldsymbol{c}=\left[\frac{1}{\sqrt{\mathbf{0 . 1 6}}}(0.16), \frac{\mathbf{1}}{\sqrt{\mathbf{0 . 3 6}}}(0.36), \frac{1}{\sqrt{\mathbf{0 . 4 8}}}(0.48)\right]=(0.40,0.60,0.69)
\end{aligned}
$$

Note: Os perfis linha são ponderados pelas massas de coluna e perfis colunas são ponderados pelas massas de linha. 
Agora, a FIGURA 3 (seção 2.3.3.6.) terá seus lados estendidos diferentemente formando um novo triângulo, não mais equilátero, mas com lados inversamente proporcionais à raiz quadrada dos valores do centróide: $1 /(0.16)^{1 / 2}=2.50$, $1 /(0.36)^{1 / 2}=1.67$ e $1 /(0.48)^{1 / 2}=1.44$, como ilustra a FIGURA 6.

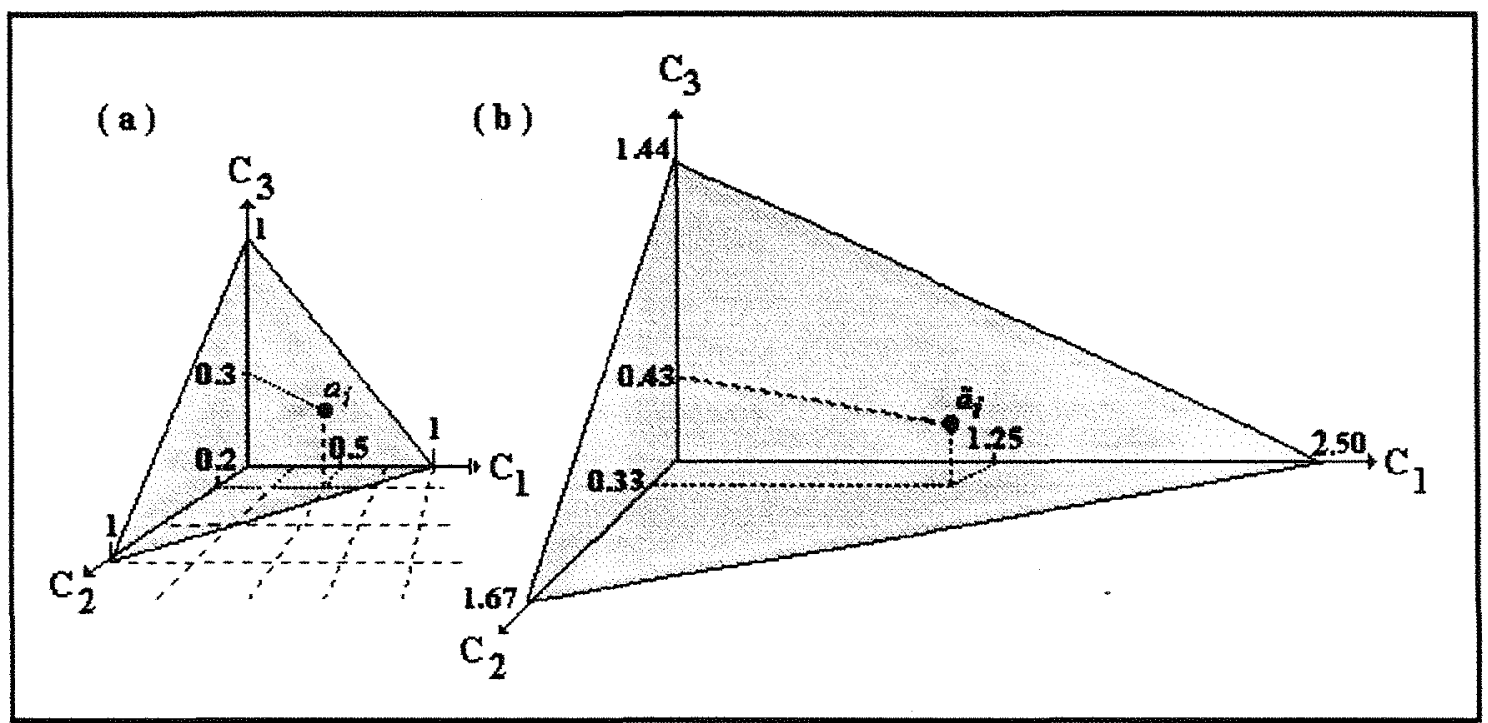

FiguRA 6. (a) Posição do perfil " $a_{i}$ " no triângulo bi-dimensional; (b) 0 "alongamento" do sistema de coordenadas baricêntrica, no qual é ponderado pelo espaço euclidiano da Análise de Correspondência. As distâncias entre os pontos são Distância $\chi^{2}$.

Portanto, realizar uma análise considerando a Distância $\chi^{2}$ é o mesmo que realizar uma análise com a Distância Euclidiana aplicada aos novos pontos linha, com suas respectivas massas, da matriz:

$$
\mathbf{R D}_{\mathbf{c}}^{-1 / 2}
$$

Analogamente, para os perfis coluna realizar uma análise considerando a Distância $\chi^{\mathbf{2}}$ é o mesmo que realizar uma análise com a Distância Euclidiana aplicada aos novos pontos coluna, com suas respectivas massas, da matriz:

$$
\mathrm{CD}_{\mathbf{r}}^{-1 / 2}
$$




\subsubsection{Redução da Dimensão}

Geralmente, quando se aplica AC, na maioria das vezes a Tabela de Contingência de interesse tem um grande número de linhas e colunas, de modo que os perfis (linhas ou colunas) encontram-se num espaço de dimensão muito alta, tornando-se dificil observá-los diretamente. Por este motivo, na AC, como em outras técnicas multivariadas, a preocupação é identificar um subespaço de dimensão reduzida, preferencialmente, não mais do que duas ou três dimensões e que esteja o mais próximo possível de todos pontos perfis. Então, neste subspaço não se têm mais as posições originais e sim, suas projeções.

As posições dos perfis neste subespaço podem ser vistas como uma aproximação das suas verdadeiras posições no espaço de origem (alta dimensão). Neste contexto, as distâncias entre os perfis projetados passam a ser Distância $\chi^{2}$ aproximada.

\section{PROBLEMADUAL}

Na AC existe o problema Dual, ora se faz análise em linha, ora em coluna, ambas na busca da redução de dimensão.

\section{EM COLUNA ( $\left.\mathbf{R}^{\mathrm{J}}\right)$}

$\mathrm{Na}$ análise em $\mathbf{R}^{\mathbf{J}}$ tem-se uma nuvem de pontos representando os $\mathbf{I}$ perfis linha, que se acomodam exatamente em um simplex de dimensão J-1.

\section{EM LINHA (R)}

$\mathrm{Na}$ análise em $\mathbf{R}^{\mathbf{I}}$ tem-se uma nuvem de pontos representando os $\mathbf{J}$ perfis coluna, que se acomodam exatamente em um simplex de dimensão I-1.

Portanto, diante do problema dual, busca-se um subespaço de dimensão reduzida que melhor represente os perfis linha, quando se trabalha em coluna, e um subespaço de dimensão reduzida que melhor represente os perfis coluna, quando se trabalha em linha.

Além disso, para o ajuste do respectivo subespaço de linha ou coluna, a AC usa um critério denominado: "Soma Ponderada das Distâncias ao Quadrado". 


\section{CARACTERIZACÃO DO CRITÉRIO}

Para análise em coluna, o critério pode ser caracterizado pela FIGURA 7, na qual, exibe uma nuvem de pontos, representando os I perfis linha sobre o espaço Euclidiano ponderado de dimensão J. Seja $\mathbf{S}$ um candidato a subespaço de dimensão $\mathbf{K}(1 \leq \mathbf{K} \leq \mathrm{J}-1)$ com uma representação esquemática através de um plano cortando completamente o espaço $\mathbf{R}^{\mathrm{J}}$, de modo que a distância $d_{i}(S)$ seja a distância $\chi^{2}$ mais próxima entre o i-ésimo perfil linha $\left(a_{i}\right)$ e sua posição projetada $\left(\tilde{a}_{i}\right)$ em $\mathbf{S}$. Além do mais, é levada em consideração a massa $\boldsymbol{r}_{\boldsymbol{i}}$ deste perfil, segundo a sua importância. Então, o ajuste deste perfil no subespaço $S$ é dado por $r_{i}\left[d_{i}(S)\right]^{2}$. Logo, o critério de ajuste de todos os perfis linha (nuvem de pontos) para $\mathrm{S}$ é a soma dessas quantidades expresso por:

$$
\text { Ajuste }_{\{\mathbf{R}\}} \text { para } S: \Rightarrow \mathbf{L}\left(\mathbf{S} ; a_{1}, a_{2}, \ldots, a_{I}\right)=\sum_{i} r_{i}\left[d_{i}(S)\right]^{2}
$$

Analogamente, para análise em linha o critério é caracterizado pela FIGURA 8. Logo, o critério de ajuste de todos os perfis coluna para $\mathbf{S}$ é expresso por:

$$
\text { Ajuste }_{\{\mathbf{C}\}} \text { para } \mathbf{S}: \Rightarrow \mathbf{L}\left(\mathbf{S} ; \boldsymbol{b}_{1}, \boldsymbol{b}_{2}, \ldots, \boldsymbol{b}_{J}\right)=\sum_{j} c_{j}\left[d_{j}(\mathbf{S})\right]^{2}
$$

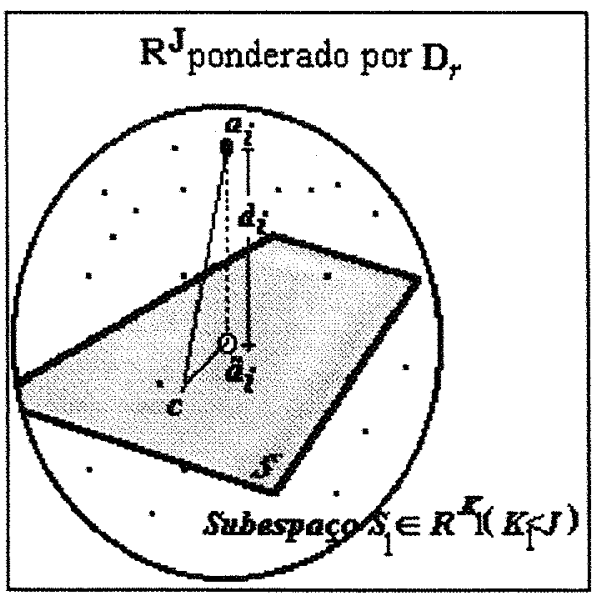

FIGURA 7. Pontos no espaço multidimensional $\mathbf{R}^{\mathrm{J}}$ e suas projeções sobre o subespaço $\mathbf{R}^{\mathrm{K}_{1}}$, representado por um plano.

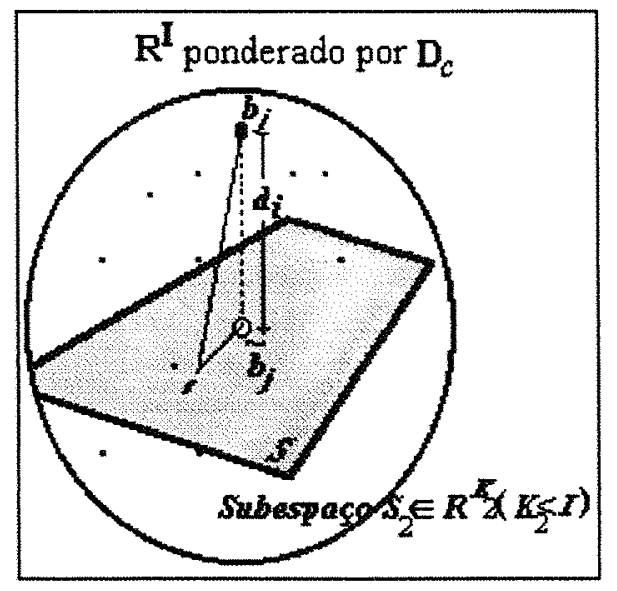

FIGURA 8. Pontos no espaço multidimensional $\mathbf{R}^{\mathbf{I}}$ e suas projeções sobre o subespaço $\mathbf{R}^{K_{2}}$, representado por um plano. 
Uma vez definido o critério, tanto para $\mathbf{R}^{\mathbf{J}}$ como para $\mathbf{R}^{\mathbf{I}}$. o problema agora é decobrir:

qual subespaço $S_{1}$ que minimiza o critério dado em (26) e

qual subespaço $S_{2}$ que minimiza o critério dado em (27)

Não será necessário aqui, deter-se nas operações matemáticas envolvidas nesta minimização, mas sim, ter em mente que a resposta para o problema acima está literalmente ligado a Técnica de decomposição de autovalores/autovetores ou na decomposição de valores singulares (D.V.S.), ora sobre uma matriz que representa o espaço das colunas, ora sobre uma matriz que representa o espaço das linhas.

\section{ADVSEAC}

\section{a) Em coluna $\left(\mathbf{R}^{\mathbf{J}}\right)$}

O problema se reduz em buscar uma nova base ortogonal, isto é, ajustar um subespaço de dimensão reduzida no sentido de Mínimos Quadrados Ponderados (M.Q.P.), de modo que, a representação dos I perfis linha sofra o mínimo de deformação ao ser projetado neste subespaço. Este procedimento é equivalente a encontrar um subespaço que contenha o máximo da inércia. A matriz dos perfis linha é representada por $\mathbf{R D}_{\mathbf{c}^{-1 / 2}}$ dada em (24) .

\section{Solução:}

Neste processo para se encontrar uma base $\mathbf{V}=\left\{\mathbf{V}_{\mathbf{1}}, \mathbf{V}_{\mathbf{2}}, \ldots, \mathbf{V}_{\mathbf{J}}\right\} \in \mathbf{R}^{\mathbf{J}}$, tal que, a inércia da nuvem de pontos linha, projetada sobre esta base seja máxima (ou que melhor represente os perfis linha), define-se uma matriz denominda de Matriz de Coordenadas Principais para as linhas, sobre os eixos procurados $V_{1}, V_{2}, \ldots, V_{J}$, que é dada por:

$$
\mathbf{F}=\left(\mathbf{R}-\mathbf{1} \mathbf{c}^{\prime}\right) \mathbf{D}_{\mathbf{c}}{ }^{-1 / 2} \mathbf{V}
$$

onde, $\mathbf{V}=\left[\mathbf{V}_{\mathbf{1}}\left|\mathbf{V}_{2}\right| \ldots \mid \mathbf{V}_{\mathbf{J}}\right] ; \mathbf{F}=\left[\mathbf{F}_{(1)}, \mathbf{F}_{(2)}, \ldots, \mathbf{F}_{(\mathrm{J})}\right] ; \mathbf{V}^{\prime} \mathbf{V}=\mathbf{I}$ 
28.

Isto é o mesmo que determinar os autovalores e autovetores associados à matriz :

$$
\mathbf{Z}=\mathbf{X}^{T} \mathbf{X}
$$

onde, $\mathbf{X}$ é a matriz definida por $\mathbf{D}_{\mathbf{r}}^{-1 / 2}\left(\mathbf{P}-\mathbf{r} \mathbf{c}^{\dagger}\right) \mathbf{D}_{\mathbf{c}} \mathbf{c}^{-1 / 2} \mathrm{e}$

$\mathbf{V}$ é a matriz de autovetores de $\mathbf{Z}$ associada aos autovalores: $\mu_{1}^{2} \geq \mu_{2}^{2} \geq \ldots \geq \mu_{\mathrm{J}}^{2} \geq 0$.

$$
\mathbf{Z V}=\mathbf{V D}_{\mu}^{2}
$$

Considerando, $\mathbf{V}$ e $\mathbf{D}_{\mu}{ }^{2}$ apenas com dimensões não nulas, tem-se que os autovetores de $\mathbf{Z}$ definem os eixos, denominados de Eixos Principais dos perfis linha. $O$ subespaço $S_{1}$ procurado, de dimensão $\mathrm{K}_{1}\left(1 \leq \mathrm{K}_{1} \leq \mathrm{J}-1\right)$ que minimize o critério em (26), está definido pelos $\mathrm{K}_{1}$ autovetores correspondente aos maiores $\mathrm{K}_{1}$ autóvalores de $\mathbf{Z}$.

As novas coordenadas dos perfis coluna, neste novo sistema de eixos são expressas pela Matriz de Coordenadas Principais dos perfis linha, dada por:

$$
\mathbf{F}=\mathbf{R D}_{\mathbf{c}^{-1 / 2} \mathbf{V}}
$$

\section{b) Em linha ( $\mathbf{R}^{\mathrm{I}}$ )}

A análise é análoga e simétrica como em $\mathbf{R}^{\mathbf{J}}$. O problema é o mesmo, encontrar uma base ortogonal que melhor caracterize os perfis coluna. A matriz que representa os perfis coluna é dada por $\mathbf{C D}_{\mathbf{r}}{ }^{-1 / 2}$ representada em (25)

\section{Solução:}

Neste processo para se encontrar uma base $\mathbf{U}=\left\{\mathbf{U}_{1}, \mathbf{U}_{2}, \ldots, \mathbf{U}_{\mathbf{I}}\right\} \in \mathbf{R}^{\mathbf{I}}$, tal que a inércia da nuvem de pontos coluna projetada sobre esta base seja máxima, define-se uma matriz, denominda de Matriz de 
Coordenadas Principais para as colunas, sobre os eixos procurados $\mathbf{U}_{\mathbf{1}}$, $\mathbf{U}_{2}, \ldots, \mathbf{U}_{\mathbf{I}}$, é dada por:

$$
\mathbf{G}=\left(\mathbf{C}-\mathbf{1} \mathbf{r}^{\prime}\right) \mathbf{D}_{\mathbf{r}}^{-1 / 2} \mathbf{U}
$$

onde, $\mathbf{U}=\left[\mathbf{U}_{\mathbf{1}}\left|\mathbf{U}_{\mathbf{2}}\right| \ldots \mid \mathbf{U}_{\mathbf{I}}\right] ; \mathbf{G}=\left[\mathbf{G}_{(1)}, \mathbf{G}_{(2)}, \ldots, \mathbf{G}_{(\mathrm{I})}\right] ; \mathbf{U}^{\prime} \mathbf{U}=\mathbf{I}$.

Isto é o mesmo que determinar os autovalores e autovetores associados à matriz :

$$
\mathrm{W}=\mathbf{X X}^{T}
$$

onde, $\mathbf{X}$ é a matriz definida por $\mathbf{D}_{\mathbf{r}}^{-1 / 2}\left(\mathbf{P}-\mathbf{r} \mathbf{c}^{\prime}\right) \mathbf{D}_{\mathbf{c}}{ }^{-1 / 2}$

$\mathbf{U}$ é a matriz de autovetores de $\mathbf{W}$ associada aos autovalores: $\psi_{1}^{2} \geq \psi_{2}^{2} \geq \ldots \geq \psi_{\mathrm{I}}^{2} \geq 0$.

$$
\mathbf{W U}=\mathbf{U} \mathbf{D}_{\psi}{ }^{2}
$$

Considerando, $\mathbf{U}$ e $\mathbf{D}_{\psi}{ }^{2}$ apenas com dimensões não nulas, tem-se que os autovetores de $\mathbf{W}$ definem os eixos, denominados de Eixos Principais dos perfis colunas. $O$ subespaço $S_{2}$ procurado de dimensão $\mathrm{K}_{2}\left(1 \leq \mathrm{K}_{2} \leq \mathrm{I}-1\right)$, que minimize o critério em (27), esta definido pelos $\mathrm{K}_{2}$ autovetores correspondente aos maiores $\mathrm{K}_{2}$ autovalores de $\mathbf{W}$.

As novas coordenadas dos perfis linha, neste novo sistema de eixos, são expressas pela Matriz de Coordenadas Principais dos perfis coluna, dada por:

$$
\mathbf{G}=\mathbf{C D}_{\mathbf{r}}^{-1 / 2} \mathbf{U}
$$




\section{c) Relação entre os espaços}

Os trabalhos realizados nos itens (a.) e (b.) foram conduzidos de forma independente para representar tanto a nuvem de pontos linha como a nuvem de pontos colunas em subespaço de dimensão reduzida.

Devido a uma estreita relação existente entre os autovalores de $\mathbf{Z}=$ $\mathbf{X}^{\prime} \mathbf{X}$ e de $\mathbf{W}=\mathbf{X X} \mathbf{X}^{\prime}$ estes subespaços podem ser sobrepostos gerando um subespaço único. Então, a idéia fundamental da Análise de Correspondência é obter as coordenadas principais dos perfis linha e coluna para este subespaço em dimensão reduzida e representá-las simultaneamente. Mais adiante será visto que esta representação se justifica graças as Relações Baricêntricas e a ortogonalidade existente entre os espaços.

Logo, as coordenadas principais dos perfis linha e coluna nesta representação são obtidas da Decomposição em Valores Singulares (DVS) da matriz X, isto é:

$$
\mathbf{X}=\mathbf{U} \mathbf{D}_{\alpha} \mathbf{V}^{T}
$$

O dimensionamento desta decomposição é : $0 \leq \mathbf{K} \leq \min \{(\mathbf{I}-1),(\mathbf{J}-1)\}$.

$$
\begin{aligned}
\text { Então, } \mathbf{U} & =\left[\mathbf{U}_{\mathbf{1}}\left|\mathbf{U}_{\mathbf{2}}\right| \ldots \mid \mathbf{U}_{\mathbf{K}}\right], \operatorname{com} \mathbf{U}^{\prime} \mathbf{U}=\mathbf{I} \\
\mathbf{V} & =\left[\mathbf{V}_{\mathbf{1}}\left|\mathbf{V}_{\mathbf{2}}\right| \ldots \mid \mathbf{V}_{\mathbf{K}}\right], \operatorname{com} \mathbf{V}^{\prime} \mathbf{V}=\mathbf{I} \mathrm{e} \\
\mathbf{D}_{\alpha} & =\operatorname{diag}\left(\alpha_{1}, \alpha_{2}, \ldots, \alpha_{\mathrm{K}}\right)
\end{aligned}
$$

onde

$\mathbf{D}_{\alpha}$ é uma matriz diagonal de valores singulares $\alpha_{\mathrm{k}}=\sqrt{\lambda_{\mathrm{k}}}: \mathrm{k}=1, \ldots$, $\mathrm{K}$, sendo que $\alpha_{\mathrm{k}}{ }^{2}=\lambda_{\mathrm{k}}: \mathrm{k}=1, \ldots, \mathrm{K}$, que são os autovalores tanto para $\mathbf{Z}$ como para $\mathbf{W}$, onde $\lambda_{1} \geq \lambda_{2} \geq \ldots \geq \lambda_{k}>0$, enquanto as colunas $\mathbf{U}_{\mathrm{k}}$ de $\mathbf{U}$ e $\mathbf{V}_{\mathrm{k}}$ de $\mathbf{V}$ são os autovetores correspondentes $\mathbf{W}$ e $Z$ respectivamente. 
As matrizes de coordenadas principais, para as respectivas nuvens de pontos linha e coluna, considerando apenas as dimensões não nulas, são:

$\mathbf{F}=\left[\mathbf{F}_{(1)}, \mathbf{F}_{(2)}, \ldots, \mathbf{F}_{(\mathrm{K})}\right]$ e $\quad \mathbf{G}=\left[\mathbf{G}_{(1)}, \mathbf{G}_{(2)}, \ldots, \mathbf{G}_{(\mathrm{K})}\right]$

$\operatorname{De}(\mathbf{a}$.$) e (b.), tem-se que:$

$$
\mathbf{F}=\mathbf{R} \mathbf{D}_{\mathbf{c}}^{-1 / 2} \mathbf{V} \quad \text { e } \quad \mathbf{G}=\mathbf{C D}_{\mathbf{r}}^{-1 / 2} \mathbf{U}
$$

Aqui, é possível perceber uma certa proporcionalidade entre os eixos de um espaço e outro através das matrizes $\mathbf{U}$ e $\mathbf{V}$, na qual, estão ligadas pelas seguintes relações

$$
\mathbf{U}=\mathbf{X ~ V ~ D ~} \mathbf{D}_{\alpha}^{-1} \quad \text { e } \quad \mathbf{V}=\mathbf{X}^{T} \mathbf{U} \mathbf{D}_{\alpha}^{-1}
$$

\section{RELAÇÕES BARICÊNTRICAS}

As correspondências entre os dois espaços vinculadas às Relações Baricêntricas, também conhecidas como Fórmulas de Transição, possibilitam transitar com as coordenadas de um espaço para outro, tornando possível representar, simultaneamente, as projeções dos pontos linhas e colunas sobre um mesmo gráfico, facilitando e enriquecendo a interpretação.

Tudo isto se justifica porque as coordenadas principais de linhas e colunas satisfazem as seguintes Fórmulas de Transição, respectivamente:

$$
\mathbf{F}=\mathbf{R} \mathbf{G ~ D}_{\alpha}^{-1} \quad \mathrm{e} \quad \mathbf{G}=\mathbf{C} \mathbf{F} \mathbf{D}_{\alpha}^{-1}
$$

Observe que as Fórmulas de Transição para Análise de Correspondência utiliza os resultados dos perfis linha (coluna) para a análise dos perfis coluna (linha). Então, as coordenadas do i-ésimo perfil linha e a coordenada do j-ésimo perfil coluna, sobre o k-ésimo eixo principal, são respectivamente:

$$
f_{i k}=1 / \sqrt{ } \lambda_{\mathrm{k}} \Sigma_{\mathrm{j}}\left(p_{i j} / p_{i}\right) \boldsymbol{g}_{\boldsymbol{j} \boldsymbol{k}} \text { e } \boldsymbol{g}_{\boldsymbol{j} \boldsymbol{k}}=1 / \sqrt{ } \lambda_{\mathrm{k}} \Sigma_{\mathrm{i}}\left(p_{i j} / p_{. j}\right) \boldsymbol{f}_{\boldsymbol{i k}}
$$


onde $\Sigma_{\mathrm{j}}\left(p_{i j} / p_{i .}\right)=1, \quad \Sigma_{\mathrm{i}}\left(p_{i j} / p_{. j}\right)=1$ e $0<\lambda_{\mathrm{k}} \leq 1$

$f_{i k}$ é o baricentro (centro de gravidade), exceto um coeficiente de dilatação $\left(1 / \sqrt{ } \lambda_{\mathrm{k}}\right.$ ) das projeções das $\mathbf{J}$ colunas sobre o mesmo eixo, sendo que cada coluna está afetada por um peso $\left(p_{i j} / p_{i}\right)$, segundo sua relativa importância $\operatorname{com} i$;

$g_{j k}$ é o baricentro (centro de gravidade), exceto um coeficiente de dilatação $\left(1 / \sqrt{ } \lambda_{\mathrm{k}}\right)$, das projeções das $\mathbf{I}$ linhas sobre o mesmo eixo, sendo que cada linha está afetada por um peso $\left(p_{i j} / p_{. j}\right)$, segundo sua relativa importância $\operatorname{com} \boldsymbol{j}$;

"Para efeito de análise prática pode-se desconsiderar os itens (a.) $e$ (b.), vistos anteriomente e, considerar apenas o item (c.). Os três itens foram abordados com objetivo de esclarecer o aspecto teórico envolvido na Análise de Correspondência."

\subsubsection{Interpretação dos Resultados}

$\mathrm{Na}$ interpretação dos resultadados a Análise de Correspondência busca auxílio em algumas medidas construídas a partir da decomposição da Inércia Total (como apresentado na secção 2.3.3.7.).

\section{AUXílio 1: Inércia Principal}

A Inércia Total $\left(\chi^{2} / \mathbf{n}\right)$ é decomposta através do conjunto de autovalores: $\lambda_{1}, \lambda_{2}, \ldots, \lambda_{\mathrm{k}}$, no qual são denominados de Inércias Principais. Como cada eixo principal $\left(\mathrm{e}_{\mathrm{k}} ; \mathrm{k}=1, \ldots, \mathrm{K}\right)$ corresponde a uma Inércia Principal $\left(\lambda_{\mathrm{k}} ; \mathrm{k}=1, \ldots, \mathrm{K}\right)$, então, pode-se obter uma "Porcentagem de Inércia" referente a cada eixo em relação à Inércia Total, isto é, quanto cada eixo principal explica da decomposição de cada nuvem de pontos, (ver tabela 3). 
TABELA 3. Representação da Inércia Principal e da Porcentagem de Inércia para os respectivos eixos principais.

\begin{tabular}{|c|c|c|}
\hline EIXO & $\begin{array}{c}\text { INÉRCIA } \\
\text { PRINCIPAL }\end{array}$ & $\begin{array}{c}\text { PORCENTAGEM } \\
\text { DE INÉRCIA }\end{array}$ \\
\hline \hline 1 & $\lambda_{1}$ & $\left(\lambda_{1} / \Sigma_{\mathrm{k}} \lambda_{\mathrm{k}}\right) 100$ \\
2 & $\lambda_{2}$ & $\left(\lambda_{2} / \Sigma_{\mathrm{k}} \lambda_{\mathrm{k}}\right) 100$ \\
$\cdot$ & $\cdot$ & $\cdot$ \\
$\cdot$ & $\cdot$ & $\cdot$ \\
$\mathrm{K}$ & $\lambda_{\mathrm{k}}$ & $\left(\lambda_{\mathrm{k}} / \Sigma_{\mathrm{k}} \lambda_{\mathrm{k}}\right) 100$ \\
\hline TOTAL & $\sum_{\mathrm{k}} \lambda_{\mathrm{k}}$ & 100 \\
\hline
\end{tabular}

Relações: Inécia Total $=\chi^{2} / \mathbf{n}=\operatorname{Tr}\left(\mathrm{D}_{\alpha}{ }^{2}\right)=\sum_{\mathrm{k}} \lambda_{\mathrm{k}}=$ Inércia Principal

Pelo fato de as Inércias principais estarem em ordem descendente, isto significa que os dois 1 os eixos contabilizam a maior porcentagem de explicação. Por exemplo, se $87 \%$ da inércia dos perfis está representada num subespaço bi-dimensional. então, a inércia residual, ou erro, que se encontra fora deste subespaço é $13 \%$. Logo, a qualidade deste ajuste é de $87 \%$ e o erro cometido nesta representação é de $13 \%$.

A FIGURA 9 exibe um gráfico que representa simultaneamente a i- ésima coordenada principal de linha e a j-ésima coordenada principal de coluna sobre o subespaço bi-dimensional formado pelos dois 1 os eixos principais, com as respectivas porcentagem de inércia.

$\mathrm{Na}$ Análise de Correspondência o gráfico que representa os pontos perfis é também chamado de "Mapa dos perfis". 


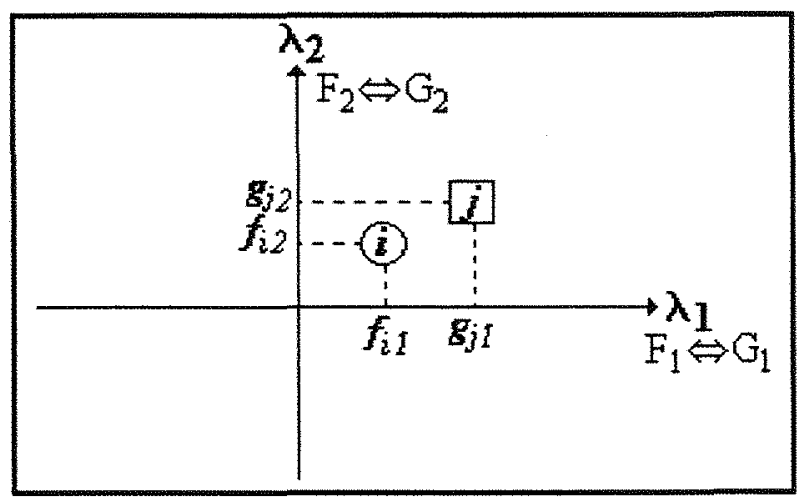

FIGURA 9. Mapa bi-dimensional respresentando simultaneamente as coordenadas principais $f_{i k}(\mathrm{k}=1, \ldots, \mathrm{K})$ e $g_{j k}(\mathrm{k}=1, \ldots, \mathrm{K})$.

Conseqüentemente cada Inércia Principal $\lambda_{\mathrm{k}}(\mathrm{k}=1, \ldots, \mathrm{K})$ pode ser decomposta em componentes correspondentes a cada perfil linha e a cada perfil coluna ao longo dos eixos principais, estes componentes estão ilustrados na TABELA 4. Esta tabela dispõe de informações numéricas de grande importância, pois além de serem úteis na interpretação da Análise de Correspondência servirão, também, de suporte para definir outras medidas auxiliares, como as "Contribuições absolutas e relativas", que serão posteriormente abordadas.

TABELA 4. Decomposição da Inércia

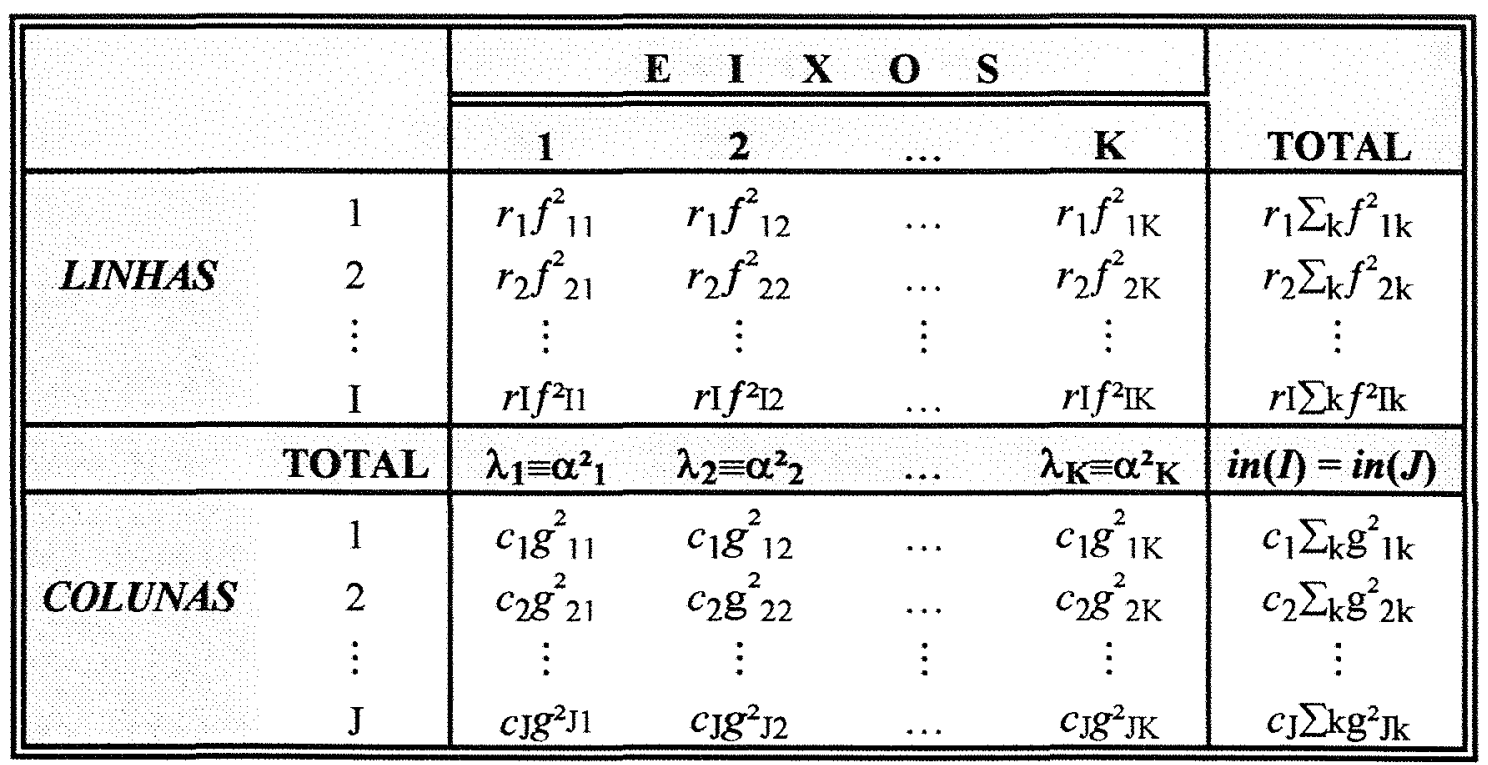




\section{AUXÍLIO 2: Contribuição Absoluta e Relativa}

Não tente interpretar, dar formas e julgar o que se vê no mapa dos perfis antes de consultar, também, as Contribuições Absolutas e as Contribuições Relativas, as quais fornecem um diagnóstico que permite identificar quais os pontos que mais contribuem na formação dos eixos principais e, por conseguinte, quantificar quão bem um ponto individual está representado.

\section{Contribuição Absoluta}

A Contribuição Absoluta é quanto um ponto expressa de contribuição na caracterização de um eixo. Então a Contribuição Absoluta do iésimo perfil linha ao k-ésimo eixo é definida por:

$$
C_{i k}^{(a)}=r_{i} f_{i k}^{2} / \lambda_{k}
$$

onde $\lambda_{\mathrm{k}}=\sum_{\mathrm{i}} \mathrm{r}_{\mathrm{i}} \mathrm{f}_{\mathrm{ik}}^{2}(\mathrm{k}=1, \ldots, \mathrm{K})$ é a inércia explicada pelo k-ésimo eixo;

$$
\Sigma_{\mathrm{i}} C_{i k}^{(a)}=1(\mathrm{k}=1, \ldots, \mathrm{K})
$$

Analogamente, a Contribuição Absoluta do j-ésimo perfil coluna ao késimo eixo é definida por:

$$
C_{j k}^{(a)}=c_{j} g_{j k}^{2} / \lambda_{k}
$$

onde $\lambda_{\mathrm{k}}=\Sigma_{\mathrm{j}} \mathrm{r}_{\mathrm{j}} \mathrm{fjk}^{2} \quad(\mathrm{k}=1, \ldots, \mathrm{K})$ é a inércia explicada pelo k-ésimo eixo;

$$
\sum_{\mathrm{j}} c_{j k}^{(a)}=1 \quad(\mathrm{k}=1, \ldots, \mathrm{K})
$$


36.

\section{Contribuição Relativa}

A Contribuição Relativa é quanto um eixo contribui na caracterização de um ponto. Então, a contribuição relativa do k-ésimo eixo ao i-ésimo perfil linha é definida por:

$$
C_{i k}^{(r)}=f_{i k}^{2} / \Sigma_{\mathrm{k}} f_{i k}^{2}
$$

Analogamente, a contribuição relativa do k-ésimo eixo ao j-ésimo perfil coluna é definida por:

$$
C_{j k}^{(r)}=g_{j k}^{2} / \Sigma_{\mathrm{k}} g_{j k}^{2}
$$

\section{Interpretação geométrica alternativa da Contribuição Relativa}

A Contribuição Relativa pode ser vista como-o cosseno quadrado de um ângulo. Considere a situação descrita pela FIGURA 10, onde $r_{i}$ é a massa do i-ésimo perfil linha $a_{i}, c$ o centróide e $d_{i}$ é a distância $\chi^{2}$ de $a_{i}$ para $c$, ainda:

. $f_{i k}$ é a coordena da principal de $a_{i}$ em relação ao k-ésimo eixo principal;

. $\lambda_{k}$ é a k-ésima inércia principal e

. $\theta_{i k}$ é o ângulo formado entre o vetor $a_{i}$ e o k-ésimo eixo principal em relação ao centróide

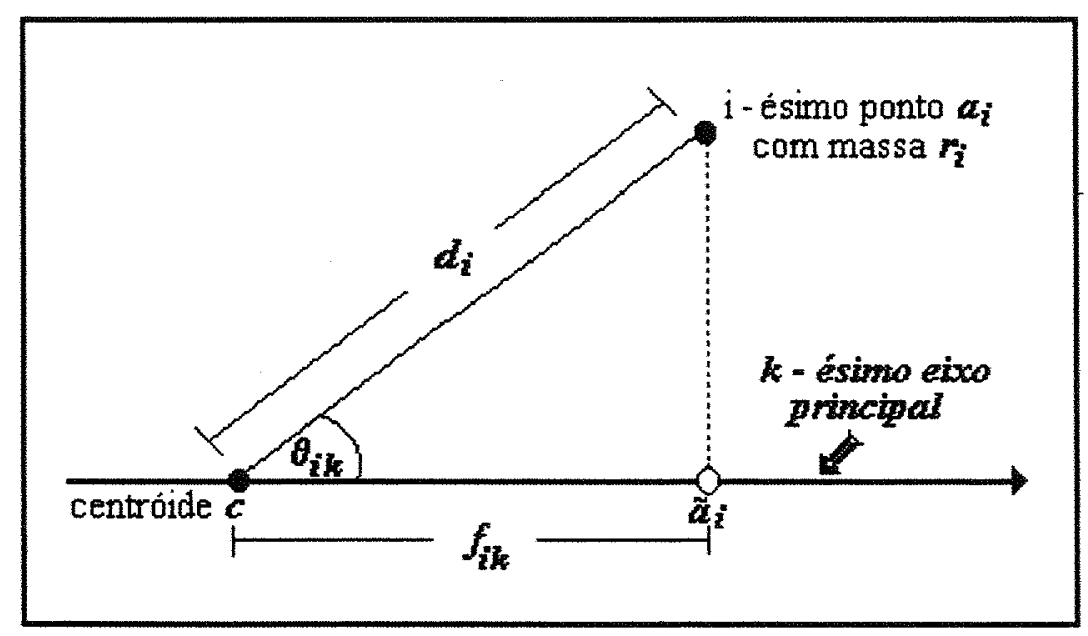

FIGURA 10, $C_{i k}^{(r)}=\cos ^{2}\left(\theta_{i k}\right)$. 
Sabe-se que: $C_{i k}{ }^{(r)}=\cos ^{2}\left(\theta_{i k}\right)=f^{2}{ }_{i k} / d^{2}{ }_{i}$, onde $d^{2}{ }_{i}=f^{2}{ }_{i 1}+f^{2}{ }_{i 2}+$ $\cdots+f_{i k}^{2}=\sum_{\mathrm{k}} f^{2}{ }_{i k}$ (Teorema de Pitágoras). Então, desde que se interpreta geometricamente o coeficiente de correlação como o cosseno de um ângulo, pode-se pensar nas Contribuições Relativas, equivalentemente, como correlações quadradas entre os perfis linha e o eixo pricipal. Esta quantidade atinge o valor máximo de 1, se o perfil linha se encontra sobre o eixo principal, e o mínimo de 0 , se o perfil linha é perpendicular ao eixo principal, uma vez que sua projeção tem comprimento zero.

Portanto, a Contribuição Relativa é um indicador da qualidade da representação de um ponto pelo eixo.

\subsubsection{Reconstrução da Tabela de Contingência}

A tabela $\mathbf{P}$, pode ser reconstruída por intermédio da seguinte expressão:

$$
\mathbf{P}=\mathbf{r c}^{\prime}+\mathbf{D}_{\mathbf{r}} \mathbf{F D}_{\alpha}^{-1} \mathbf{G}^{T} \mathbf{D}_{\mathbf{c}}
$$

onde $\boldsymbol{p}_{\boldsymbol{i} \boldsymbol{j}} \cong \boldsymbol{p}_{\boldsymbol{i}} \boldsymbol{p}_{. j}\left(1+\Sigma_{\mathrm{k}} f_{i k} g_{j k} / \sqrt{ } \lambda_{\mathrm{k}}\right)$ é a estimativa da frequência relativa da interação entre iésima categoria de linha com a j-ésima categoria de coluna calculada sobre os $k$ eixos ajustados. A partir desta expressão é possível perceber claramente que a Análise de Correspondência (AC) tem como característica, decompor os resíduos da esperança de P, sob a hipótese de independência $\left(p_{i j}=p_{i} p_{. j}\right.$ a menos de uma situação aleatória). É gerado um modelo nesta decomposição definido como: modelo de independência para AC (TABELA 5). Os resíduos deste modelo são decompostos e plotados. Desta forma fica explícita a interação entre linhas e colunas.

TABELA 5. Resultado dos parâmetro para o modelo de AC.

\begin{tabular}{|l|c|c|}
\hline Parâmetro & Notacão & $\mathbf{N}^{\circ}$ de parâmetros (gl) \\
\hline marginal linha & $p_{i}$ & $\mathrm{I}-1$ \\
\hline marginal coluna & $p_{j}$ & $\mathrm{~J}-1$ \\
\hline autovalor & $\sqrt{\lambda_{\mathrm{k}}}$ & $\mathrm{K}$ \\
\hline escores linha & $\mathbf{U}_{\mathrm{ik}}$ & $\mathrm{IK}-2 \mathrm{~K}-\mathrm{K}(\mathrm{K}-1) / 2$ \\
\hline escores coluna & $\mathbf{V}_{\mathrm{ik}}$ & $\mathrm{JK}-2 \mathrm{~K}-\mathrm{K}(\mathrm{K}-1) / 2$ \\
\hline Total & & $(\mathbf{I}+\mathbf{J})(\mathrm{K}+\mathbf{1})-\mathbf{2}-\mathbf{K}^{2}-\mathbf{2}$ \\
\hline
\end{tabular}


38.

\subsubsection{Pontos Suplementares}

Os pontos suplementares são linhas e/ou colunas adicionais de uma tabela de contingência. Eles, não interferem na análise, não participam no ajuste dos eixos e não contribuem no cálculo da inércia. As massas desses pontos são iguais a zero, por isso, eles também são chamados de pontos passivos, mesmo assim, é possível projetá-los num gráfico (mapa) que já se encontra estabilizado. O propósito de representar pontos suplementares é geralmente para facilitar e enriquecer a interpretação e até mesmo validar a análise.

Podem-se citar três situações comuns na utilização de pontos suplementares linhas e/ou colunas (TABELA 6):

1 - quando uma ou mais linhas adicionais haviam sido excluídas;

2 - quando uma ou mais colunas adicionais haviam sido excluídas e

3 - quando uma diferente linha e/ou coluna foi adicionada.

TABELA 6. Pontos suplementares na tabela de contingência

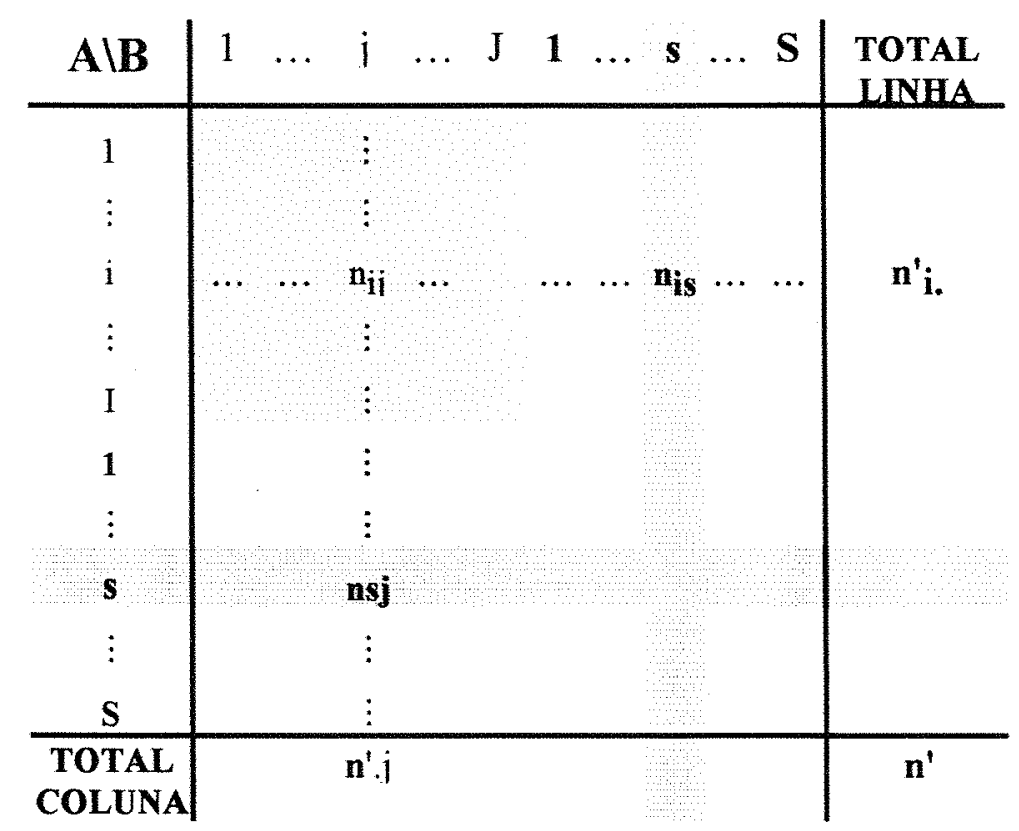


As projeções dos pontos suplementares, para linhas e colunas, são fornecidas utilizando as expressões apresentadas em (39). Assim, a projeção de uma linha suplementar $\mathbf{s}$, com valores $\mathbf{n}_{\mathbf{s j}}$ sobre o k-ésimo eixo principal será:

$$
f_{s k}=a_{s}^{\prime} \mathbf{G ~ D}_{\alpha}^{-1}
$$

onde $a_{s}^{\prime}=1 / n_{s .}\left(n_{s 1}, n_{s 2}, \ldots, n_{s J}\right)^{T}, \operatorname{com} n_{s .}=\Sigma_{j} n_{s j}$

Analogamente, a projeção de uma coluna suplementar s, com valores $\mathbf{n}_{\text {is }}$ sobre o mesmo eixo principal será:

$$
g_{s k}=b_{s}^{\prime} F^{-1}{ }_{\alpha}
$$

onde $b_{s}^{\prime}=1 / n_{. s}\left(n_{1 s}, n_{2 s} \ldots, n_{I s}\right)^{T}, \operatorname{com} n_{. s}=\Sigma_{i} n_{i s}$.

\subsubsection{Extensões e Softwares}

Os ítens apresentados anteriormente são essenciais para execução de uma Análise de Correspondência Simples sobre uma tabela de contingência de dupla entrada, o mesmo procedimento pode ser exatamente aplicado em outras tabelas obtendo-se excelentes resultados, como por exemplo: a Análise de Correspondência Múltipla a que está relacionada com a representação das categorias de mais de duas variáveis discretas (Tabela de "Burt"). A Análise de Correspondência pode ser integrada aos Modelos Log-Lineares, a Análise Longitudinal de Dados Categórizados e outros.

Os cálculos matemáticos do algoritmo da Análise de Correspondência são todos processados utilizando equipamentos computacionais através de "Softwares Estatísticos". Segundo GREENÁCRE (1993), é conveniente dividir os softwares em dois grupos: O Geral e o Específico. O software Geral, dentre os quais podem-se citar: BMDP, SPSS e SAS, é aquele que não se concentra numa área particular de aplicação. Entretanto, o software Específico, no qual podem-se citar: CANOCO, DUAL3, MAPWISE, NTSYS-pc, PC-MDS e SimCA, é direcionado para uma área particular de aplicação, tal como pesquisa de mercado, ecologia, arqueologia ou biologia. 
É possível avaliar a eficiência dos softwares mencionados em relação à Análise de Correspondência levando em consideração pontos importantes como:

1. A entrada dos dados;

2. A saída numérica e gráfica $e$

3. A qualidade e o conteúdo do documento.

Mais detalhes sobre o método, suas extensões e comparativos entre softwares encontram-se nas referências bibliográficas.

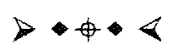

"A Análise de Correspondência deve ser compreendida como a "arte" de reexpressar dados categórizados numa forma ilustrativa de fácil interpretação." 


\section{MATERIAL E MÉTODOS}

\subsection{Material}

Os dados são provenientes de uma amostra de 85 criações intensivas de suínos, selecionadas ao acaso, situadas na região Oeste de Santa Catarina e no Sudoeste do Paraná, com número de matrizes que variou entre 20 a 100.

Os dados foram coletados mediante a aplicação de um questionário (ANEXO 1), composto de 158 variáveis (quantitativas e qualitativas). O questionário continha variáveis que caracterizavam o problema patológico estudado, "Diarréia do Ieitão", e um conjunto de variáveis ligadas ao ecossistema do suíno. Muitas das informações requeriam o acompanhamento diário dos animais.

A tarefa de coleta dos dados foi realizada ao longo dos meses, num período compreendido entre os anos de 1988 a 1992 (TABELA 7).

TABELA 7. Indicação dos meses (国) dentro de ano, onde pelo menos uma granja foi avaliada.

\begin{tabular}{|c|c|c|c|c|c|c|c|c|c|c|c|c|}
\hline \multirow[b]{2}{*}{ ANO } & \multicolumn{5}{|r|}{$\overline{\mathbf{M}}$} & \multirow{2}{*}{$\frac{\hat{\mathbf{E}}}{\text { Jun }}$} & \multirow{2}{*}{$\frac{\mathbf{S}}{\mathrm{Jul}}$} & \multirow{2}{*}{$\frac{\mathbf{E}}{\text { Ago }}$} & \multicolumn{4}{|l|}{ S } \\
\hline & Jan & Fev & Mar & $\mathrm{Abr}$ & Mai & & & & Set & Out & Nov & $\overline{\mathrm{Dez}}$ \\
\hline 1988 & & $\mathrm{X}$ & [] & [x] & {$[\mathbf{X}$} & $\mathbb{\mathbf { X }}$ & [ख] & [x] & & 区] & {$[\mathbf{x}]$} & {$[\mathbf{x}$} \\
\hline 1989 & $\mathbf{X}$ & & & & & & & & & 凶 & {$[\mathbf{E}$} & \\
\hline 1990 & & [ख] & & & & & & 区 & 凶] & 凶 & $\underline{\square}$ & [ब] \\
\hline 1991 & {$[\overline{\mathbf{X}}$} & [X] & [凶] & [D] & {$[\mathbf{x}$} & {$[\mathbf{X}]$} & {$[\mathbf{x}$} & {$[\mathbf{x}]$} & [ & & & \\
\hline 1992 & & & 凶. & {$[\mathbf{x}$} & $\sqrt{\mathrm{B}}$ & {$[\mathbf{X}]$} & {$[\mathrm{E}]$} & & & & & \\
\hline
\end{tabular}




\subsection{Métodos}

\subsubsection{Realização da Coleta de Dados no Sistema de Produção}

Num sistema de produção, a maternidade é o local onde ocorre o parto, a lactação (amamentação ou aleitamento) e a desmama. O questionário foi aplicado desde o momento do parto até o desmame dos leitões (FIGURA 11).

A unidade experimental era composta pela porca e sua leitegada A FIGURA 12, exibe uma porca com sua leitegada no momento da mamada. O número de porcas e leitegadas, acompanhadas por granja, variava de 4 a 8 e o tamanho das leitegadas esteve entre 2 a 13 leitões desmamados.

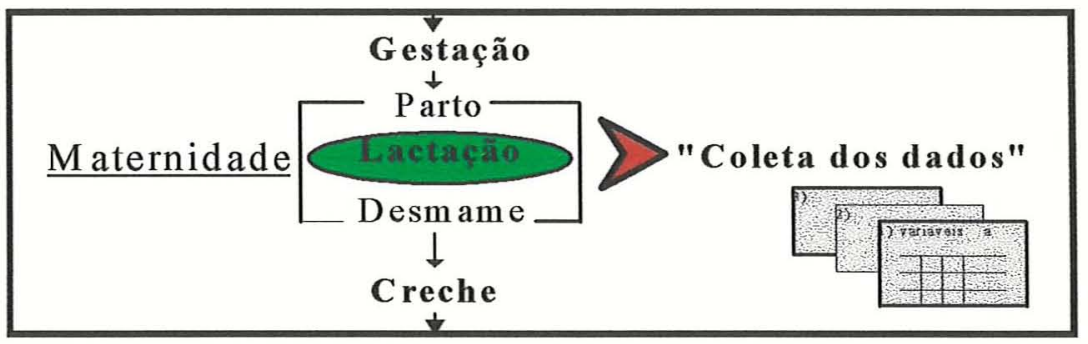

FIGURA 11. Ponto de realização da coleta de dados.

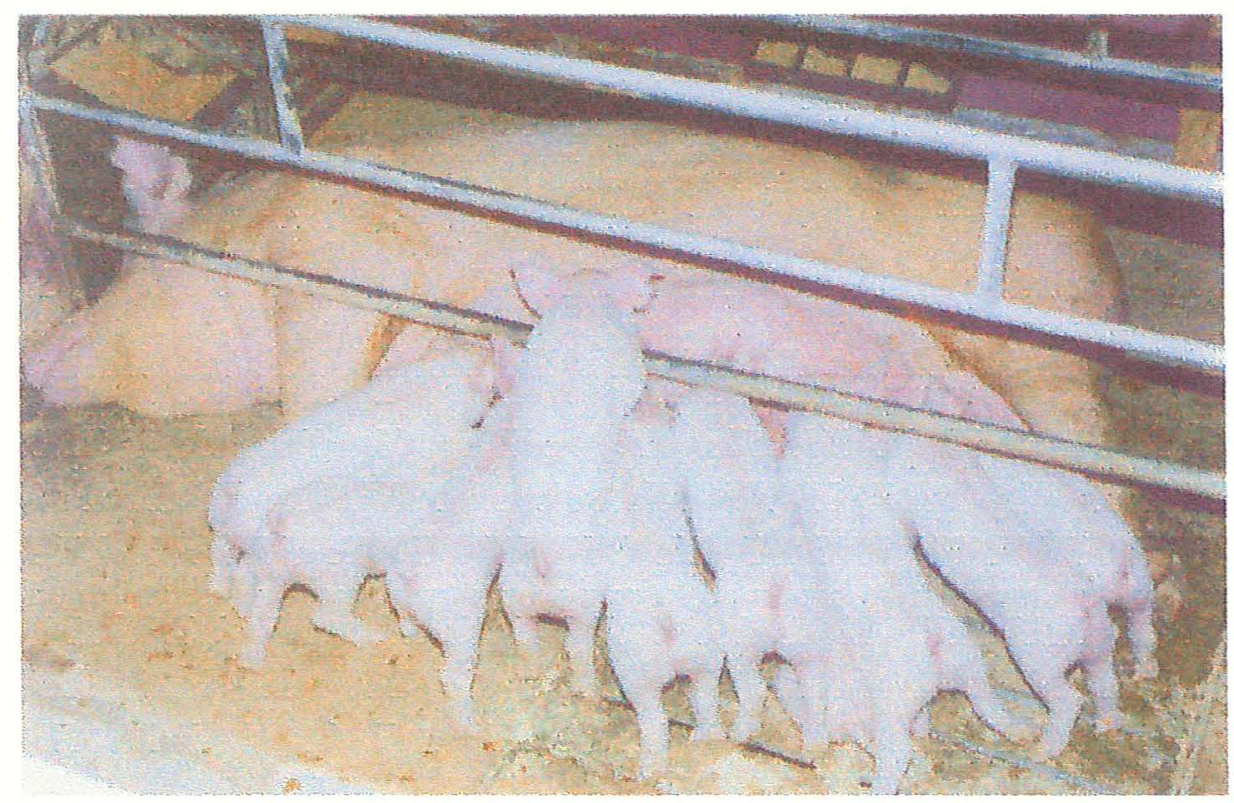

FIGURA 12. Uma fêmea com seus leitões num sistema confinado. 


\subsubsection{Dados Recolhidos deste o Parto até o Desmame}

As informações eram registradas em planilhas adequadas, onde eram registrados dados sobre a alimentação (composição, qualidade e quantidade), manejo, instalação (tipo, temperatura, higrometria, ventilação), profilaxia (desparasitação externa e interna, vacinações e terapêutica), performance dos leitões (pesagem individual) e saúde das porcas e suas leitegadas (FIGURA 13).

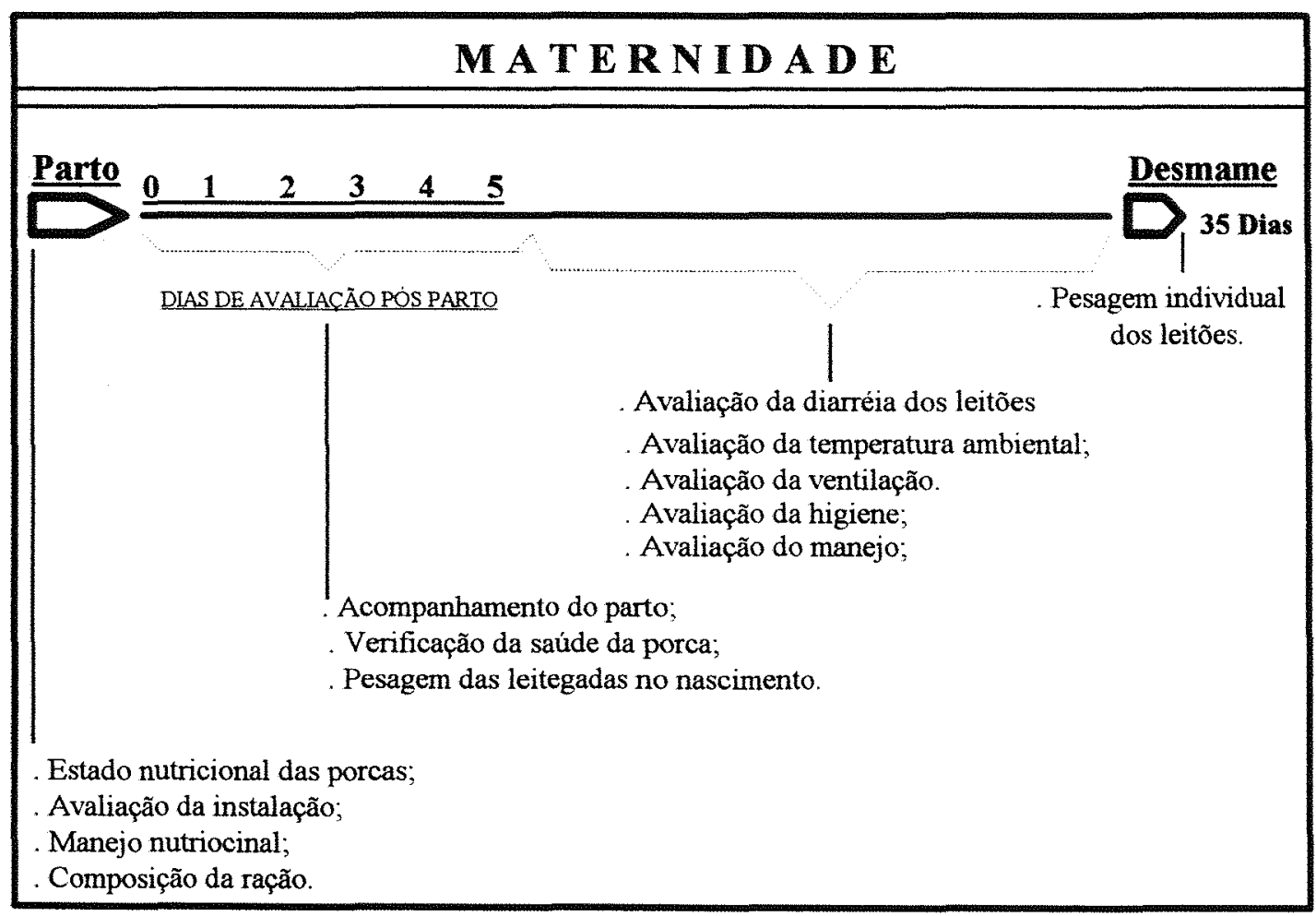

FIGURA 13. Esquema de coleta dos dados, desde parto até o desmame.

\subsubsection{Descrição das Variáveis}

No final de 5 anos de trabalho (1988 a 1992), os questionários de investigação, aplicados nas 85 propriedades amostradas, geraram um arquivo de dados que continha informações referentes ao leitão, à diarréia, à granja, à leitegada, à temperatura, ao manejo e ao puerpério. Este arquivo comportava 158 variáveis por 442 leitegadas, divididas da seguinte maneira: 


\section{I) VARIÁVEIS REFERENTES AO LEITÃO:}

NLV : número de leitões nascidos vivos;

PMV : peso médio da leitegada no nascimento $(\mathrm{kg})$;

NLD : número de leitões desmamados;

PAR : parasitismo nos leitões e fêmeas;

IMD : idade média do desmame;

PD1 : peso do leitão $n^{\circ} 01$ no desmame;

PD2 : peso do leitão $n^{\circ} 02$ no desmame;

PD3 : " $\quad$ n 03 ;

PD4 : " $\quad$ n $04 \quad$;

PD5 : " $\quad$ n $05 \quad$ "

PD6 : " $\quad$ n 06 "

PD7 : " $\quad$ n $07 \quad$;

PD8 : " $\quad$ n $08 \quad$ ";

PD9 : " n " 09 ;

PD10: " $\mathrm{n}^{\circ} 10$ "

PD11: " $\mathrm{n}^{\circ} 11 \quad$ "

PD12: " $\quad \mathrm{n}^{\circ} 12 \quad$ "

PD13: peso do leitão $n^{\circ} 13$ no desmame;

\section{II) VARIÁVEIS REFERENTES À DIARRÉIA:}

DIAR08: ocorrência de diarréia na maternidade no $8^{\circ}$ dia de vida; DIAR09: ocorrência de diarréia na maternidade no $9^{\circ}$ dia de vida; DIAR10: ocorrência de diarréia na maternidade no $10^{\circ}$ dia de vida;

DIAR35: ocorrência de diarréia na maternidade no $35^{\circ}$ dia de vida;

$\Rightarrow$ OBS: 1: presença de diarréia ; 2: ausência de diarréia 


\section{III) VARIÁVEIS REFERENTES AO MANEJO E AS INSTALACÕES:}

AC: vacina contra colibacilose (1: $\operatorname{sim} ; 2$ : não); NUT: estado nutricional médio das porcas (média do grupo de porcas acompanhadas);

ALEI: assistência ao leitão, com corte de dentes e desinfecção do umbigo (1: sim; 2: não);

vS: vazio sanitário: (1: sistema contínuo

$$
\begin{aligned}
& 2: 1 \leq \text { vazio sanitário } \leq 5 \text { dias } \\
& \text { 3: } \quad \text { vazio sanitário }>5 \text { dias); }
\end{aligned}
$$

AG: aleitamento em grupo (1:sim, 2: não);

PSH: parecer sobre a higiene (1: boa; 2 : regular; 3 : ruim);

PONF: porcentagem de onfalite (\%);

PART: porcentagem de artrite (\%);

AT: avaliação de tosse (\%);

AE: avaliação de espirro (\%);

PD: altura do pé direito $(\mathrm{m})$;

LM: largura da maternidade (m);

CM: comprimento da maternidade (m);

CP: comprimento do pontalete $(\mathrm{m})$;

NCP: número de celas parideiras;

NLP: número de leitegadas presentes;

VAL: volume de ar por leitegada $\left(\mathrm{m}^{3}\right)$;

ACP: área da cela parideira $\left(\mathrm{m}^{2}\right)$;

PAJ: abertura de portas e janelas externas, pela área lateral (\%);

TP: tipo de piso (1: compacto; 2: semi-ripado; 3: totalmente ripado);

TF: presença de forro (1: $\operatorname{sim} 2:$ não);

TC: tipo de cobertura (1: telha de barro; 2 : cimento amianto; 3 : outros);

PE: presença de escamoteador (1: sim; 2: não);

FSC: fonte suplementar de calor (1: $\operatorname{sim} ; 2$ : não);

PTE: presença de tampa no escamoteador (1:sim; 2:não);

ARE: área do escamoteador $\left(\mathrm{m}^{2}\right)$. 


\section{V) VARIÁVEIS REFERENTES À TEMPERATURA AMBIENTAL:}

TMAX01: temperatura máxima ambiental na maternidade no dia 01; TMAX02: temperatura máxima ambiental na maternidade no dia 02; :

TMAX30: temperatura máxima ambiental na maternidade no dia 30;

$$
=\| I I I=
$$

TMIN01: temperatura mínima ambiental na maternidade no dia 01; TMIN02: temperatura mínima ambiental na maternidade no dia 02 ;

TMIN30: temperatura mínima ambiental na maternidade no dia 30;

\section{VI) VARIÁVEIS REFERENTES AO PUERPÉRIO:}

PNP: problema no parto (1: $\operatorname{sim} ; 2$ : não);

DDP: data do parto ( dia/mês/ano);

ODP: ordem do parto;

TRF1: temperatura retal da porca $1 / 2 \mathrm{~h}$. após o arraçoamento no dia 1 ;

TRF5: temperatura retal da porca $1 / 2 \mathrm{~h}$. após o arraçoamento no dia 5; CVP1: corrimento vulvar purulento no dia 1 (1: sim; 2: não);

CVP5: corrimento vulvar purulento no dia 5 (1: sim; 2: não); APN1: apetite da porca no dia 1 (1: com apetite; 2 : sem apetite);

APN5: apetite da porca no dia 5 (1: com apetite; 2 : sem apetite);

MMA1: mamite, mastite e agalaxia no dia 1 (1: ausência; 2 : presença);

MMA5: mamite, mastite e agalaxia no dia 5 (1: ausência; 2 : presença); TCO: tratamento com ocitocina (1: $\operatorname{sim} ; 2$ : não);

TRA: tramento com antibiótico (1: $\operatorname{sim} ; 2$ : não); 


\subsubsection{Método Estatístico}

Na metodologia definida na França, por MADEC \& JOSSE (1984), existe uma fase de análise estatítica para investigação dos problemas patológicos de suínos criados intensivamente.

O esquema apresentado pela FIGURA 14, documenta as diversas etapas usadas no procedimento de identificação dos fatores de risco, associados à diarréia dos leitões. Este esquema de análise estatística dos dados dividi-se em dois processamentos: Prévio e Específico.

\section{Processamento Prévio:}

Neste processamento se teve o primeiro contacto com os dados, a partir dai realizou-se um trabalho exploratório que compreende testes estatísticos descritivos (análise de variância, testes paramétricos, testes não paramétricos, regressão, histogramas), que possibilitou a uniformização das informações, a categorização, a definição de variáveis: respostas, explicativas e suplementares, e a eliminação de variáveis sem associação com o problema.

O módulo BASICO do SAS, através das operações lógicas e aritméticas, e PROCs: CHART, CORR, FREQ, MEANS e UNIVARIATE deram fundamental apoio na geração de novas variáveis, na correção e separações em classes. No modulo ESTATÍSTICO, utilizando o PROC REG, foi possivel corrigir (estimar) algumas variáveis (por ex.: ganho de peso) em relação à idade dos leitões, também utilizou-se do PROC ANOVA para confirmar se as categorias das variáveis (fonte de variação) estavam bem definidas em relação ao valor original da variável (fator).

$O$ objetivo final deste processamento foi gerar um arquivo que contivesse somente variáveis qualitativas. $O$ enfoque matemático e estatístico, aplicado na geração deste arquivo é descrito, mais adiante; no item 3.3. "Processamento dos Dados".

\section{Processamento Especifico:}

As variáveis resultantes do processamento prévio formaram o "input" para o processamento específico, isto é, definiu-se um arquivo de trabalho, que possibilitou, através da aplicação da Análise de Correspondência, a identificação dos fatores de risco associados à diarréia e à performance dos leitões. Ainda neste processo construiram-se Mapas dos fatores de risco.

Para a Análise de Correspondência utilizou-se do PROC CORRESP do SAS, e usando arquivos de saída (output data set) como entrada (input) para os PROCs: GPLOT ou PLOT para a geração dos mapas. 
O tradicional desta fase de análise estatística, é processar as etapas Prévia e Especifica por intermédio de "softwares" distintos, isto é, usar um programa de manipulação de dados para o processamento prévio, geralmente "planilhas" de dados, e depois um programa específico de Análise de Correspôndência (AC), que englobe estudos gráficos para representação dos Mapas dos fatores de risco.

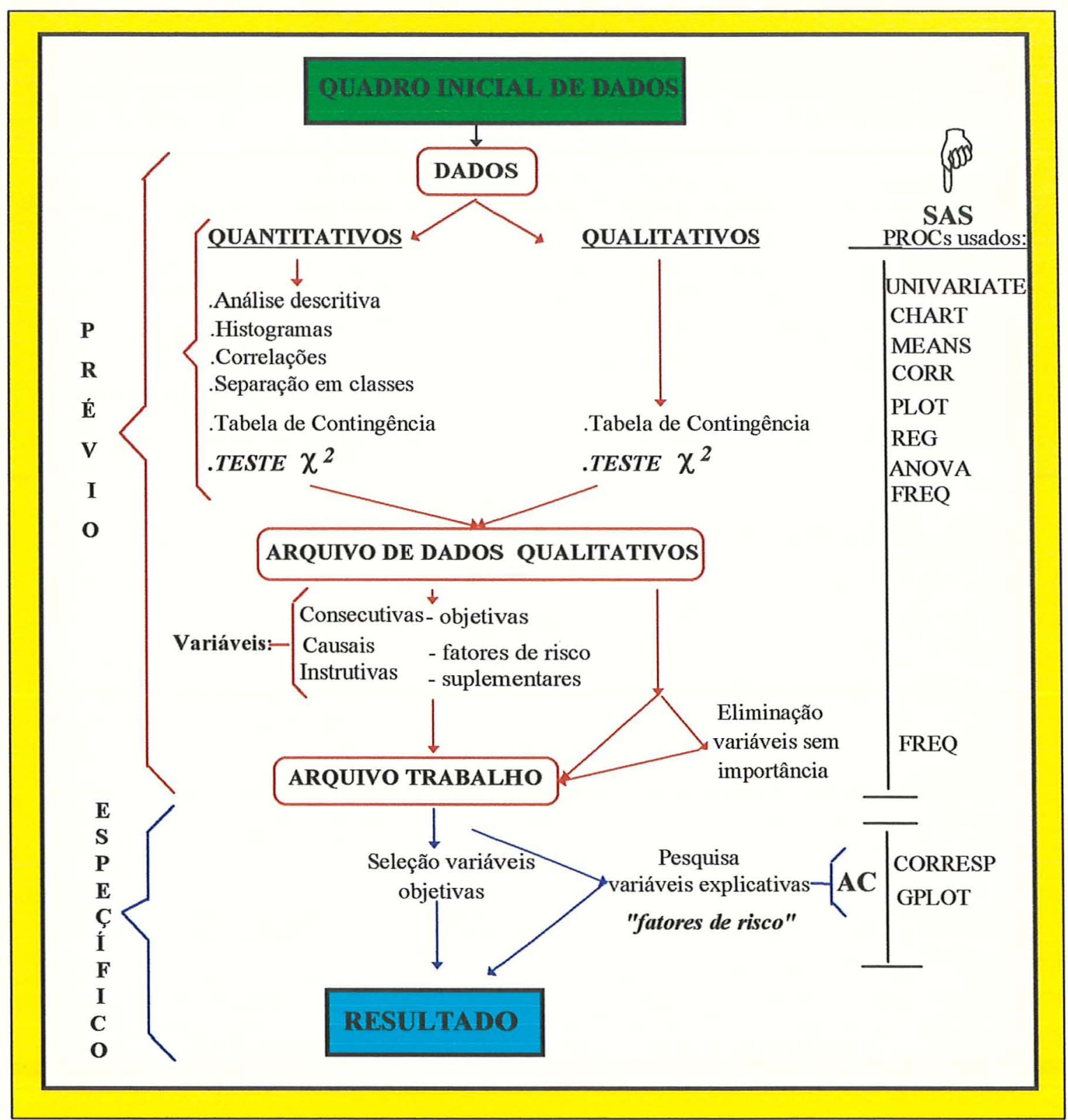

FONTE : MADEC \& JOSSE (1984)

FIGURA 14. Esquema geral das principais operações na identificação dos fatores de risco. 


\subsection{Processamento dos Dados}

As informações dos questionários, ao passo que iam sendo obtidas na tarefa de campo, eram lançadas em planilhas especiais (gabarito de digitação). Esses dados foram posteriomente registrados em arquivos, mediante recursos computacionais.

\subsubsection{Registro dos Dados}

Os dados registrados continham informações, tanto de variáveis qualitativas como quantitativas. Quanto às variáveis quantitativas é importante ressaltar que foram registrados os valores efetivos da escala de medida previamente definida, não o resultado de sua classificação. Para as variáveis qualitativas, apesar das categorias serem relativamente subjetivas, procurou-se dar uma classificação o mais conveniente possivel pelo que se observava. Este procedimento propiciou estudos exploratórios mais detalhados sobre os dados. Além de conservar o máximo de sua representatividade, também ajudou na criação, na correção, no descarte e na classificação de algumas variáveis, segundo as necessidades do tratamento estatístico.

\subsubsection{Criação de Arquivo}

Os dados referentes à seção 3.2.3., foram digitados em arquivos "dbase" e posteriomente lidos pelo sistema SAS (Statistical Analysis System), através do qual, foi gerado um único arquivo de dados endereçado pelas variáveis: "CDG" código da granja e "MDF" número da porca.

Como mencionado anteriomente, este arquivo de trabalho continha 158 variáveis por 442 observações, provenientes dos questionários aplicados nas 85 propriedades visitadas no período de 1988 a 1992. Este arquivo foi básico para o processamento dos dados, até a identificação dos fatores de risco. 
50.

A estrutura deste arquivo pode ser vista na TABELA 8, onde cada linha representa a informação de uma porca de uma respectiva granja, a qual foi submetida o questionário.

TABELA 8: Estrutura do arquivo de dados das variáveis originais

\begin{tabular}{|c|c|c|c|c|c|c|c|}
\hline & \multicolumn{5}{|c|}{ CONJUNTO DE VARIAYEIS ESTUDADAS } \\
\hline & & & LEITÓES & DIARRÉLA & GRANJA & TEMPERATURA & PUERPÉRIO \\
\hline oBs & $\mathrm{CDG}$ & MDF & PD1 ... PD13 & DIAR8 $\cdots$ DIAR35 & VC $\cdots$ ARE & TMAX1 ‥ TMIN30 & PNP ... TRA \\
\hline 01 & 01 & 163 & $4.6 \cdots * *$ & $2 \cdots 1$ & $1 \cdots 0.6$ & $26 \cdots 22$ & $1 \cdots 1$ \\
\hline 02 & 02 & 270 & $7.0 \cdots \cdot$ & $1 \cdots 1$ & $1 \cdots 0.6$ & $26 \cdots 22$ & $1 \cdots 1$ \\
\hline 03 & 03 & 481 & $7.4 \cdots \cdot$ & $2 \cdots 1$ & $1 \cdots 0.6$ & $26 \cdots 22$ & $2 \cdots 2$ \\
\hline$\vdots$ & $\vdots$ & $\vdots$ & $\vdots$ & $\vdots$ & $\vdots$ & $\vdots$ & $\vdots$ \\
\hline 441 & 84 & 197 & $10.0 \ldots$ & $1 \cdots 2$ & $2 \cdots 0.7$ & $25 \cdots 22$ & $2 \cdots 1$ \\
\hline 442 & 85 & 321 & $8.5 \ldots$ & $1 \cdots 1$ & $2 \cdots 0.7$ & $25 \cdots 22$ & $2 \cdots 2$ \\
\hline
\end{tabular}

$\left(^{*}\right)=$ Não ocorrência de observação

\subsubsection{Geração de Variáveis a partir das Variáveis Originais}

O questinário aplicado nas propriedades foi elaborado com o objetivo de caracterizar o máximo do ecossistema do suíno na maternidade, onde para isso as informações colhidas foram as mais detalhadas possiveis.

Neste processo muitas das variáveis originais não têm um significado prático quando estudadas isoladamente, por outro lado, novas variáveis de fundamental importância podem ser geradas quando combinadas com uma ou mais variáveis observadas na granja. Por este motivo, utilizando da versatilidade do sitema SAS na manipulação dos dados, foi possível corrigir, criar e classificar novas variáveis.

As novas variáveis, descrição e forma de sua geração, para os referidos grupos de variáveis: Leitão, Diarréia, Instalação, Temperatura e Puerpério, são apresentadas a seguir: 


\section{I) NOVAS VARIÁVEIS GERADAS REFERENTES AO LEITÃO:}

Como o desmame dos leitões não seguia um padrão, isto é, eram desmamados em diferentes idades, então, gerou-se a variável "PMD35": peso médio dos leitões no desmame corrigidos pela idade aos 35 dias por leitegada. Esta correção é representada pela seguinte formula (SVENSMARK et al, 1989):

$P M D 35_{i j k}=\left[\sum_{i=1}^{I} \frac{P D(i)_{j k}^{*} 35}{I M D}\right] / I$

onde $2 \leq I \leq 13 \Rightarrow$ número de leitões;

$j=1, \ldots, 442 \Rightarrow$ porca $\Leftrightarrow$ leitegada $\mathrm{e}$

$k=1, \ldots, 85 \Rightarrow$ granja.

$P D(i)_{j k}$ : peso individual do i-ésimo leitão da j-ésima porca na $k$ ésima granja;

CV35: "coeficiente de variação para o peso dos leitões desmamados corrigidos aos 35 dias por leitegada;

GPM35 $=(P M D 35-P M N) / 35 \Rightarrow$ ganho de peso médio diário dos leitões por leitegadas aos 35 dias;

$T M O R T E=\left[\frac{(N L V-N L D)}{N L V}\right] * 100 \Rightarrow$ taxa de mortalidade/granja (\%) 
52.

\section{II) NOVAS VARIÁVEIS GERADAS REFERENTES À DIARRÉIA:}

As informações sobre a diarréia dos leitões foram coletadas a partir da segunda semana pós parto até o desmame, ou seja deste o $8^{\circ}$ até o $35^{\circ}$ dia. A variável diarréia (DIAR) é uma variável qualitativa com duas respostas: 1: ausência e 2: presença de diarréia na leitegada. A variável DIAR é a variável mais importante deste trabalho, pois ela é eleita a variável resposta (objetiva) da patologia em estudo. Então, com objetivo de saber a incidência de diarréia no período observado geraram-se três novas variáveis, mostradas a seguir, sendo que, para efeito de análise, considerou-se apenas a variável reposta "PDLAR35".

$$
\begin{aligned}
& \operatorname{PDIARI4}_{j k}=\left[\sum_{i=1}^{I} D I A R(i)=2 / I\right] 100,8 \leq \mathrm{I} \leq 14 \text { (dias); } \\
& \text { PDIAR21 }_{j k}=\left[\sum_{i=1}^{I} D I A R(i)=2 / I\right] 100,8 \leq \mathrm{I} \leq 21 \text { (dias); } \\
& \text { PDIAR35 }_{j k}=\left[\sum_{i=1}^{I} D I A R(i)=2 / I\right] 100,8 \leq \mathrm{I} \leq 35 \text { (dias). }
\end{aligned}
$$

Onde:

$\operatorname{DIAR}(\boldsymbol{i})_{j k}$ : é o i-ésimo dia de observação da diarréia da j-ésima leitegada na k-ésima granja;

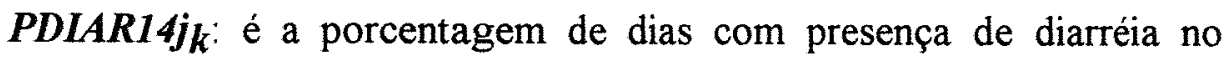
período de 8 a 14 dias;

PDLAR21jk: é a porcentagem de dias com presença de diarréia no periodo de 8 a 21 dias;

PDIAR35j $_{k}$ : é a porcentagem de dias com presença de diarréia no período de 8 a 35 dias. 


\section{III) NOVAS VARIÁVEIS GERADAS REFERENTE À INSTALACÃO:}

As instalações de uma maternidade e seus dispositivos têm fundamental papel no estado de conforto, em que porcas e leitões são submetidos. Neste item, foram geradas duas novas variáveis: " $\boldsymbol{V A L}$ " que expressa o volume de ar por leitegada na maternidade e "ADISP "que significa a área total disponível por leitegada, sendo assim expressas por:

$$
\begin{aligned}
& V A L=[C M * L M *(P D+C P / 2)] / N L P \\
& A D I S P=A C P+A R E
\end{aligned}
$$

onde

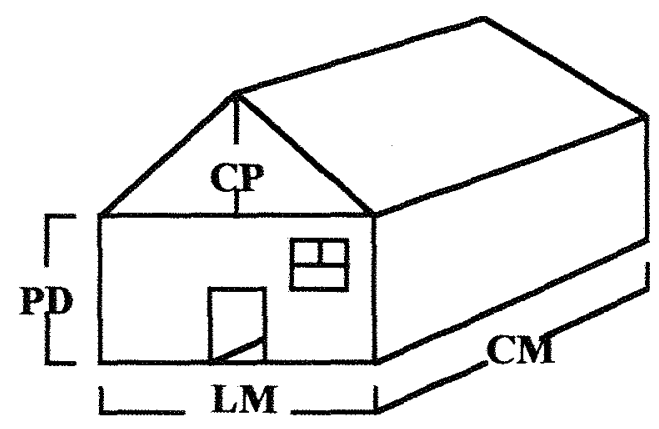

\section{V) NOVAS VARIÁVEIS GERADAS REFERENTES À TEMPERATURA:}

As temperaturas $\left({ }^{\circ} \mathrm{C}\right)$, máximas e mínimas, foram medidas por volta das 8 horas da manhã, por um termômetro colocado no centro da maternidade. Após a leitura, o termômetro era zerado para não infuenciar na medida do dia seguinte.

As temperaturas máximas e mínimas foram registradas todos os dias, no entanto, por haver informação completa sobre as temperaturas em apenas 21 dos 30 dias pós parto propostos nos protocolos, é de ressaltar que as novas variáveis geradas, no que diz respeito à amplitude, ao "stress" e ao conforto térmico dos leitãos, valem somente para este período. 
54.

\section{a) Amplitude térmica}

A partir das temperaturas máximas e mínimas gerou-se a variável "AMPLI": amplitude térmica até os 21 dias após o nascimento dos leitões, expressa por:

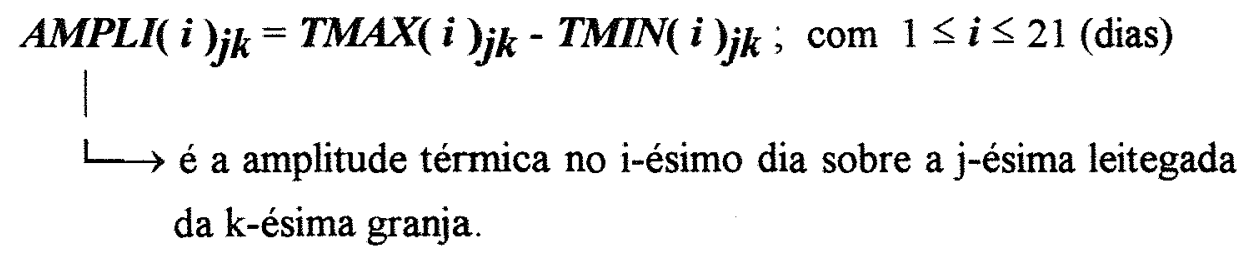
da k-ésima granja.

A partir da variável "AMPLI", gerou-se outra variável: "DAMPLI6", que quantificava o número de dias, com amplitude maior que $6^{\circ} \mathrm{C}$, à qual os leitões eram submetidos.

$$
\text { DAMPLI }_{j k}=\sum_{i=1}^{21}\left[A M P L I(i){ }_{j k}>6^{\circ} \mathrm{C}\right]
$$

b) Limite de "stress" em relação à temperatura ideal para os leitões

DTMAX28 : é o número de dias $/ 21$ com temperatura máxima $\geq 28^{\circ} \mathrm{C}$.

$D_{T M A X 28_{j k}}=\sum_{i=1}^{21}\left[T M A X(i) \geq 28^{\circ} \mathrm{C}\right]$

DTMIN16 : é o número de dias $/ 21$ com temperatura mínima $\leq 16^{\circ} \mathrm{C}$.

$$
\operatorname{DTMIN16}_{j k}=\sum_{i=1}^{21}\left[\operatorname{TMIN}(i) \leq 16^{\circ} \mathrm{C}\right]
$$


55.

c) Conforto térmico para os leitões (Zona de conforto)

As variáveis "CT1824" $e$ "CT1622" indicam o número de dias, para os quais as temperaturas mínimas e máximas ficaram entre "18 a 24 " ou "16 a 22 " ${ }^{\circ} \mathrm{C}$ respectivamente, no interior da maternidade.

$$
\begin{aligned}
& { }_{\text {CT1824 }}{ }_{j k}=\sum_{i=1}^{21}\left[\operatorname{TMIN}(i)>18^{\circ} \mathrm{C}, \operatorname{TMAX}(i)<24^{\circ} \mathrm{C}\right] \\
& \mathrm{CT1622}_{j k}=\sum_{i=1}^{21}\left[\operatorname{TMIN}(i)>16^{\circ} \mathrm{C}, \operatorname{TMAX}(i)<22^{\circ} \mathrm{C}\right]
\end{aligned}
$$

Uma outra alternativa é calcular a média das temperaturas máximas e mínimas, nos 21 dias na maternidade das granjas, obtendo-se as seguintes variáveis:

1) Média das temperaturas máximas;

2) Média das temperaturas minimas;

3) Amplitude das médias das temperaturas máximas e minimas; $\mathrm{e}$

4) Conforto térmico em relação às médias das temperaturas máximas e minimas. Com as respectivas expressões:

$$
\begin{aligned}
& \text { 1) } \operatorname{MTMAX}(k)=\sum_{i=1}^{21} \operatorname{TMAX}(i) / 21 \\
& \text { 2) } \operatorname{MTMIN}(k)=\sum_{i=1}^{21} \operatorname{TMIN}(i) / 21 \\
& \text { 3) } \operatorname{MAMPLI}(k)=\operatorname{MTMAX}(k)-\operatorname{MTMIN}(k) \\
& 4 a) M C T 1824 k=\sum_{i=1}^{21}\left[M T M I N(i)>18^{\circ} \mathrm{C}, M T M A X(i)<24^{\circ} \mathrm{C}\right] \\
& 4 b) M C T 1622_{k}=\sum_{i=1}^{21}\left[\operatorname{MTMIN}(i)>16^{\circ} \mathrm{C}, \operatorname{MTMAX}(i)<22^{\circ} \mathrm{C}\right]
\end{aligned}
$$




\section{VI) NOVAS VARIÁVEIS GERADAS EM RELACÃO AO PUERPÉRIO}

PUERPÉRIO é o periodo compreendido do pós parto até o retorno à normalidade dos orgãos genitais e o estado geral da porca.

Uma porca pode ser diagnosticada quanto a patologia do parto levando-se em consideração o acompanhamento simultâneo nos cinco primeiros dias $(1,2,3,4$ e 5), pós parto, das seguintes variáveis:

TRF: Temperatura retal $\{$ TRF $1, \cdots$, TRF5 $\}$; se $>39,8^{\circ} \mathrm{C} \Rightarrow$ "Problema";

APN: Apetite da porca $\{$ APN1, $\cdots$, APN5 $\} ; \Rightarrow$ 1:aus. 2:pres.;

CVP: Corrimento vulvar purulento $\{$ CVP1, $\cdots$, CVP5 $\} ; \Rightarrow 1$ :aus. 2:pres. e

MMA: Mamite, mastite e agalaxía $\{$ MMA1, $\cdots$, MMA5\}. $\Rightarrow$ 1:aus. 2:pres.

$\Rightarrow$ OBS.:O dia 0(zero) que representa o dia do parto foi desconsiderado nas variáveis: TRF, CVP, APN e MMA, por falta de informação.

O ideal para que uma porca esteja saudável pós parto, é que ela se encontre dentro da faixa de normalidade, nos 5 dias acompanhados pós parto, para as 4 variáveis mencionadas anteriormente, isto é, temperatura retal $\leq 39,8^{\circ} \mathrm{C}$, ausência de corrimento, presença de apetite, $e$ ausência de mamite, mastite e agalaxia.

Diante deste fato, gerou-se uma nova variável que torna possível a interpretação da patologia do parto pela combinação das quatro variáveis originais (TRN, APN, CVP e MMA), criando uma pontuação quando aparece o problema, da seguinte maneira:

a) Para a variável TRF (temperatura retal): a cada dia (1, 2, 3, 4 e 5) que a temperatura ultrapassar $39,8^{\circ} \mathrm{C}$, recebe 1 ponto;

b) Para a variável CVP (corrimento vulval purulento): a cada dia $(1,2$, 3, 4 e 5) com presença, recebe 1 ponto;

c) Para a variável APN (apetite da porca): a cada dia (1, 2, 3, 4 e 5) sem apetite, recebe 1 ponto;

d) Para a variável MMA (mastite, mamite e agalaxia): a cada dia $(1,2$, 3,4 e 5) com presença, também recebe 1 ponto. 
INTERPRETAÇÃO: A partir da soma dos pontos recebido por cada porca, nos 5 dias, referentes aos ítens a, b, $\mathbf{c}$ e d, formou-se a variável "PATOPAR" (patologia do parto). Este processo é representado pela seguinte expressão:

$$
\begin{aligned}
& \operatorname{PATOPAR}(j)_{k}=\sum_{i=1}^{5}\left[\operatorname{TRF}(i)_{j k}>39.8\right]+\sum_{i=1}^{5}\left[C V P(i)_{j k}=2\right]+\sum_{i=1}^{5}\left[\operatorname{APN}(i)_{j k}=2\right]+\sum_{i=1}^{5}\left[\operatorname{MMA}(i)_{j k}=2\right] \\
& \mid \hookrightarrow \text { é o total de pontos recebido pela porca } j \text { na maternidade da k-ésima granja. } \\
& \text { 「1: } \quad \text { PATOPAR } \leq 1 \Rightarrow \text { a j-ésima porca sem problema; } \\
& \llcorner\{2: 1<P A T O P A R<6 \Rightarrow \text { a j-ésima porca com problema moderado; } \\
& \text { L3: } \quad \boldsymbol{P A T O P A R} \geq 6 \Rightarrow \text { a j-ésima porca com problema grave. }
\end{aligned}
$$

\subsubsection{Arquivo Resultante após Geração de Variáveis}

O trabalho de geração de variáveis foi muito importante, pois além do melhor conhecimento das variáveis levantadas em campo, o trabalho ainda ajudou na decisão de como combiná-las, de modo a reter o máximo da informação. E excluir algumas variáveis sem informação ou pouco confiáveis para análise.

Pelo fato de muitas das variáveis geradas dependerem da combinação de duas ou mais variáveis, houve uma redução de 158 para 40 variáveis no arquivo de dados. Sobre este arquivo resultante desenvolveu-se toda a metodologia de análise estatística na identificação dos fatores de risco pertinentes à diarréia e à performance dos leitões na lactação. Este arquivo é composto por dois grupos de variáveis: As qualitativas e as quantitativas.

\section{GRUPO1: Referente às Variáveis Qualitativas.}

As variáveis que compõem este grupo são qualitativas por "natureza", isto é, já têm suas próprias classes pré definidas durante a elaboração do questionário. Estas variáveis estão representadas na TABELA 9, com suas respectivas classes. 
TABELA 9. Lista das variáveis qualitativas

\begin{tabular}{|c|c|c|c|c|}
\hline \multirow[b]{2}{*}{ DE S C R I C Ã O } & \multirow[b]{2}{*}{ SIGLA } & \multicolumn{3}{|c|}{ CLA S S E S } \\
\hline & & 1 & 2 & 3 \\
\hline 01. vacina contra colibacilose. & $\mathrm{VC}$ & $\operatorname{sim}$ & não & -.. \\
\hline $\begin{array}{l}\text { 02. assistência aos leitões com corte de } \\
\text { dentes e desinfecção do umbigo. }\end{array}$ & ALEI & $\overline{\operatorname{sim}}$ & não & $-\cdots$ \\
\hline 03. vazio sanitário (dias). & vs & contínuo & $\geq 1 \leq 5$ dias & $>5$ dias \\
\hline 04. aleitamento em grupo. & $\mathrm{AG}$ & $\operatorname{sim}$ & não & $\ldots$ \\
\hline 05. parecer sobre a qualidade de higiene. & PSH & bom & regular & ruim \\
\hline 06. tipo de piso. & TP & compacto & semi-ripado & tot. ripado \\
\hline 07. presença de forro. & PF & $\operatorname{sim}$ & não & - \\
\hline 08. presença de escamoteador. & $\mathrm{PE}$ & $\operatorname{sim}$ & não & -- \\
\hline 09. fonte suplementar de calor & FSC & $\operatorname{sim}$ & não & -- \\
\hline 10. presença da tampa no escamoteador. & PTE & $\operatorname{sim}$ & não & -- \\
\hline 11. parasitismo nas fêmeas e nos leitões. & PAR & não & $\operatorname{sim}$ & $\ldots$ \\
\hline 12. problema no parto. & PNP & não & $\operatorname{sim}$ & -- \\
\hline 13. tratamento com oxitocina. & TCO & não & $\operatorname{sim}$ & $-\cdots$ \\
\hline 14. tratamento com antibiótico. & TRA & não & $\operatorname{sim}$ & -- \\
\hline
\end{tabular}

\section{GRUPO 2: Referente às Variáveis Quantitativas:}

Neste tipo de trabalho, as informações coletadas vêm sempre na forma de dados mistos, isto é, algumas variáveis com dados qualitativos e outras com dados quantitativos.

Como o método propõe que a análise estatística se desenvolva apenas sobre dados qualitativos, houve aqui, a necessidade de separar em classes as variáveis quantitativas.

O número de classes e os limites foram baseados essencialmente em função da distribuição dos dados e dos coeficientes técnicos recomendados pela EMBPAPA-SC através de publicações como: Documento técnico, Circular técnica e Periódico técnico cientifico, destinados ao ecossistema dos suínos na fase de aleitamento, para as condições da região sul brasileira.

É de ressaltar que as classes das variáveis não são definitivas, caso seja necessário, existe a flexibilidade do método em reclassificá-las 
Na TABELA 10, encontram-se a descrição das variáveis quantitativas com suas respectivas condições de classes, após o procedimento de categorização.

TABELA 10. Lista de variáveis quantitativas após a categorização.

\begin{tabular}{|c|c|c|c|c|}
\hline \multirow[b]{2}{*}{ DES CRICCÃO } & \multirow[b]{2}{*}{ SIGLA } & \multicolumn{3}{|c|}{ CLASSES } \\
\hline & & 1 & 2 & 3 \\
\hline 01. estado nutricional das porcas (pontos) & NUT & $\begin{array}{l}\leq 3 \\
\text { ruim }\end{array}$ & $\begin{array}{c}>3 \leq 3,6 \\
\text { regular }\end{array}$ & $\begin{array}{l}>3,6 \\
\text { bom }\end{array}$ \\
\hline $\begin{array}{l}\text { 02. altura do pé direito na maternidade } \\
\text { (m) }\end{array}$ & PD & $<2,8$ & $\geq 2,8 \leq 3,5$ & -- \\
\hline $\begin{array}{l}\text { 03. abertura de janelas e portas externas } \\
\text { por área lateral }(\%)\end{array}$ & PAJ & $\leq 5$ & $>5 \leq 20$ & $>20$ \\
\hline 04. área do escamoteador $\left(\mathrm{m}^{2}\right)$ & ARE & $=0,0$ & $>0 \leq 0,7$ & $>0,7$ \\
\hline 05. ordem do parto & ODP & $=1$ & $<1 \leq 4$ & $>4$ \\
\hline 06. número de leitões nascidos vivos & NLV & $\leq 8$ & $>8 \leq 11$ & $>11$ \\
\hline $\begin{array}{l}\text { 07. número de leitões desmamados aos } 35 \\
\text { dias }\end{array}$ & NLD & $\leq 8$ & $>8 \leq 11$ & $>11$ \\
\hline 08. peso médio da leitegada no nasc. $(\mathrm{kg})$ & PMN & $<1,3$ & $\geq 1,3 \leq 1,5$ & $>1,5$ \\
\hline $\begin{array}{l}\text { 09. peso médio dos leitões/leitegada aos } \\
35 \text { dias }(\mathrm{kg})\end{array}$ & PMD35 & $<7$ & $\geq 7<9$ & $\geq 9$ \\
\hline $\begin{array}{l}\text { 10. ganho de peso médio diário dos leitões } \\
\text { por leitegada aos } 35 \text { dias ( } \mathrm{g} \text { ) }\end{array}$ & GPM35 & $\leq 160$ & $>160 \leq 200$ & $>200$ \\
\hline $\begin{array}{l}\text { 11. coeficiente de variação do peso dos } \\
\text { leitões por leitegada aos } 35 \text { dias (\%) }\end{array}$ & CV35 & $\leq 12$ & $>12 \leq 20$ & $>20$ \\
\hline $\begin{array}{l}\text { 12. taxa de mortalidade por granja aos } 35 \\
\text { dias (\%) }\end{array}$ & TMORTE & $\leq 6$ & $>6 \leq 12$ & $>12$ \\
\hline $\begin{array}{l}\text { 13. porcentagem de dias com presença de } \\
\text { diarréia no periodo de } 27 \text { ( } 08 \text { a 35) dias } \\
\text { (\%) }\end{array}$ & $\begin{array}{l}\text { PDIAR35 } \\
\qquad \begin{array}{l}\Omega \\
\text { DIARREIA }\end{array}\end{array}$ & $\begin{array}{c}=0 \\
\sqrt{ } \\
\text { aus. } \\
\text { diarréia } \\
\end{array}$ & $\begin{array}{c}>0 \leq 18,5 \\
\mathbb{Z} \\
(1 \text { a } 5) \text { dias } \\
\text { com diar. }\end{array}$ & $\begin{array}{c}>18,5 \\
\Omega \\
>5 \text { dias } \\
\text { com diar. }\end{array}$ \\
\hline 14. volume de ar por leitegada $\left(\mathrm{m}^{3}\right)$ & VAL & $\leq 20$ & $>20 \leq 27$ & $>27$ \\
\hline 15. número de celas parideiras & $\mathrm{NCP}$ & $\leq 10$ & $>10$ & - \\
\hline
\end{tabular}




\section{continua}

\begin{tabular}{|c|c|c|c|c|}
\hline \multirow[b]{2}{*}{ D E S C R I C Ã O } & \multirow[b]{2}{*}{ SIGLA } & \multicolumn{3}{|c|}{ C L A S S E S } \\
\hline & & 1 & 2 & 3 \\
\hline 16. área da cela parideira $\left(\mathrm{m}^{2}\right)$ & $\mathrm{ACP}$ & $<3,96$ & $\geq 3,96$ & $-\cdots$ \\
\hline 17. número de leitegadas presentes & NLP & $\leq 10$ & $>10 \leq 15$ & $>15$ \\
\hline $\begin{array}{l}\text { 18. area total disponivel por leitegada } \\
\left(\mathrm{m}^{2}\right)\end{array}$ & ADISP & $<4$ & $\geq 4$ & -- \\
\hline $\begin{array}{l}\text { 19. número de dias com amplitude térmica } \\
\text { maior que } 6{ }^{\circ} \mathrm{C} \text { no interior da maternidade, } \\
\text { no período de } 21 \text { dias pós parto (dias) }\end{array}$ & DAMPLI6 & $\leq 7$ & $>7 \leq 14$ & $>14$ \\
\hline $\begin{array}{l}\text { 20. número de dias com temperatura } \\
\text { máxima maior ou igual a } 28{ }^{\circ} \mathrm{C} \text { no interior } \\
\text { da maternidade, no periodo de } 21 \text { dias pós } \\
\text { parto (dias) }\end{array}$ & DTMAX28 & $\leq 10$ & $>10$ & -- \\
\hline $\begin{array}{l}\text { 21. número de dias com temperatura } \\
\text { mínima menor ou igual a } 16{ }^{\circ} \mathrm{C} \text { no interior } \\
\text { da maternidade no periodo de } 21 \text { dias pós } \\
\text { parto (dias) }\end{array}$ & DTMIN16 & $\leq 5$ & $>5$ & --- \\
\hline $\begin{array}{l}\text { 22. número de dias com temperatura } \\
\text { variando de } 18 \text { a } 24{ }^{\circ} \mathrm{C} \text { (conforto térmico) } \\
\text { no interior da maternidade, no periodo de } \\
21 \text { dias pós parto (dias) }\end{array}$ & CT1824 & $=0$ & $\geq 1$ & -- \\
\hline $\begin{array}{l}\text { 23. média das temperaturas máximas no } \\
\text { interior da maternidade, no periodo de } 21 \\
\text { dias pós parto por granja }\left({ }^{\circ} \mathrm{C}\right)\end{array}$ & MTMAX & $<28$ & $\geq 28$ & $--\cdot$ \\
\hline $\begin{array}{l}\text { 24. média das temperaturas mínimas no } \\
\text { interior da maternidade, no periodo de } 21 \\
\text { dias pós parto por granja }\left({ }^{\circ} \mathrm{C}\right)\end{array}$ & MTMIN & $\leq 16$ & $>16$ & -- \\
\hline $\begin{array}{l}\text { 25. amplitude térmica média no interior da } \\
\text { maternidade, no periodo de } 21 \text { dias pós } \\
\text { parto por granja }\left({ }^{\circ} \mathrm{C}\right)\end{array}$ & MAMPLI & $\leq 6$ & $>6$ & -- \\
\hline 26. patologia do parto (pontos) & PATOPAR & $\leq 1$ & $>1<6$ & $\geq 6$ \\
\hline
\end{tabular}




\section{RESULTADOS E DISCUSSÃO}

O arquivo resultante da seção 3.3.3.1. do capítulo anterior, é definido como o arquivo de dados iniciais para o procedimento de análise estatística proposta pela metodologia aplicada na identificação dos fatores de risco. Esta análise é efetuada, seguindo a continuação das etapas do processamento prévio para o específico.

\subsection{Resultado do Processamento Prévio}

No decorrer desta fase, produziu-se um arquivo básico de dados composto de 40 variáveis, todas qualitativas (conforme, exigido pela metodologia) por 442 leitegadas (observações) através do qual, se desenvolve toda análise estatística.

A TABELA 11, mostra a descrição e a separação das variáveis segundo a sua finalidade, considerando também as siglas, nome de classes, limites, frequências absolutas e relativas (\%) respectivamente.

TABELA 11. Lista de variáveis resultante do processamento prévio dos dados .

\begin{tabular}{|c|c|c|c|c|}
\hline \multicolumn{5}{|c|}{ PARAMETROS DE SAÚDE E PERFORMANCE } \\
\hline Descricão & $\overline{\text { Sigla }}$ & Classes : limites & Freq. Abs. & Freq. Rel. \\
\hline $\begin{array}{l}\text { 1. ocorrência de diarréia no período } \\
08 \text { a } 35 \text { dias (número de dias). }\end{array}$ & $\underset{*}{\text { DIARREIA }}$ & $\begin{array}{l}\text { DIAR1: }=0 \\
\text { DIAR2: de } 1 \text { a } 5 \text { dias } \\
\text { DIAR3: }>5 \text { dias }\end{array}$ & $\begin{array}{r}210 \\
180 \\
52 \\
\end{array}$ & $\begin{array}{l}47,50 \\
40,70 \\
11,80 \\
\end{array}$ \\
\hline $\begin{array}{l}\text { 2. peso médio dos leitões/leitegada } \\
\text { aos } 35 \text { dias }(\mathrm{Kg}) \text {. }\end{array}$ & PMD35* & $\begin{array}{l}\text { PMD1: }<7 \\
\text { PMD2: } \geq 7<9 \\
\text { PMD3: } \geq 9\end{array}$ & $\begin{array}{r}141 \\
212 \\
89\end{array}$ & $\begin{array}{l}31,90 \\
48,00 \\
20,10\end{array}$ \\
\hline $\begin{array}{l}\text { 3. ganho de peso médio dos leitões } \\
\text { por leitegada aos } 35 \text { dias (g). }\end{array}$ & GPM35* & $\begin{array}{l}\text { GPM1: } \leq 160 \\
\text { GPM2: }>160 \leq 200 \\
\text { GPM3: }>200\end{array}$ & $\begin{array}{l}137 \\
171 \\
134\end{array}$ & $\begin{array}{l}31,0 \\
38,7 \\
30,3\end{array}$ \\
\hline
\end{tabular}


62.

continua

\begin{tabular}{|c|c|c|c|c|}
\hline \multicolumn{5}{|c|}{ PARAMETROS DE SAÚDE E PERTORMANCEV } \\
\hline$\overline{\text { Descricão }}$ & Sigla & Classes : limites & Freq. Abs. & Freq. Rel. \\
\hline $\begin{array}{l}\text { 4. coeficiente de variação do peso } \\
\text { dos leitões/leitegada aos } 35 \text { dias (\%). }\end{array}$ & CV35* & $\begin{array}{l}\text { CVA1: } \leq 12 \\
\text { CVA2: }>12 \leq 20 \\
\text { CVA3: }>20\end{array}$ & $\begin{array}{l}105 \\
194 \\
143\end{array}$ & $\begin{array}{l}23,8 \\
43,9 \\
32,4\end{array}$ \\
\hline $\begin{array}{l}\text { 5. taxa de mortalidade/granja aos } 35 \\
\text { dias }(\%) \text {. }\end{array}$ & TMORTE* & $\begin{array}{l}\text { MORT1: } \leq 6 \\
\text { MORT2: }>6 \leq 12 \\
\text { MORT3: }>12\end{array}$ & $\begin{array}{r}97 \\
128 \\
217 \\
\end{array}$ & $\begin{array}{l}21,9 \\
29,0 \\
49,1 \\
\end{array}$ \\
\hline \multicolumn{5}{|c|}{ VARIAVEIS EXPLICATIVAS• } \\
\hline Descricão & $\overline{\text { Sigla }}$ & Classes : limites & Freq. Abs. & Freq. Rel. \\
\hline 6. vacina contra colibacilose. & VC & $\begin{array}{l}\text { VCC1: sim } \\
\text { VCC2: não }\end{array}$ & $\begin{array}{r}68 \\
374\end{array}$ & $\begin{array}{l}15,4 \\
84,6\end{array}$ \\
\hline $\begin{array}{l}\text { 7. assistência aos leitôes com corte } \\
\text { de dentes e desinfecção do umbigo. }\end{array}$ & ALEI & $\begin{array}{l}\text { ALE1: sim } \\
\text { ALE2: não }\end{array}$ & $\begin{array}{l}220 \\
220\end{array}$ & $\begin{array}{l}49,8 \\
50,2 \\
\end{array}$ \\
\hline 8. vazio sanitário. & VS & $\begin{array}{l}\text { VAZ1: continuo } \\
\text { VAZ2: } \leq 5 \text { dias } \\
\text { VAZ3: }>5 \text { dias }\end{array}$ & $\begin{array}{r}294 \\
75 \\
73 \\
\end{array}$ & $\begin{array}{l}66,5 \\
17,0 \\
16,5\end{array}$ \\
\hline 9. aleitamento em grupo. & $\overline{\mathrm{AG}}$ & $\begin{array}{l}\text { AGR1: } \operatorname{sim} \\
\text { AGR2: não }\end{array}$ & $\begin{array}{l}342 \\
100\end{array}$ & $\begin{array}{l}77,4 \\
22,6 \\
\end{array}$ \\
\hline $\begin{array}{l}\text { 10. parecer sobre a qualidade de } \\
\text { higiene. }\end{array}$ & $\mathrm{PSH}^{(86)}$ & $\begin{array}{l}\text { PSH1: boa } \\
\text { PSH2: regular } \\
\text { PSH3: ruim }\end{array}$ & $\begin{array}{c}150 \\
119 \\
87 \\
\end{array}$ & $\begin{array}{l}42,1 \\
33,4 \\
24,4 \\
\end{array}$ \\
\hline 11. tipo de piso. & $\mathrm{TP}^{(6)}$ & $\begin{array}{l}\text { TPO1: compacto } \\
\text { TPO2: semi ripado } \\
\text { TPO3: tot ripado }\end{array}$ & $\begin{array}{c}328 \\
101 \\
7 \\
\end{array}$ & $\begin{array}{r}75,2 \\
23,2 \\
1,6 \\
\end{array}$ \\
\hline 12. presença de forro. & $\overline{\mathrm{PF}}$ & $\begin{array}{l}\text { PFO1: sim } \\
\text { PFO2: não }\end{array}$ & $\begin{array}{c}93 \\
349 \\
\end{array}$ & $\begin{array}{l}21,0 \\
79,0\end{array}$ \\
\hline 13. presença de escamoteador. & $\mathrm{PE}$ & $\begin{array}{l}\text { PES1: sim } \\
\text { PES2: não }\end{array}$ & $\begin{array}{l}220 \\
222 \\
\end{array}$ & $\begin{array}{l}49,8 \\
50,2 \\
\end{array}$ \\
\hline 14. fonte suplementar de calor. & FSC & $\begin{array}{l}\text { FSC1: sim } \\
\text { FSC2: não }\end{array}$ & $\begin{array}{c}426 \\
16\end{array}$ & $\begin{array}{c}96,4 \\
3,6\end{array}$ \\
\hline $\begin{array}{l}\text { 15. presença da tampa no escamotea- } \\
\text { dor. }\end{array}$ & PTE $^{(11)}$ & $\begin{array}{l}\text { PTE1: sim } \\
\text { PTE2: não }\end{array}$ & $\begin{array}{ll}224 \\
207\end{array}$ & $\begin{array}{l}52,0 \\
48,0 \\
\end{array}$ \\
\hline $\begin{array}{l}\text { 16. parasitismo nas fêmeas. e nos } \\
\text { leitões. }\end{array}$ & $\mathrm{PAR}^{(37)}$ & $\begin{array}{l}\text { PAR1: sim } \\
\text { PAR2: não }\end{array}$ & $\begin{array}{l}128 \\
277 \\
\end{array}$ & $\begin{array}{l}31,6 \\
68,4 \\
\end{array}$ \\
\hline 17. problema no parto. & PNP & $\begin{array}{l}\text { PNP1: não } \\
\text { PNP2: sim }\end{array}$ & $\begin{array}{r}391 \\
51 \\
\end{array}$ & $\begin{array}{l}88,5 \\
11,5 \\
\end{array}$ \\
\hline 18. tratamento com oxitocina. & $\mathrm{TCO}$ & $\begin{array}{l}\text { TCO1: sim } \\
\text { TCO2: não }\end{array}$ & $\begin{array}{c}389 \\
53 \\
\end{array}$ & $\begin{array}{l}88,0 \\
12,0 \\
\end{array}$ \\
\hline 19. tratamento com antibiótico. & TRA & $\begin{array}{l}\text { TRA1: sim } \\
\text { TRA2: não }\end{array}$ & $\begin{array}{l}284 \\
158\end{array}$ & $\begin{array}{l}64,3 \\
35,7 \\
\end{array}$ \\
\hline 20. estado nutricional das porcas. & NUT $^{*}$ & $\begin{array}{lc}\text { NUT1 }: \leq 3 & \text { ruim } \\
\text { NUT2 }:>3 \leq 3,6 \text { reg. } \\
\text { NUT3: }>3,6 \quad \text { bom }\end{array}$ & $\begin{array}{c}37 \\
68 \\
337 \\
\end{array}$ & $\begin{array}{c}8,4 \\
15,4 \\
76,2 \\
\end{array}$ \\
\hline $\begin{array}{l}\text { 21. altura do pé direito na materni- } \\
\text { dade }(\mathrm{m}) \text {. }\end{array}$ & $\mathrm{PD}^{(19) \%}$ & $\begin{array}{l}\text { PDI1: }<2,8 \\
\text { PDI2: } \geq 2,8\end{array}$ & $\begin{array}{c}366 \\
57 \\
\end{array}$ & $\begin{array}{l}86,5 \\
13,5 \\
\end{array}$ \\
\hline
\end{tabular}




\section{continua}

\begin{tabular}{|c|c|c|c|c|}
\hline \multicolumn{5}{|c|}{ VARIÁVEIS EXPLICATIVAS } \\
\hline Descricão & Sigla & Classes : limites & Freq. Abs. & Freq. Rel. \\
\hline $\begin{array}{l}\text { 22. abertura de portas e janelas exter- } \\
\text { nas por área lateral }(\%) \text {. }\end{array}$ & PAJ $(11) \$$ & $\begin{array}{l}\text { PAJ1: } \leq 5 \\
\text { PAJ2: }>5 \leq 20 \\
\text { PAJ3: }>20\end{array}$ & $\begin{array}{c}41 \\
208 \\
182 \\
\end{array}$ & $\begin{array}{c}9,5 \\
48,3 \\
42,2\end{array}$ \\
\hline 23. área do escamoteador $\left(\mathrm{m}^{2}\right)$. & $\mathrm{ARE}^{*}$ & $\begin{array}{l}\text { ARE1: }=0,0 \\
\text { ARE2: }>0,0 \leq 0.7 \\
\text { ARE3: }>0,7\end{array}$ & $\begin{array}{c}244 \\
108 \\
90 \\
\end{array}$ & $\begin{array}{l}55,2 \\
24,2 \\
20,4 \\
\end{array}$ \\
\hline 24. ordem do parto. & $\mathrm{ODP}^{(55)^{4}}$ & $\begin{array}{l}\text { ODP1: }=1 \\
\text { ODP2: }>1 \leq 4 \\
\text { OPD3: }>4\end{array}$ & $\begin{array}{c}81 \\
230 \\
76\end{array}$ & $\begin{array}{l}20,9 \\
59,4 \\
19,6\end{array}$ \\
\hline 25. número de leitões nascidos vivos & $\mathrm{NLV}^{*}$ & $\begin{array}{l}\text { NLV1: } \leq 8 \\
\text { NLV2: }>8 \leq 11 \\
\text { NLV3: }>11\end{array}$ & $\begin{array}{l}101 \\
196 \\
145\end{array}$ & $\begin{array}{l}22,9 \\
44,3 \\
32,8\end{array}$ \\
\hline $\begin{array}{l}\text { 26. número de letões desmamados } \\
\text { aos } 35 \text { dias. }\end{array}$ & $\mathrm{NLD}^{*}$ & $\begin{array}{l}\text { NLD1: } \leq 8 \\
\text { NLD2: }>8 \leq 11 \\
\text { NLD3: }>11\end{array}$ & $\begin{array}{c}156 \\
249 \\
37 \\
\end{array}$ & $\begin{array}{c}35,3 \\
56,3 \\
8,4 \\
\end{array}$ \\
\hline $\begin{array}{l}\text { 27. peso médio da leitegada no } \\
\text { nasci-mento }(\mathrm{kg}) \text {. }\end{array}$ & $\mathrm{PMN}^{*}$ & $\begin{array}{l}\text { PMN1: }<1,3 \\
\text { PMN2: } \geq 1,3 \leq 1,5 \\
\text { PMN3: }>1,5\end{array}$ & $\begin{array}{l}115 \\
160 \\
167 \\
\end{array}$ & $\begin{array}{l}26,0 \\
36,2 \\
37,8 \\
\end{array}$ \\
\hline 28. volume de ar por leitegada $\left(\mathrm{m}^{3}\right)$ & VAL ${ }^{(19) *}$ & $\begin{array}{l}\text { VAL1: } \leq 20 \\
\text { VAL2: }>20 \leq 27 \\
\text { VAL3: }>27\end{array}$ & $\begin{array}{c}65 \\
160 \\
198 \\
\end{array}$ & $\begin{array}{l}15,4 \\
37,8 \\
46,8 \\
\end{array}$ \\
\hline 29. número de celas parideiras. & NCP* & $\begin{array}{l}\text { NCP1: } \leq 10 \\
\text { NCP2 }:>10\end{array}$ & $\begin{array}{ll}204 \\
238 \\
\end{array}$ & $\begin{array}{l}46,2 \\
53,8 \\
\end{array}$ \\
\hline 30. número de leitegadas presentes. & NLP\$ & $\begin{array}{l}\text { NLP1: } \leq 10 \\
\text { NLP2: }>10 \leq 15 \\
\text { NLP3: }>15\end{array}$ & $\begin{array}{c}225 \\
72 \\
145 \\
\end{array}$ & $\begin{array}{l}50,9 \\
16,3 \\
32,8 \\
\end{array}$ \\
\hline 31. área da cela parideira $\left(\mathrm{m}^{2}\right)$. & $A C P^{(5) *}$ & $\begin{array}{l}\text { ACP1: }<3,96 \\
\text { ACP2: } \geq 3,96\end{array}$ & $\begin{array}{l}335 \\
102 \\
\end{array}$ & $\begin{array}{l}76,7 \\
23,3 \\
\end{array}$ \\
\hline $\begin{array}{l}\text { 32. área total disponível por } \\
\text { leitegada }\left(\mathrm{m}^{2}\right) \text {. }\end{array}$ & $\mathrm{ADISP}^{(9) *}$ & $\begin{array}{l}\text { ADS1: }<4 \\
\text { ADS2: } \geq 4\end{array}$ & $\begin{array}{l}256 \\
181 \\
\end{array}$ & $\begin{array}{l}58,6 \\
41,4 \\
\end{array}$ \\
\hline $\begin{array}{l}\text { 33. número de dias com amplitude } \\
\text { térmica maior que } 6^{\circ} \mathrm{C} \text { no interior } \\
\text { da maternidade, no período de } 21 \\
\text { dias pós parto (dias). }\end{array}$ & DAMPLI6* & $\begin{array}{l}\text { AMP1: } \leq 7 \\
\text { AMP2: }>7 \leq 14 \\
\text { AMP3: }>14\end{array}$ & $\begin{array}{c}52 \\
93 \\
297\end{array}$ & $\begin{array}{l}11,8 \\
21,0 \\
67,2\end{array}$ \\
\hline $\begin{array}{l}\text { 34. número de dias com temperatura } \\
\text { máxima maior ou igual a } 28{ }^{\circ} \mathrm{C} \text { no } \\
\text { interior da maternidade, no período } \\
\text { de } 21 \text { dias pós parto (dias). }\end{array}$ & DTMAX28 & $\begin{array}{l}\text { TMX1: } \leq 10 \\
\text { TMX2: }>10\end{array}$ & $\begin{array}{l}200 \\
242\end{array}$ & $\begin{array}{l}45,2 \\
54,8\end{array}$ \\
\hline $\begin{array}{l}\text { 35. número de dias com temperatura } \\
\text { mínima menor ou igual a } 16^{\circ} \mathrm{C} \text { no } \\
\text { interior da maternidade, no periodo } \\
\text { de } 21 \text { dias pós parto (dias). }\end{array}$ & DTMIN16 & $\begin{array}{l}\text { TMI1: } \leq 5 \\
\text { TMI2: }>5\end{array}$ & $\begin{array}{l}258 \\
184\end{array}$ & $\begin{array}{l}58,4 \\
41,6\end{array}$ \\
\hline
\end{tabular}




\section{continua}

\begin{tabular}{|c|c|c|c|c|}
\hline \multicolumn{5}{|c|}{ VARIÁVEIS EXPLICATIVAS* } \\
\hline Descricão & Sigla & Classes : limites & Freq. Abs. & Freq. Rel. \\
\hline $\begin{array}{l}\text { 36. número de dias com temperatura } \\
\text { variando de } 18 \text { a } 24^{\circ} \mathrm{C} \text { "conforto } \\
\text { térmico" no interior da maternidade } \\
\text { no período de } 21 \text { dias pós parto } \\
\text { (dias). }\end{array}$ & CT1824* & $\begin{array}{l}\text { CTE1: }=0 \\
\text { CTE2: }>0\end{array}$ & $\begin{array}{l}314 \\
128\end{array}$ & $\begin{array}{l}71,0 \\
29,0\end{array}$ \\
\hline $\begin{array}{l}\text { 37. média das temperaturas máximas } \\
\text { no interior da maternidade no } \\
\text { período de } 21 \text { dias pós parto por } \\
\text { granja }\left({ }^{\circ} \mathrm{C}\right) \text {. }\end{array}$ & MTMAX & $\begin{array}{l}\text { MTX1: }<28 \\
\text { MTX2: } \geq 28\end{array}$ & $\begin{array}{l}204 \\
238\end{array}$ & $\begin{array}{l}46,2 \\
53,8\end{array}$ \\
\hline $\begin{array}{l}38 . \quad \text { média das temperaturas } \\
\text { minimas no interior da maternidade } \\
\text { no periodo de } 21 \text { dias pós parto por } \\
\text { granja }\left({ }^{\circ} \mathrm{C}\right) \text {. }\end{array}$ & $\mathrm{MTMIN}^{*}$ & $\begin{array}{l}\text { MTM1: } \leq 16 \\
\text { MTM2: }>16\end{array}$ & $\begin{array}{l}117 \\
325\end{array}$ & $\begin{array}{l}26,5 \\
73,5\end{array}$ \\
\hline $\begin{array}{l}\text { 39. amplitude térmica média no } \\
\text { interior da maternidade no periodo } \\
\text { de } 21 \text { dias pós parto por granja }\left({ }^{\circ} \mathrm{C}\right) \text {. }\end{array}$ & MAMPLI & $\begin{array}{l}\text { MAM1: } \leq 6 \\
\text { MAM2: }>6\end{array}$ & $\begin{array}{c}72 \\
370\end{array}$ & $\begin{array}{l}16,3 \\
83,7\end{array}$ \\
\hline 40. patologia do parto. & $\begin{array}{c}\text { PATOPAR } \\
*\end{array}$ & $\begin{array}{l}\text { PAT1: sem problema } \\
\text { PAT2: prob. moder. } \\
\text { PAT3: prob. graves }\end{array}$ & $\begin{array}{c}276 \\
148 \\
18\end{array}$ & $\begin{array}{c}62,4 \\
33,4 \\
4,1\end{array}$ \\
\hline
\end{tabular}

(N) = Número de "missing" na variável.

* = Variáveis que foram categorizadas.

$\nabla=$ Parâmetros de saúde e performance $\Rightarrow$ variáveis objetivas.

$\checkmark=$ Variáveis explicativas $\Rightarrow$ possíveis fatores de risco.

De posse deste conjunto de variáveis procurou-se pesquisar os fatores associados com a diarréia dos leitões, mas devido à dificuldade na interpretação da Análise de Correspondência diante deste grande número de variáveis, a metodologia francesa propõe ainda um "enxugamento" das variáveis fazendo cruzamento da variável resposta DIARREIA com as demais, com objetivo de descartar aquelas variáveis sem importância. A tomada de decisão para esta eliminação foi feita usando a Estatística $\chi^{2}$ de Pearson.

Neste processo, selecionaram-se as variáveis explicativas (candidatas a fatores de risco) com maior associação $(p \leq \mathbf{0 , 0 5})$ com DIARREIA. A TABELA 12, apresenta as probabilidades do Teste $\chi^{2}$ (teste de independência), entre as variáveis que avaliam os parâmetros de saúde e performance, e entre parâmetros de saúde e performance com as variáveis explicativas, respectivamente. 
TABELA 12. Lista das variáveis cruzadas com as respectivas probabilidades, segundo a Estatística $\chi^{2}$ de Pearson.

\begin{tabular}{|c|c|c|c|c|c|}
\hline \multirow{2}{*}{$\begin{array}{c}\text { VARIAVEIS } \\
\text { EXPLICATIVAS }\end{array}$} & \multicolumn{5}{|c|}{$\begin{array}{l}\text { PARA M TROS DE SA ÚDE E } \\
\text { PERFORMA N C E }\end{array}$} \\
\hline & PMD35 & GPM35 & CV35 & TMORTE & DIARREIA \\
\hline $01 . \mathrm{VC}$ & 0.480 & 0.605 & 0.302 & 0.022 & 0.001 \\
\hline 02. ALEI & 0.000 & 0.000 & 0.000 & 0.646 & 0.442 \\
\hline $03 . \mathrm{VS}$ & 0.001 & 0.001 & 0.004 & 0.000 & 0.014 \\
\hline 04. AG & 0.006 & 0.035 & 0.170 & 0.000 & 0.002 \\
\hline 05. PSH & 0.000 & 0.000 & 0.060 & 0.000 & 0.075 \\
\hline 06. TP & 0.000 & 0.001 & 0.002 & 0.087 & 0.018 \\
\hline 07. PF & 0.004 & 0,021 & 0.097 & 0.035 & 0.002 \\
\hline 08. PE & 0.041 & 0.102 & 0.170 & 0.007 & 0.001 \\
\hline 09. FSC & 0.311 & 0.532 & 0.715 & 0.102 & 0.239 \\
\hline 10. PTE & 0.018 & 0.029 & 0.225 & 0.029 & 0.001 \\
\hline 11. PAR & 0.000 & 0.004 & 0.425 & 0.000 & 0.157 \\
\hline 12. PNP & 0.319 & 0.089 & 0.952 & 0.543 & 0.610 \\
\hline 13. TCO & 0.469 & 0.443 & 0.441 & 0.426 & 0.151 \\
\hline 14. TRA & 0.151 & 0.977 & 0.774 & 0.058 & 0.262 \\
\hline 15. NUT & 0.790 & 0.482 & 0.711 & 0.214 & 0.704 \\
\hline 16. PD & 0.038 & 0.007 & 0.212 & 0.008 & 0.136 \\
\hline 17. PAJ & 0.003 & 0.003 & 0.103 & 0.000 & 0.012 \\
\hline 18. ARE & 0.000 & 0.000 & 0.000 & 0.000 & 0.000 \\
\hline 19. ODP & 0.342 & 0.301 & 0.133 & 0.059 & 0.107 \\
\hline 20. NLV & 0.000 & 0.000 & 0.240 & 0.002 & 0.819 \\
\hline 21. NLD & 0.003 & 0.069 & 0.126 & 0.112 & 0.586 \\
\hline 22. $\mathrm{PMN}$ & 0.000 & 0.001 & 0.034 & 0.001 & 0.346 \\
\hline 23. VAL & 0.005 & 0.076 & 0.327 & 0.000 & 0.039 \\
\hline 24. NCP & 0.000 & 0.000 & 0.032 & 0.809 & 0.037 \\
\hline 25. NLP & 0.000 & 0.001 & 0.003 & 0.087 & 0.005 \\
\hline 26. ACP & 0.457 & 0.336 & 0.524 & 0.092 & 0.382 \\
\hline 27. ADISP & 0.131 & 0.179 & 0.433 & 0.000 & 0.538 \\
\hline 28. DAMPLI6 & 0.088 & 0.041 & 0.353 & 0.200 & 0.017 \\
\hline 29. DTMAX28 & 0.000 & 0.000 & 0.439 & 0.024 & 0.519 \\
\hline 30. DTMIN16 & 0.000 & 0.000 & 0.534 & 0.731 & 0.013 \\
\hline 31. CT1824 & 0.029 & 0.036 & 0.690 & 0.704 & 0.001 \\
\hline 32. MTMAX & 0.000 & 0.000 & 0.596 & 0.012 & 0.738 \\
\hline 33. MTMIN & 0.000 & 0.023 & 0.351 & 0.000 & 0.264 \\
\hline 34. MAMPLI & 0.249 & 0.113 & 0.191 & 0.038 & 0.033 \\
\hline 35. PATOPAR & 0.725 & 0.157 & 0.611 & 0.063 & 0.053 \\
\hline
\end{tabular}


66.

continua

\begin{tabular}{|c|c|c|c|c|c|}
\hline \multirow{2}{*}{$\begin{array}{c}\text { PARAMETROS DE } \\
\text { SAÚDE E } \\
\text { PERFORMANCE }\end{array}$} & \multicolumn{5}{|c|}{$\begin{array}{c}\text { PARA METROS DE SA UDE E } \\
\text { PER FOR MAN CE }\end{array}$} \\
\hline & PMD35 & GPM35 & CV35 & TMORTE & DIARRELA \\
\hline 1. PMD35 & . & 0.000 & 0.000 & 0.012 & 0.000 \\
\hline 2. GPM35 & 0.000 & 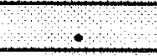 & 0.000 & 0.008 & 0.000 \\
\hline 3. CV35 & 0.000 & 0.000 & - & 0.134 & 0.006 \\
\hline 4. TMORTE & 0.012 & 0.008 & 0.143 & 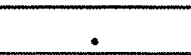 & 0.012 \\
\hline 5. PDIAR35 & 0.000 & 0.000 & 0.006 & 0.012 & \\
\hline
\end{tabular}

$\Rightarrow$ Celas com valor em negrito, significa associação entre as variáveis $(p \leq 0,05)$ pelo Teste $\chi^{2}$ de Pearson.

Finalmente, as variáveis selecionadas, segundo o teste $\chi^{2}$, formaram o arquivo de trabalho para o processamento específico dos dados, isto é, para o "input" da Análise de Correspondência.

\subsection{Resultado do Processamento Específico}

Nesta fase, aplicou-se a Análise de Correspondência aos dados, considerando a seguinte estratégia de análise: Uma análise estudando a performance dos leitões, usando-se como variável resposta "GPM35" e uma outra enfocando a sanidade dos leitões, usando-se como resposta "DIARREIA".

\subsubsection{Análise de Correspondência para "DIARREIA"}

$\mathrm{Na}$ identificação das variáveis associadas à "DIARREIA" foram selecionadas primeiramente 16 variáveis $(\boldsymbol{p} \leq \mathbf{0 , 0 5}$; ver TABELA 12) como candidatas a fatores de risco: VC, VS, AG, TP, PF, PTE, PAJ, ARE, VAL, NCP, NLP, DAMPLI6, DTMIN16, CT1824 e MAMPLI. As variáveis: GPM35, CV35, PMD35 e TMORTE foram consideradas como suplementares.

A partir deste grupo de 16 variáveis procederam-se várias Análise de Correspondência (usando o PROC CORRESP do SAS - ANEXO 2), até se elegerem 11 variáveis como fatores de risco que melhor explicam a variável resposta DIARREIA, das quais, três eram suplementares. Esses fatores são os seguintes:

1. VC: vacina contra colibacilose;

2. VS: vazio sanitário;

3. TP: tipo de piso;

4. PF: presença de forro;

5. PE: presença de escamoteador; 
6. ARE: área da cela parideira;

7. NLP: número de leitegadas presentes;

8. NCP: número de celas parideiras;

9. GPM35: ganho de peso médio diário dos leitões por leitegada aos 35 dias;

10. CV35: coeficiente de variação do peso dos leitões por leitegada aos 35 dias;

11. TMORTE: taxa de mortalidade por granja aos 35 dias.

A tabela de contingência, referente a esta Análise de Correspondência final, é mostrada pela TABELA 13

TABELA 13. Diarréia dos leitões pelos fatores de risco.

\begin{tabular}{|c|c|c|c|c|c|}
\hline \multirow{2}{*}{\begin{tabular}{|c|} 
FATORES \\
DE \\
RISCO
\end{tabular}} & \multirow[b]{2}{*}{ CLASSE } & \multicolumn{3}{|c|}{$\begin{array}{l}\text { VARIÁVEL RESPOSTA } \\
\text { "DIARREIA" }\end{array}$} & \multirow{2}{*}{$\begin{array}{l}\text { TOTAI } \\
\text { LINHA }\end{array}$} \\
\hline & & DIAR1 & DIAR2 & DIAR3 & \\
\hline \multirow[t]{2}{*}{$01 . \mathrm{VC}$} & $\overline{\mathrm{VCC} 1}$ & 22 & 30 & 16 & 68 \\
\hline & $\mathrm{VCC} 2$ & 185 & 147 & 36 & 368 \\
\hline \multirow{3}{*}{ 02. VS } & VAZ1 & 127 & 127 & 34 & 288 \\
\hline & VAZ2 & 32 & 32 & 11 & 75 \\
\hline & VAZ3 & 48 & 18 & 7 & 73 \\
\hline \multirow[t]{2}{*}{ 03. TP } & TPO1 & 148 & 141 & 39 & 328 \\
\hline & $\mathrm{TPO} 2$ & 59 & 36 & 13 & 108 \\
\hline \multirow{2}{*}{ 04. PF } & PFO1 & 32 & 53 & 8 & 93 \\
\hline & $\mathrm{PFO} 2$ & 175 & 124 & 44 & 343 \\
\hline \multirow[t]{2}{*}{ 05. PE } & PES1 & 111 & 69 & 34 & 214 \\
\hline & PES2 & 96 & 108 & 18 & 222 \\
\hline \multirow{3}{*}{ 06. ARE } & ARE1 & 109 & 116 & 19 & 244 \\
\hline & ARE2 & 44 & 37 & 27 & 108 \\
\hline & ARE3 & 54 & 24 & 6 & 84 \\
\hline \multirow{3}{*}{ 07. NLP } & NLP1 & 113 & 82 & 24 & 219 \\
\hline & NLP2 & 27 & 28 & 17 & 72 \\
\hline & NLP3 & 67 & 67 & 11 & 145 \\
\hline \multirow[t]{2}{*}{ 08. NCP } & NCP1 & 107 & 68 & 23 & 198 \\
\hline & $\mathrm{NCP} 2$ & 100 & 109 & 29 & 238 \\
\hline TOTAL COLUNA & $|\||\||\||\||||||$ & 1656 & 1416 & 416 & 3488 \\
\hline
\end{tabular}

A Análise de Correspondência fornece uma série de resultados, apresentados na TABELA 14. Estes resultados possibilitam a geração e a interpretação de um gráfico bidimensional - Mapa dos Fatores de Risco - definido pelas coordenadas principais da $1^{\underline{a}}$ e $2^{\underline{a}}$ dimensão. 
68.

TABELA 14. Saída da Análise de Correspondência para a variável resposta "DIARREIA".

\begin{tabular}{|c|c|c|c|c|c|c|c|c|c|c|}
\hline \multirow[b]{2}{*}{ OBS } & \multirow[b]{2}{*}{ Variável } & \multirow[b]{2}{*}{ Categ. } & \multirow[b]{2}{*}{ Massa } & \multirow[b]{2}{*}{ Inércia } & \multicolumn{2}{|c|}{ Coordenadas } & \multicolumn{2}{|c|}{ Contribuições } & \multicolumn{2}{|c|}{$\begin{array}{l}\text { Cosseno } \\
\text { quadrado }\end{array}$} \\
\hline & & & & & dim. & $\frac{2}{\mathrm{a}}$ & $\begin{array}{l}1 \underline{\mathrm{a}} \\
\operatorname{dim} .\end{array}$ & $\begin{array}{l}2 \mathrm{a} \\
\text { dim. }\end{array}$ & $\begin{array}{c}1 \underline{\mathrm{a}} \\
\operatorname{dim} .\end{array}$ & $\begin{array}{c}2 \underline{\mathrm{a}} \\
\text { dim. }\end{array}$ \\
\hline 01 & Risco & vcc1 & 0.020 & 0.099 & -0.046 & 0.402 & 0.003 & 0.205 & 0.013 & 0.987 \\
\hline 02 & Risco & $v c c 2$ & 0.106 & 0.018 & 0.009 & -0.074 & 0.001 & 0.038 & 0.013 & 0.987 \\
\hline 03 & Risco & $\operatorname{vaz} 1$ & 0.083 & 0.014 & -0.070 & 0.023 & 0.024 & 0.003 & 0.900 & 0.100 \\
\hline 04 & Risco & $\operatorname{vaz} 2$ & 0.022 & 0.008 & -0.036 & 0.105 & 0.002 & 0.015 & 0.104 & 0.896 \\
\hline 05 & Risco & vaz3 & 0.021 & 0.089 & 0.313 & -0.120 & 0.122 & 0.054 & 0.711 & 0.289 \\
\hline 06 & Risco & tpo1 & 0.094 & 0.008 & -0.048 & 0.017 & 0.013 & 0.002 & 0.882 & 0.118 \\
\hline 07 & Risco & tpo2 & 0.031 & 0.023 & 0.145 & -0.053 & 0.039 & 0.006 & 0.882 & 0.118 \\
\hline 08 & Risco & pfo1 & 0.027 & 0.092 & -0.333 & 0.020 & 0.176 & 0.001 & 0.996 & 0.004 \\
\hline 09 & Risco & pfo2 & 0.098 & 0.025 & 0.090 & -0.005 & 0.048 & 0.000 & 0.996 & 0.004 \\
\hline 10 & Risco & pes 1 & 0.061 & 0.066 & 0.174 & 0.063 & 0.111 & 0.016 & 0.884 & 0.116 \\
\hline 11 & Risco & pes2 & 0.064 & 0.063 & -0.168 & -0.061 & 0.107 & 0.015 & 0.884 & 0.116 \\
\hline 12 & Risco & are1 & 0.070 & 0.061 & -0.147 & -0.080 & 0.090 & 0.029 & 0.772 & 0.228 \\
\hline 13 & Risco & are2 & 0.031 & 0.156 & 0.153 & 0.373 & 0.043 & 0.280 & 0.144 & 0.856 \\
\hline 14 & Risco & are3 & 0.024 & 0.085 & 0.230 & -0.248 & 0.076 & 0.096 & 0.462 & 0.538 \\
\hline 15 & Risco & nсp1 & 0.057 & 0.033 & 0.124 & -0.057 & 0.052 & 0.013 & 0.817 & 0.183 \\
\hline 16 & Risco & nср2 & 0.068 & 0.028 & -0.103 & 0.049 & 0.043 & 0.011 & 0.817 & 0.183 \\
\hline 17 & Risco & nlp1 & 0.063 & 0.013 & 0.061 & -0.056 & 0.014 & 0.013 & 0.543 & 0.457 \\
\hline 18 & Risco & nlp2 & 0.021 & 0.087 & 0.058 & 0.364 & 0.004 & 0.178 & 0.025 & 0.975 \\
\hline 19 & Risco & nlp3 & 0.042 & 0.031 & -0.121 & -0.097 & 0.036 & 0.025 & 0.609 & 0.391 \\
\hline 20 & Suple & CVA1 & & & 0.108 & -0.208 & & & 0.213 & 0.787 \\
\hline 21 & Suple & CVA2 & & & -0.021 & -0.061 & 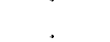 & & 0.109 & 0.891 \\
\hline 22 & Suple & CVA3 & & & -0.048 & 0.230 & & . & 0.042 & 0.958 \\
\hline 23 & Suple & MORT1 & . & . & 0.150 & -0.078 & & & 0.787 & 0.213 \\
\hline 24 & Suple & MORT2 & & & 0.045 & 0.207 & & . & 0.043 & 0.957 \\
\hline 25 & Suple & MORT3 & & & -0.096 & -0.091 & . & . & 0.529 & 0.471 \\
\hline 26 & Suple & GPM1 & . & . & -0.347 & 0.151 & . & . & 0.835 & 0.165 \\
\hline 27 & Suple & GPM2 & & & -0.013 & -0.018 & & & 0.305 & 0.695 \\
\hline 28 & Suple & GPM3 & & & 0.380 & -0.134 & & & 0.887 & 0.113 \\
\hline 29 & DIAR & diar1 & 0.475 & 0.264 & 0.102 & -0.087 & 0.292 & 0.233 & 0.578 & 0.422 \\
\hline 30 & DIAR & diar2 & 0.406 & 0.310 & -0.157 & 0.009 & 0.592 & 0.002 & 0.996 & 0.004 \\
\hline 31 & DIAR & diar3 & 0.120 & 0.426 & 0.128 & 0.314 & 0.117 & 0.764 & 0.143 & 0.857 \\
\hline
\end{tabular}

De acordo com a Análise de Correspondência plotam-se simultaneamente neste mapa os fatores de risco, as variáveis suplementares e a variável resposta, possibilitando assim, confirmar que categorias dos fatores de risco e das variáveis suplementares correspondem às categorias da variável DIARREIA. O Mapa dos fatores de risco associados à DIARREIA é exibido pela FIGURA 15. 
FIGURA 15. Mapa dos fatores de risco para variável resposta "DIARREIA".

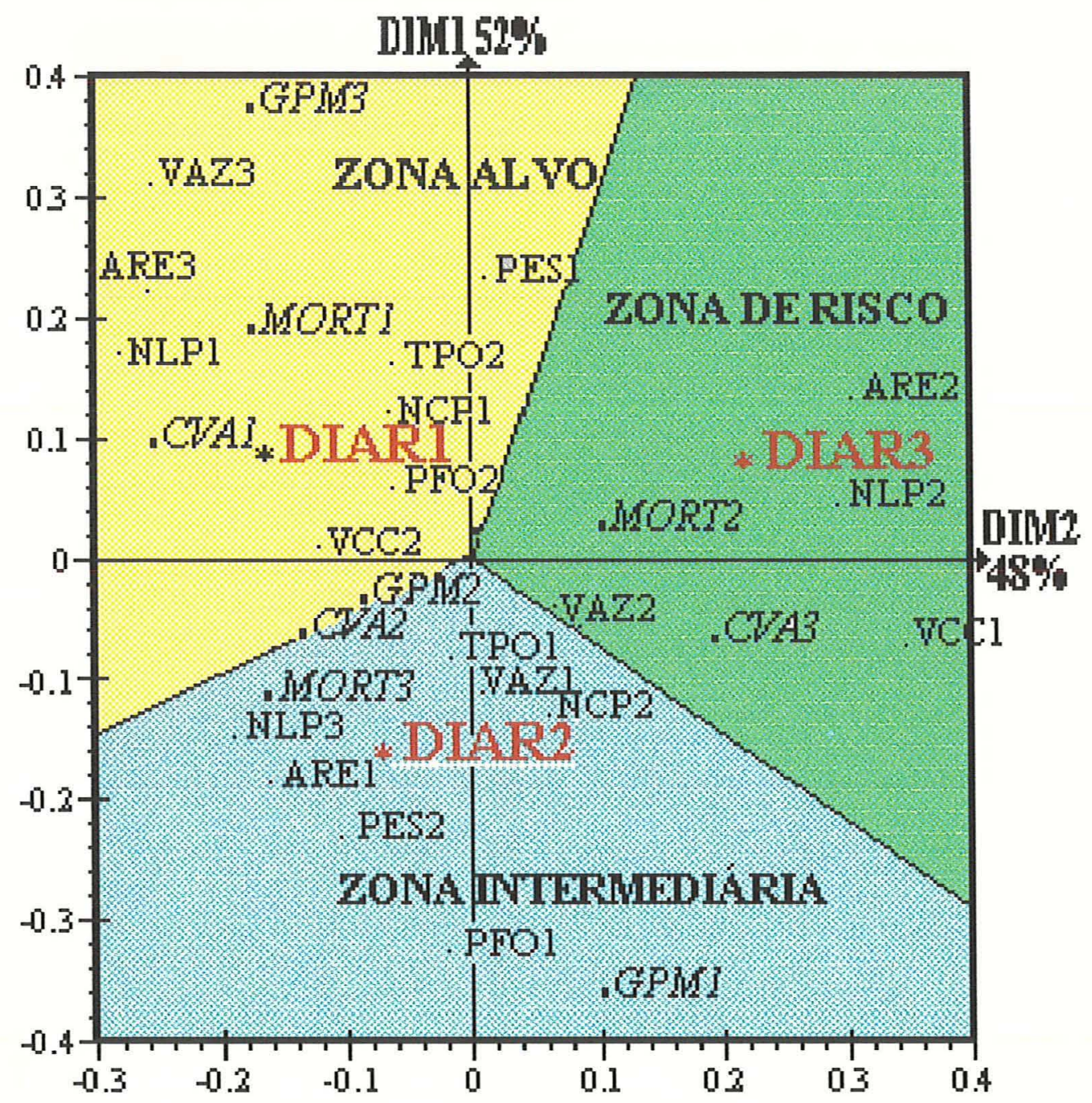

- Variável Suplementar * Variável Resposta .Fator de Risco

\subsubsection{Interpretação do Mapa para "DIARREIA"}

Observa-se que, pelo eixo vertical $\left(1^{\circ}\right.$ eixo) ausência de diarréia (DIAR1) se opõe à diarréia intermediária (DIAR2), sendo que, pelo lado positivo, a ausência contribui em $29,2 \%$ na formação deste eixo, e pelo lado negativo, intermediária contribui em 59,2\% (ausência e intermediária explicam $88,4 \%$ na formação do eixo).

Já, para o eixo horizontal $\left(2^{\circ}\right.$ eixo), verifica-se que, à alta diarréia (DIAR3), se opõe a ausência de diarréia (DIAR1), sendo que, pelo lado positivo a alta contribui em $74,4 \%$ na formação do eixo, e que pelo lado negativo, a ausência contribui 
em 23,3\% (ausência e alta explicam 99,7\% na formação deste eixo). Assim, este segundo eixo pode ser caracterizado como incidência de diarréia.

Então, ao longo do primeiro eixo estão os fatores associados com ausência ou diarréia intermediária conforme o lado em que eles se encontram no mapa, e ao longo do segundo eixo estão os fatores associados com ausência ou alta diarréia dependendo do lado em que eles se localizam.

Logo, os fatores de risco se dispersam por três zonas. Como neste caso duas dimensões explicam $100 \%$ da inércia total, estas zonas são limitadas pelas bissetrizes dos vetores DIAR1, DIAR2 e DIAR3, referentes às categorias da variável resposta DIARREIA em relação à origem $(0,0)$. A decisão de um fator pertencer a uma ou outra região foi baseada nas contribuições do $1^{\circ}$ e $2^{\circ}$ eixo. As regiões são designadas por:

Zona Alvo: correspondente à região onde se encontram distribuidos os fatores de risco associados à ausência de diarréia (DIAR1). Estes fatores em ordem de importância são os seguintes:

VAZ3: Mais de cinco dias de vazio sanitário;

ARE3: Área do escamoteador acima de $0,70 \mathrm{~m}^{2}$;

PES1: Presença de escamoteador;

NCP1: Baixo número de celas parideiras $(<10$ por sala $)$;

TFO2: Ausência de forro;

TPO2: Piso semi-ripado;

NLP1: Baixo número de leitegadas presentes $(<10$ por sala);

VCC2: Ausência de vacinação contra colibacilose.

Zona Intermediária: correspondente à região onde se encontram distribuídos os fatores de risco associados à incidência intermediária de diarréia (DIAR2). Estes fatores são os seguintes:

PFO1: Presença de forro;

PES2: Ausência de escamoteador;

ARE1: Ausência de área para escamoteador;

NCP2: Alto número de celas parideiras ( $>10$ por sala);

NLP3: Alto número de leitegadas presentes;

VAZ1: Ausência de vazio sanitário;

TPO1: Piso compacto;

Zona de Risco: correspondente à região onde se encontram distribuidos os fatores associados à alta incidência de diarréia (DIAR3). Estes fatores são os seguintes:

ARE2: Área do escamoteador intermediária;

VCC1: Vacinação contra colibacilose;

NLP2: Número intermediário de leitegadas presentes;

VAZ2: Vazio sanitário intermediário. 
$\mathrm{Na}$ interpretação das variáveis suplementares $G P M 35, C V 35$ e TMORTE, consideraram-se no mapa duas regiões: Uma região favorável, definida pela Zona Alvo e uma outra região desfavorável definida pelas Zonas Intermediária e de Risco. Desta forma pode-se dizer que:

- Na região favorável (Zona Alvo) verifica-se que, o alto ganho de peso "GPM3", a baixa taxa de mortalidade "MORTI" e a homogeneidade da leitegadas "CVAI" correspondem à ausência de diarréia "DIAR1".

- Na região desfavorável (Zona Intermediária e Zona de Risco) verifica-se que ganho de peso de médio para baixo - "GPM2" para "GPMI" - , taxa de mortalidade de média para alta - "MORT2" para "MORT3" - e leitegada heterogênea "CVA2" para "CVA3" - correspondem à presença de diarréia - "DIAR2" para "DIAR3".

\subsubsection{Análise de Correspondência para "GPM35"}

Aqui, a análise decorreu de forma similar à da DIARREIA. Então, na identificação das variáveis associadas com GPM35 selecionaram-se, primeiramente, 22 variáveis ( $p \leq 0,05$; ver TABELA 12) candidatas a fatores que afetam o ganho de peso, dadas por: ALEI, VS, AG, PSH, TP, PF, PTE, PAR, PD, PAJ, ARE, NLV, NLD, PMN, NCP, NLP, DAMPLI6, DTMAX28, DTMIN16, CT1824, MTMAX e MTMIM, e quatro suplementares: DIARREIA, CV35, PMD35 e TMORTE.

A partir deste grupo de 22 variáveis, também procederam várias Análises de Correspondência (usando o PROC CORRESP do SAS - ANEXO 3), até se elegerem 14 variáveis que melhor explicam GPM35, das quais duas eram suplementares.

Esses fatores são os seguintes:

1. ALEI: assistência aos leitões com corte de dentes e desinfeç̧ão do umbigo;

2. AG: aleitamento em grupo;

3. VS: vazio sanitário;

4. TP: tipo de piso;

5. PF: presença de forro;

6. ARE: área da cela parideira;

7. NLP: número de leitegadas presentes;

8. NCP: número de celas parideiras;

9. NLV: número de leitões nascidos vivos;

10. NLD: número de leitões desmamados;

11. DTMAX28: número de dias com temperatura máxima $\geq 28^{\circ} \mathrm{C}$;

12. MTMAX: média das temperaturas máximas no interior da maternidade;

13. CV35: coeficiente de variação do peso dos leitões por leitegada aos 35 dias;

14. DIARREIA: ocorrência de diarréia. 
A tabela de contingência referente a esta Análise de Correspondência final, é mostrada pela TABELA 15.

TABELA 15. Ganho de peso médio diário dos leitões por leitegada aos 35 dias pelas variáveis explicativas.

\begin{tabular}{|c|c|c|c|c|c|}
\hline \multirow{2}{*}{$\begin{array}{c}\text { VARLAVEIS } \\
\text { EXPLICATIVAS }\end{array}$} & \multirow[b]{2}{*}{ CLASSE } & \multicolumn{3}{|c|}{$\begin{array}{l}\text { VARIAVEL RESPOSTA } \\
\text { "GPM35" }\end{array}$} & \multirow{2}{*}{$\begin{array}{l}\text { TOTAL } \\
\text { LINHA }\end{array}$} \\
\hline & & GPM1 & GPM2 & GPM3 & \\
\hline \multirow[t]{2}{*}{ 01. ALEI } & ALE1 & 42 & 89 & 83 & 214 \\
\hline & ALE2 & 94 & 81 & 47 & 222 \\
\hline \multirow{3}{*}{ 02. VS } & $\mathrm{VAZ1}$ & 108 & 110 & 70 & 288 \\
\hline & VAZ2 & 17 & 30 & 28 & 75 \\
\hline & VAZ3 & 11 & 30 & 32 & 73 \\
\hline \multirow[t]{2}{*}{$03 . \mathrm{AG}$} & AGR1 & 95 & 134 & 107 & 336 \\
\hline & AGR2 & 41 & 36 & 23 & 100 \\
\hline \multirow[t]{2}{*}{ 04. PF } & PFO1 & 39 & 34 & 20 & 93 \\
\hline & PFO2 & 97 & 136 & 110 & 343 \\
\hline \multirow{3}{*}{ 05. ARE } & ARE1 & 82 & 99 & 63 & 244 \\
\hline & ARE2 & 37 & 45 & 26 & 108 \\
\hline & ARE3 & 17 & 26 & 41 & 84 \\
\hline \multirow{3}{*}{ 06. NLV } & NLV1 & 17 & 37 & 45 & 99 \\
\hline & NLV2 & 65 & 77 & 52 & 194 \\
\hline & NLV3 & 54 & 56 & 33 & 143 \\
\hline \multirow{3}{*}{ 07. NLD } & NLD1 & 40 & 56 & 57 & 153 \\
\hline & NLD2 & 82 & 97 & 67 & 246 \\
\hline & NLD3 & 14 & 17 & 6 & 37 \\
\hline \multirow[t]{2}{*}{ 08. TP } & TPO1 & 113 & 128 & 87 & 328 \\
\hline & TPO2 & 23 & 42 & 43 & 108 \\
\hline \multirow[t]{2}{*}{ 09. NCP } & NCP1 & 43 & 76 & 79 & 198 \\
\hline & NCP2 & 93 & 94 & 51 & 238 \\
\hline \multirow{3}{*}{ 10. NLP } & NLP1 & 59 & 78 & 82 & 219 \\
\hline & NLP2 & 33 & 27 & 12 & 72 \\
\hline & NLP3 & 44 & 65 & 36 & 145 \\
\hline \multirow[t]{2}{*}{ 11. DTMAX28 } & TMX1 & 38 & 78 & 78 & 194 \\
\hline & TMX2 & 98 & 92 & 52 & 242 \\
\hline \multirow[t]{2}{*}{ 12. MTMAX } & MTM1 & 42 & 78 & 78 & 198 \\
\hline & MTM2 & 94 & 92 & 52 & 238 \\
\hline TOTAL COLUNA & IIIIIIIIIII & 1632 & 2040 & 1560 & 5232 \\
\hline
\end{tabular}

Os resultados fornecidos pela Análise de Correspondência, estão apresentados na TABELA 16, os quais possibilitam a geração e a interpretação de um 
gráfico bidimensional (mapa dos fatores que afetam o ganho de peso) definido pelas coordenadas da $1 \underline{a}$ e $2 \underline{\text { a }}$ dimensão.

TABELA 16. Saída da Análise de Correspondência para variável resposta "GPM35".

\begin{tabular}{|c|c|c|c|c|c|c|c|c|c|c|}
\hline \multirow[b]{2}{*}{ OBS } & \multirow[b]{2}{*}{ Variável } & \multirow[b]{2}{*}{ Categ. } & \multirow[b]{2}{*}{ Massa } & \multirow[b]{2}{*}{ Inéricia } & \multicolumn{2}{|c|}{ Coordenadas } & \multicolumn{2}{|c|}{ Contribuições } & \multicolumn{2}{|c|}{$\begin{array}{l}\text { Cosseno } \\
\text { guadrado }\end{array}$} \\
\hline & & & & & $\frac{1 \mathrm{a}}{\mathrm{dim} .}$ & dim. & dim. & $\begin{array}{c}2 \underline{a} \\
\text { dim. }\end{array}$ & $\frac{19}{\operatorname{dim}}$ & $\begin{array}{r}2 \underline{a} \\
\operatorname{dim} .\end{array}$ \\
\hline 01 & Risco & ale1 & 0.040 & 0.072 & 0.262 & -0.054 & 0.073 & 0.062 & 0.960 & 0.040 \\
\hline 02 & Risco & ale2 & 0.042 & 0.070 & -0.253 & 0.052 & 0.070 & 0.060 & 0.960 & 0.040 \\
\hline 03 & Risco & vaz1 & 0.055 & 0.031 & -0.151 & 0.016 & 0.033 & 0.008 & 0.988 & 0.012 \\
\hline 04 & Risco & vaz2 & 0.014 & 0.015 & 0.205 & -0.021 & 0.016 & 0.003 & 0.990 & 0.010 \\
\hline 05 & Risco & vaz3 & 0.014 & 0.052 & 0.385 & -0.044 & 0.054 & 0.014 & 0.987 & 0.013 \\
\hline 06 & Risco & agr1 & 0.064 & 0.007 & 0.063 & -0.018 & 0.007 & 0.011 & 0.922 & 0.078 \\
\hline 07 & Risco & agr2 & 0.019 & 0.023 & -0.212 & 0.062 & 0.022 & 0.038 & 0.922 & 0.078 \\
\hline 08 & Risco & pfo1 & 0.018 & 0.027 & -0.243 & 0.050 & 0.027 & 0.024 & 0.959 & 0.041 \\
\hline 09 & Risco & pfo2 & 0.065 & 0.007 & 0.066 & -0.014 & 0.007 & 0.006 & 0.959 & 0.041 \\
\hline 10 & Risco & are1 & 0.047 & 0.009 & -0.083 & -0.032 & 0.008 & 0.026 & 0.867 & 0.133 \\
\hline 11 & Risco & are2 & 0.021 & 0.008 & -0.114 & -0.055 & 0.007 & 0.033 & 0.811 & 0.189 \\
\hline 12 & Risco & are3 & 0.016 & 0.070 & 0.386 & 0.165 & 0.062 & 0.230 & 0.846 & 0.154 \\
\hline 13 & Risco & nlv1 & 0.019 & 0.068 & 0.380 & 0.033 & 0.071 & 0.011 & 0.993 & 0.007 \\
\hline 14 & Risco & niv2 & 0.037 & 0.005 & -0.068 & -0.014 & 0.005 & 0.004 & 0.958 & 0.042 \\
\hline 15 & Risco & nlv3 & 0.027 & 0.020 & -0.171 & -0.003 & 0.021 & 0.000 & 0.999 & 0.001 \\
\hline 16 & Risco & nld1 & 0.029 & 0.020 & 0.161 & 0.049 & 0.020 & 0.037 & 0.915 & 0.085 \\
\hline 17 & Risco & nld2 & 0.047 & 0.004 & -0.061 & -0.009 & 0.005 & 0.002 & 0.979 & 0.021 \\
\hline 18 & Risco & nld3 & 0.007 & 0.015 & -0.261 & -0.142 & 0.013 & 0.076 & 0.771 & 0.229 \\
\hline 19 & Risco & tpo1 & 0.063 & 0.011 & -0.084 & -0.001 & 0.011 & 0.000 & 0.999 & 0.001 \\
\hline 20 & Risco & tpo2 & 0.021 & 0.033 & 0.255 & 0.002 & 0.035 & 0.000 & 0.999 & 0.001 \\
\hline 21 & Risco & nсp1 & 0.039 & 0.059 & 0.251 & 0.012 & 0.062 & 0.003 & 0.998 & 0.002 \\
\hline 22 & Risco & nсp2 & 0.045 & 0.049 & -0.209 & -0.010 & 0.051 & 0.003 & 0.998 & 0.002 \\
\hline 23 & Risco & nlp1 & 0.042 & 0.029 & 0.153 & 0.069 & 0.026 & 0.106 & 0.831 & 0.169 \\
\hline 24 & Risco & nip2 & 0.014 & 0.043 & -0.355 & 0.031 & 0.045 & 0.007 & 0.993 & 0.008 \\
\hline 25 & Risco & nip3 & 0.028 & 0.012 & -0.055 & -0.118 & 0.002 & 0.210 & 0.174 & 0.826 \\
\hline 26 & Risco & $\operatorname{tm} \times 1$ & 0.037 & 0.073 & 0.281 & -0.025 & 0.076 & 0.013 & 0.992 & 0.008 \\
\hline 27 & Risco & $\operatorname{tm} \times 2$ & 0.046 & 0.059 & -0.226 & 0.020 & 0.061 & 0.010 & 0.992 & 0.008 \\
\hline 28 & Risco & $m+x 1$ & 0.038 & 0.059 & 0.250 & -0.009 & 0.062 & 0.001 & 0.999 & 0.001 \\
\hline 29 & Risco & $m+x 2$ & 0.045 & 0.049 & -0.209 & 0.007 & 0.051 & 0.001 & 0.999 & 0.001 \\
\hline 30 & Suple & DIAR+ & & & -0.273 & 0.003 & & & 0.999 & 0.001 \\
\hline 31 & Suple & DIAR- & & . & 0.302 & -0.003 & & . & 0.999 & 0.001 \\
\hline 32 & Suple & CVA1 & & . & 0.373 & 0.007 & & . & 0.999 & 0.001 \\
\hline 33 & Suple & CVA2 & & & 0.118 & 0.035 & & & 0.921 & 0.079 \\
\hline 34 & Suple & CVA3 & & & -0.425 & -0.052 & & & 0.985 & 0.015 \\
\hline 35 & GPM35 & gpm1 & 0.312 & 0.475 & -0.246 & 0.035 & 0.488 & 0.199 & 0.980 & 0.020 \\
\hline 36 & GPM35 & gpm2 & 0.390 & 0.028 & -0.000 & -0.054 & 0.000 & 0.610 & 0.001 & 0.999 \\
\hline 37 & GPM35 & gpm3 & 0.298 & 0.499 & 0.257 & 0.035 & 0.512 & 0.191 & 0.982 & 0.018 \\
\hline
\end{tabular}

Neste mapa representam-se simultaneamente as categorias das variáveis explicativas, das variáveis suplementares e da variável resposta; possibilitando assim, confirmar que categorias correspondem às categorias da variável resposta GPM35. O Mapa dos fatóres que afetam o ganho de peso é mostrado pela FIGURA 16. 
FIGURA 16. Mapa dos fatores que afetam o ganho de peso "GPM35".

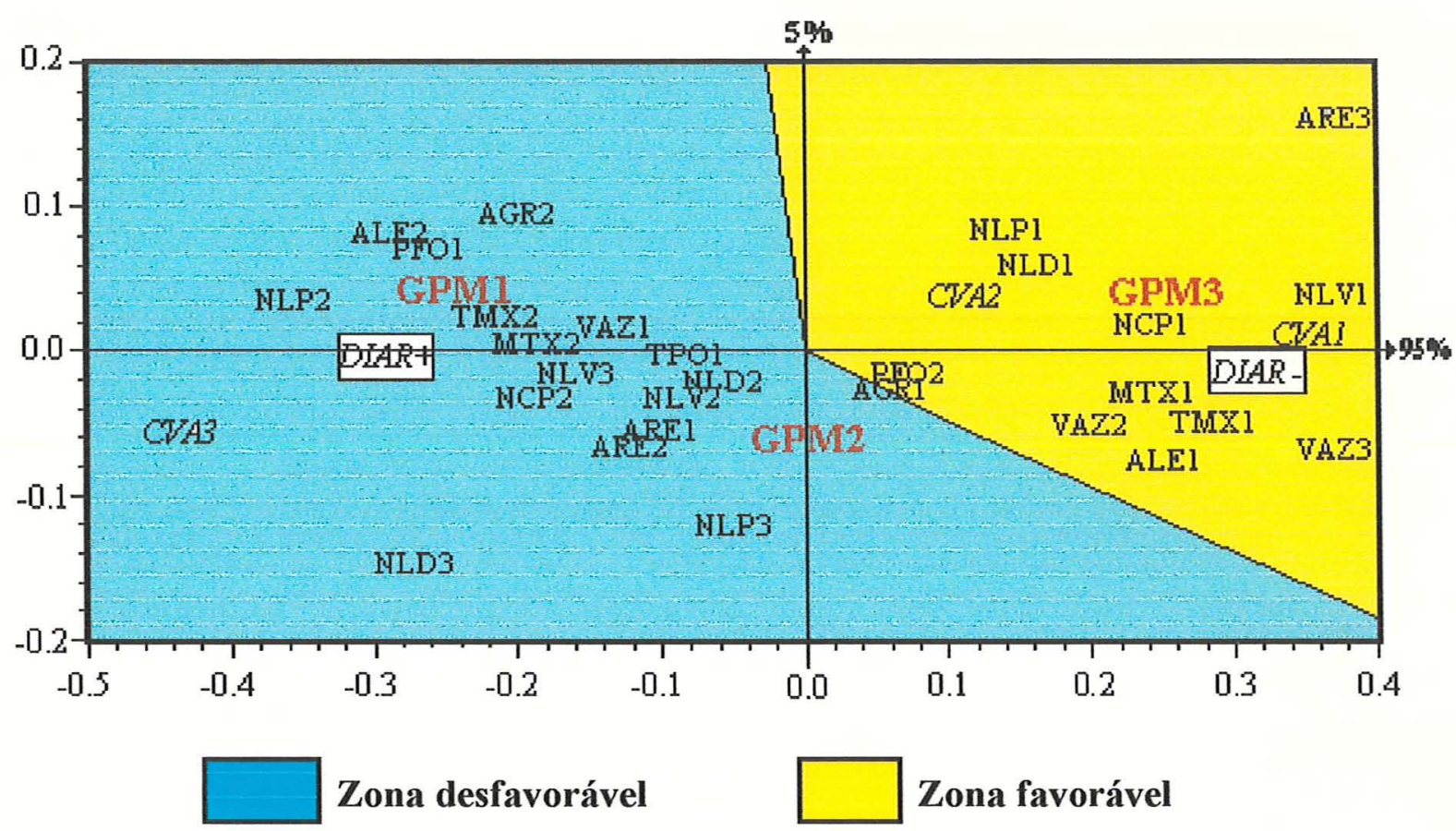

\subsubsection{Interpretação do Mapa para "GPM35"}

Verifica-se que, ao longo do eixo horizontal ( $1^{\circ}$ eixo), o baixo ganho de peso (GPM1) se opõe ao alto ganho de peso (GPM3), sendo que, pelo lado negativo, o baixo contribui em $49 \%$ na formação do eixo e, pelo lado positivo, o alto contribui em $51 \%$ (alto e baixo explicam $100 \%$ da formação do eixo!). Assim, este primeiro eixo representa o ganho de peso, e, ao longo deste, estão dispostos os fatores que se associam a alto ou baixo ganho de peso conforme o lado em que eles se encontram no mapa.

A partir daí pode-se dizer que:

Na região amarela "Zona favorável" encontram-se distribuídos os fatores associados ao Alto ganho de peso (GPM3), representados em ordem de importância por:

TMX1 : Até 10 dias com temperatura máxima $\left(\geq 28^{\circ} \mathrm{C}\right)$;

do umbigo;

ALE1 : Assistência aos leitões com corte de dentes e desinfecção

NLV1 : Baixo número de leitões nascidos vivos;

NCP1 : Baixo número de celas parideiras;

MTX1: Média das temperaturas máximas não ultrapasse $28^{\circ} \mathrm{C}$; 
75.

ARE3: Área do escamoteador acima de $0,70 \mathrm{~m}^{2}$;

VAZ2 $\Rightarrow$ VAZ3: Pelo menos um dia de vazio sanitário;

TPO2: Piso semi-ripado;

NLP1: Baixo número de leitegada presente;

NLD1: Baixo número de leitões desmamados;

PFO2: Ausência de forro;

AGR1: Aleitamento em grupo.

$\mathrm{Na}$ região azul "Zona desfavorável" encontram-se os fatores que contrapõem ao Alto ganho de peso (GPM3). Logo, neste região distribuem os fatores associados ao Baixo ganho de peso (GPM1), representados em ordem de importância por:

desinfecção do umbigo;

ALE2: Não dar assistência aos leitões com corte de dentes e

TMX2: Mais de 10 dias com temperatura máxima acima de $28^{\circ} \mathrm{C}$;

MTM2: Média das temperaturas máximas acima de $28^{\circ} \mathrm{C}$;

NCP2: Alto número de celas parideiras;

NLP2 $\Rightarrow$ NLP3: Número de leitegadas presentes de médio pra alto;

VAZ1: Ausência de vazio sanitário;

PFO1: Presença de forro;

AGR2: Não usar aleitamento em grupo;

NLV2 $\Rightarrow$ NLV3: Número de leitões vivos de médio pra alto;

NLD2 $\Rightarrow$ NLD3: Número de leitões desmamados de médo pra alto; TPO1: Piso compacto;

ARE1 $\Rightarrow$ ARE2: Área do escamoteador de nada a $0,70 \mathrm{~m}^{2}$.

Das variáveis DIARREIA e CV35, consideradas como linhas suplementares, pode-se dizer que:

Leitegadas com ausência de diarréia "DIAR-" e relativamente homogêneas "CVA2" para "CVAI" (coeficiente de variação do peso ao desmame de médio para baixo) correspondem ao Alto ganho de peso (GPM3) - região amarela, de forma oposta à presença de diarréia "DIAR+" e leitegadas muito heterogêneas "CVA3" (coeficiente de variação do peso ao desmame alto) correspondem ao Baixo ganho de peso (GPM1) - região azul. 


\subsection{Considerações Finais}

a) É importante mencionar, que neste trabalho houve muitas variáveis com "valores perdidos" e, que mesmo aquelas associadas às variáveis resposta "GPM35" e "DIARREIA" ( $\boldsymbol{p} \leq \mathbf{0 , 0 5}$ - Teste $\left.\chi^{2}\right)$, contendo mais do que 10 valores perdidos, optou-se pela sua exclusão na Análise de Correspondência. Referentes a DIARREIA foram excluídas as seguintes variáveis: PTE, VAL e PAJ, e referentes a GPM35 foram excluídas as variáveis: PSH, PTE, PAR e PAJ. Estas variáveis quando presentes na análise interferiam sensivelmente nos mapas, criando interpretações pouco condizentes com o fenômeno.

b) De acordo com os mapas exibidos anteriormentes, ficou evidente a associação da DIARREIA com as variáveis de performance (GPM35, CV35, PMD35 e TMORTE) dos leitões. Então, procurou-se uma forma de quantificar em que grau a diarréia afeta no desempenho dos leitões. Esta avaliação foi feita processando quatro Análises de Variância $\left(\mathrm{Y}_{\mathrm{ij}}=\mu+t_{i}+e_{i j}\right)$, utilizando como resposta as variáveis GPM35, PMD35, CV35 e TMORTE respectivamente, e tendo como fator (fonte de variação), para ambas análises, a DIARREIA com apenas dois niveis: Ausência e Presença. Observe na TABELA 17 os resultados alcançados neste estudo.

TABELA 17. Médias (e erro padrão da média) das variáveis de performance em relação a presença e ausência de diarréia, com os respectivos coeficientes de variação "CV(\%)" das análises de variância (ANOVA).

\begin{tabular}{|l|r|r|c|}
\hline \hline Variáveis Caracterizando a & \multicolumn{2}{|c|}{ DIARRÉA } & ANOVA \\
\cline { 2 - 4 } Performance dos Leitões & Ausênte & Presente & CV (\%) \\
\hline \hline GPM35 (gr) & $197(3,1)^{\mathbf{a}^{\mathbf{k}}}$ & $170(2,5)^{\mathbf{b}}$ & 23,06 \\
PMD35 (kg) & $8,37(0,12)^{\mathbf{a}}$ & $7,39(0,09)^{\mathbf{b}}$ & 19,52 \\
CV35 (\%) & $16,62(0,47)^{\mathbf{a}}$ & $18,32(0,48)^{\mathbf{b}}$ & 40,49 \\
MORTE (\%) & $11,67(0,49)^{\mathbf{a}}$ & $12,55(0,49)^{\mathbf{a}}$ & 60,84 \\
\hline
\end{tabular}

* Médias com Letras diferente na linha, são significativamente diferentes $(p \leq 0,05)$ pelo "teste $F$ ".

Verifica-se que, leitegadas com presença de diarréia têm uma redução de 27 gramas no ganho de peso médio diário (GPM35), uma redução de 980 gramas para o peso médio ao desmame (PMD35) e 1,70\% a mais de heterogeneidade. Já para a Taxa de Mortalidade (TMORTE) onde esperava-se um valor bem superior à da ausência de diarréia, obteve-se um valor relativamente igual. Portanto, independentemente da presença ou ausência de diarréia observou-se uma taxa média de mortalidade de $12,12 \%$. Este fato, pode ter ocorrido por haver outros fatores interferindo no rebanho, que não foram observados, além da diarréia. 


\section{CONCLUSÕES}

De acordo com a metodologia empregada neste trabalho, e com base nos resultados obtidos, pode-se chegar às seguintes conclusões:

1) A metodologia mostrou-se adequada, fornecendo resultados coerentes tanto para à diarréia como para o ganho de peso, o que permitirá efetuar diagnósticos e simulações nas granjas, visando melhor performance e sanidade do rebanho. Além desta metodologia ser uma alternativa de análise para um conjunto de variáveis mistas (qualitativas e quantitativas), poderá também ser estendida para outras áreas de aplicação da medicina preventiva para doenças multifatoriais.

2) Maternidades das granjas com presença de escamoteador e área disponível para os leitões de pelo menos $0,70 \mathrm{~m}^{2}$, com prática de vazio sanitário acima de 5 dias, com piso semi-ripado e com até 10 leitegadas presentes por sala previnem a diarréia.

3) Maternidades das granjas com vazio sanitário acima de 5 dias, com baixa número de leitegadas presente, com área disponivel para os leitões de pelo menos $0,70 \mathrm{~m}^{2}$, com temperatura interna menor que $28{ }^{\circ} \mathrm{C}$ e assistência aos leitões com corte de dentes e desenfecção do umbigo, são práticas que propiciam maior ganho de peso dos leitão.

4) A redução da performance dos leitões está associada com a diarréia. 
78.

5) O mapa para à diarréia é mais representativo quando comparado com o mapa do ganho de peso, portanto, ele discrimina melhor o fenômeno. Então, dependendo da variável resposta em estudo, a Análise de Correspondência irá gerar mapas com maior ou menor facilidade de interpretação.

6) Deve-se tomar precauções na aplicação dos questionários para que sejam evitadas perdas de informações, uma vez que, a ausência de valores pode afetar a representação geométrica dos dados, nos mapas gerados pela Análise de Correspondência.

7) Apesar de haver softwares especificos para Análise de Correspondência o SAS (Statistical Analysis Sistem), mostrou-se eficiente em todas as etapas da análise. 


\section{REFERÊNCIAS BIBLIOGRÁFICAS}

ANDERSEN, E. B. The statistical analysis of categorical data. 2. ed. Copenhagen, 1991. 532p.

BARIONI JR., W. ; PACKER, I. U.; VILLALOBOS-AGUAYO, M. T.; MORES, N; SOBESTIANSK, J; VIEIRA, R. P. Análise de correspondência via SAS em estudos ecopatológicos com suínos. In. CONGRESSO BRASILEIRO DE USUÁRIOS SAS, 4, Piracicaba. 1995, Anais-Piracicaba, ESALQ-USP, 1995 p. p668.

BARCELLOS, D.E.S.N. de; GUIZZARDI, I. I. ; FALLAVENA, L.C.B. Frequência e causa de diarréias bacterianas e suinos nas zonas Criatórias do vale do Taquari e Missões, Rio Grande do Sul, Brasil. Boletim do Instituto de Pesquisa Veterinária Desidério Finamor, Porto Alegre, 14(4): 469-72, 1983.

BATSCHELET, E. Introdução a matemática para biocientistas. Rio de Janeiro, Interciência, 1984. 618p.

BENZÉCRI, J. P. L'analyse des données. I. La taxinomie. II L'anlyse des correspondences. Dunod, Ed. Paris. 1976. 2v.

BENZÉCRI, J. P. Correspondence analysis handbook. New York, Marcel Dekker, 1992. v. 125 . 
BUDDLE, J. R. ; MERCY, A. R. ; SKIRROW, S. Z. ; MADEC, F; NICHOLLS, R. R Epidemiological studies of pig diseases: 1. Identification of risk factors; final report. s.1., Pig Research and Development Corporation, 1992. 82p. (Project UMUR,5P).

BURT, C. The factorial analysis of qualitative data. British Journal of Psychology, Leicester , England, 3: 166-85, 1950.

CALLEGARI - JACQUES, S.M. Análise de correspondência: aplicações em genética. In: Cadernos de Matemática e Estatística. Série F, Porto Alegre, 1991. 27p.

CAPRON, L. La notion de facteur de risque. Revie du Praticien, Paris, 36: 75-81, 1986.

DEPIZZOLATTI-VERANI, A. L. A análise de correspondência e a tabela de contingência de conceitos versus departamento da Universidade Federal de Santa Catarina. Piracicaba, 1988. 89p. (Mestrado - Escola Superior de Agricultura "Luiz de Queiroz "/USP).

EMPRESA BRASILEIRA DE PESQUISA AGROPECUÁRIA. Centro Nacional de Pesquisa de Suínos e Aves. Plano diretor do Centro Nacional de Pesquisa de Suínos e Aves - CNPSA. Brasília, 1993. 39p.

FENELON, J. P. Qu'est-ce que 1'analyse des données ?. Lefonen, Ed. Paris, 1981.

FISHER, R. A. The precision of discriminant function. Annals of Eugenics, Cambrigde, 10: 422-9, 1940.

GOMES, M. F. M.; GIROTTO, A. F.; TALAMINI, D. J. D.; LIMA G. J. M. M. de; MORES, N.; TRAMONTINI, $P$. Análise prospectiva do complexo agroindustrial de suínos no Brasil. Concórdia, EMBRAPA-CNPSA, 1992. 108p. (EMBRAPA - CNPSA. Documento, 26) 
GREENACRE, M. J. Correspondence analysis in pratice. London, Academic Press, 1993. $193 \mathrm{p}$.

GREENACRE, M. J. \& HASTIE, T. The geometric interpretation of correspondence analysis. Journal of the American Satistical Association, Washington, 82:437 $47,1987$.

GREENACRE, M. J. Theory and applications of correspondence analysis. New York, Academic Press, 1984. 364 p.

GRUNDY, P. F. A rational approach to the " at risk " concept. Lancet, London, 2:1489, 1973.

GUTTMAN, L. The quantification of a class of attributes: a theory and method of scale construction, in the prediction of personal adjustment. eds. P. Horst, et al. , New York: Social Science Research Council.. 1941.

HAYASHI, C. On the quantification of qualitative data from the mathematico-statistical point of view. Annals of the Institute of Statistical Mathematics, 2(1): $35-47$, 1950.

HIRSHFIELD, H. O. A connection between correlation and contingency: Philosophical Society Proceedings, Cambridge, 31: 520-4, 1935.

JAMBU, M. \& LEBREAUX, M.O. Classification automatique pour l'analyse des données. I. Méthodes et algorithmes. II. Logiciels. Dunod, Ed. Paris. 1978.

JENICEK, M. \& CLEROUX, R. Epidémiologie; principes, techniques, applications. Québec, Edisem, 1982. 454 p.

JUDEZ, L.A. Técnicas de análises de dados multidimensionales, Madrid, Ministério de Agricultura, Pesca y Alimentacion, 1988. 297p. 
KRZANOWSKY, W. J. Attribute selection in correspondence analysis of incidence matrices. Applied Statistics, London, 42(3): 529-41, 1993.

LEBART, L. \& FENELON, J.P. Statistique et informatique appliqués. Dunod, Ed. Paris, 1975.

LECCE, J.C. Dietary regimen, rotavirus and hemolytic enterophatogenic Escherichia Coli in weaning diarrhea of pigs. Annales de Recherche Veterinaires, Paris, 14(4): 463-8, 1983.

MENDES, P. G. Manual de intrudução ao SAS. Brasilia, EMBRAPA, 1984. 1v.

MADEC, F. \& JOSSE, J. Influence of environmental factores on the outset of digestive disorders of the weaned piglet. Annales de Recherche Veterinaires, Paris, 14(4): 456-62, 1983.

MADEC, F. \& JOSSE, J. Utilisation des methodes d'alnalyse des données pour l'etudes maladies d'elevage - application du porc. Epidemiologie et Santé Animale, Paris, 6: $35-63,1984$.

MADEC, F. \& TILLON, J. P. The ecophatological approach in pig veterinary pratice. Its application to the control of enzootic respiratory disease in intensive pig units. Pig Veterinary Society Proceedings, Cambridge, 15: 7-26, 1986.

MADEC, F. \& TILLON, J. P. Ecophatologie et facteurs de risque en médicine vetérinaire. Recueil de Medecine Véterinaire, Maisons Alfort, 164: 607-16, 1988.

MADEC, F. ; JOSSE, J. ; CARIOLET, R. Influence des conditions de milieu sur la santé et les peformance de porcelet sous la mère. Physiologie et pathologie périnatales chez les animaux de ferme. In: JOURNEES DE GRENIER DE THEIX, 14, Proceedings-Paris. 1984, Paris, INRA, 1984. p.455-64. 
MADEC, F.; JOSSE, J. ; CHANTAL, A. Evaluation d'une methode multifactorielle dans l'analyses des troubles digestifs de sevrage. Journees de la Recherche Porcine en France, Paris, 14: 379-86, 1982.

MANDEL, J. Use of the singular value decomposition in regression analysis. The American Statistician, Alexandria, VA., 36(1): 15-23, 1982.

MARDIA, K. V. ; KENT, J. T. ; BIBBY, J.M. Multivariate analysis. London, Academic Press, 1979. 519p.

MORES, N. Influência de fatores nutricionais na prevenção de diarréia pós desmame em leitões, associada com Escherichia Coli Enteropatogênica. Concórdia, EMBRAPA-CNPSA, 1987.

MORES, N.; SOBESTIANSKY, J. ; CIACCI, J. R. ; BARIONI JR., W. ; MADEC, F ; AMARAL, A. L. do. PROJETO: Estudos ecopatologicos dos problemas entéricos em leitões lactantes e na desmama. Concórdia, EMBRAPA-CNPSA, 1988 .

NICOLET, J. Les maladies respiratoires du porc. Med. Vet. Porc. Fev., 10: 98-102, 1981

PERESTRELO, R.; PERESTRELO, H.; MADEC, F ; TLLLON, J. P. Factores associados à eclosão da patologia das vias urinárias nas fêmeas da espécie suina exploradas intensivamente. Revista Portuguesa de Ciências Veterinária, Lisboa, 86(497): 4-12, 1991.

PROHASZKA, L. \& BARON, F. The predisposing role of high dietary protein suppleis in enteropathogenic Escherichia Coli infections of weaned pigs. Zentralblatt fuer Veterinaermedizin, Berlin, 27(3): 222-32, 1980.

RICHARDSON, M. \& KUDER, G. F. Marking a rating scale that measures. Personnel Journal, Costa Mesa, CA, 2: 36-40, 1933. 
SAS INSTITUTE INC. SAS/BASIC user's guide; version 6.03. Cary, 1987.

SAS INSTITUTE INC. SAS/STAT user's guide; version 6.03. Cary, 1987.

SOBESTIANSK, J. Relatório do projeto de pesquisa. Concórdia, 1987. (EMBRAPACNPSA Relatório de Projeto).

SCHLOTZHAUER, S. D. \& LITTELL, R. C. SAS System for elementary statistical analysis. Cary, SAS Institute Inc., 1987. 416p.

SVENSMARK, B; JORSAL, S. E.; NIELSEN, K.; WILLEBERG, P. Epidemiological studies of piglet diarrhoea in intensively managed danish sow herds. Acta Veterinaria Scandinavica, Copenhagen, 30(1): 43-53, 1989.

TILLON, J. P. Epidémiologie des maladies du porc liées l'elevage intensif. Journnées de la Recherche Porcine en France, Paris, 12: 361-80, 1980.

TILLON, J. P. Quelques indicateurs à prendre en consideration dans 1 apreciation d' elevage intensif. Journnées de la Recherche Porcine en France, Paris, 13: 89$110,1981$.

TUFFERY, E. Epidémiologie animale et informatique. Recueil de Medicine Veterinaire, Maisons Alfort, 162: 785-95, 1986.

TZIPORI, S.; CHANDLER, D.M.; MAKIN, T.; HENNESSY, D. Factors contributing to post-weaning diarrhoea in a large intensive piggery. Australian Veterinary Jornal,_Victoria, 56: 274-8, 1980.

VANNIER, P. ; TILLON, J. P. ; MADEC, F. ; MORISSE, J. P. Environment and gastro-enterits. Annales de Recherche Veterinaires, Paris, 14(4): 450-5, 1983.

VIEIRA, R. P. Epidemiologia das afecções dos suínos em amostras da população explorada intensivamente em Portugal. Lisboa, 1989. 313p. (Doutorado Escola Superior de Medicina Veterianária de Lisboa). 
VIEIRA, R. P. ; VIEIRA, H. P. ; MADEC, F. Aplicação da análise multidimensional na prevenção da patologia digestiva do desmame em suinocultura intensiva. Revista Portuguesa de Ciências Veterinária, Lisboa, 84(492): 229-41, 1989.

VILLALOBOS-AGUAYO, M. T. Análise de correspondência e modelos loglineares: um enfoque integrado para a análise exploratória de dados categóricos. Campinas, 1993. 147p. (M. S.- Instituto de Matemática, Estatística e Ciência da Computação - UNICAMP).

WENTZ, I. Ocorrência de rotavirus em leitões com sintomas clínicos de diarréia e prevalência de anticorpus em plantéis de suínos de Santa Catarina. Concórdia EMBRAPA-CNPSA, 1987. 
86.

ANEXOS 


\section{QUESTIONÁRIO}

EMBRAPA Empresa Brasileira de Pesquisa Agropecuária

CNPSA Centro Nacional de Pesquisa de Suínos e Aves

\section{PROJETO DE ECOPATOLOGLA}

\section{PATOLOGIA DO LEITÃo EM AMAMENTAÇÃo}

DATA DA REALIZAÇÃO DO QUESTIONÁRIO

DATA DO ENVIO AO CNPSA

GRANJA:

NOME DO CRIADOR :

ENDEREÇO :

CIDADE :

CÓDIGO POSTAL :

TELEFONE :

RESPONSÁVEL PELO PREENCHIMENTO DO QUESTIONÁRIO

NOME

FUNÇÃO

ENDEREÇO

CIDADE

TELEFONE

EMBRAPA - CNPSA

CX. POSTAL 21

89700-000 CONCÓRDIA SC

FONE (0494) 440122 
88.

\section{FICHA DE PESO DOS LEITÓES}

\section{PESO DA LEITEGADA AO NASCER}

Acompanhar no mínimo 4 porcas, suas leitegadas e identificação individualmente

\begin{tabular}{|c|c|c|c|c|c|c|c|c|}
\hline $\begin{array}{c}\text { Moss } \\
\text { a } \\
\text { Porca }\end{array}$ & $\begin{array}{c}\text { Data } \\
\text { transferên- } \\
\text { cia para } \\
\text { Matenidade }\end{array}$ & $\begin{array}{c}\text { Ordem } \\
\text { Parto }\end{array}$ & $\begin{array}{c}\text { Data } \\
\text { Parto }\end{array}$ & \multicolumn{2}{|c|}{$\begin{array}{c}\text { Número } \\
\text { de leitões } \\
\text { nascidos }\end{array}$} & $\begin{array}{c}\text { Peso } \\
\text { leite- } \\
\text { gada }\end{array}$ & $\begin{array}{c}\text { Peso } \\
\text { Médio }\end{array}$ & $\begin{array}{c}\text { Observações } \\
\text { transferências } \\
\text { e } \\
\text { mortalidade. }\end{array}$ \\
\hline & & & & & & & & \\
\hline & & & & & & & & \\
\hline & & & & & & & & \\
\hline & & & & & & & & \\
\hline & & & & & & & & \\
\hline
\end{tabular}

\section{PESO INDIVIDUAL DOS LEITÕES AO DESMAME} DATA DO DESMAME

IDADE MÉDIA

\begin{tabular}{|l|l|l|l|l|l|l|l|l|l|l|l|l|l|l|}
\hline $\begin{array}{l}\text { Identificação da } \\
\text { Porca }\end{array}$ & \multicolumn{10}{|c|}{ Peso Invidual dos Leitões } \\
\hline & 01 & 02 & 03 & 04 & 05 & 06 & 07 & 08 & 09 & 10 & 11 & 12 & 13 & 14 \\
\hline & & & & & & & & & & & & & & \\
\hline & & & & & & & & & & & & & & \\
\hline & & & & & & & & & & & & & \\
\hline & & & & & & & & & & & & & & \\
\hline & & & & & & & & & & & & & & \\
\hline & & & & & & & & & & & & & & \\
\hline & & & & & & & & & & & & & & \\
\hline
\end{tabular}

Número de Leitões Desmamados

Desvio Padrão $\mathrm{CV}$

Utiliza Vacina Contra Colibacilose PMD35 dias $=(\mathrm{PMD} * 35 / \mathrm{TMD})=$
Taxa de Mortalidade

GMP

Marca 


\section{ACOMPANHAMENTO ANTÍ E PÓS PARTO}

\begin{tabular}{|c|c|c|c|c|c|c|c|c|c|c|c|c|c|c|c|c|c|c|}
\hline \multirow[b]{2}{*}{ Dia de Acompanhamento } & \multicolumn{6}{|c|}{ PORCA 1: } & \multicolumn{6}{|c|}{ PORCA 2: } & \multicolumn{6}{|c|}{ PORCA 3: } \\
\hline & 0 & 1 & 2 & 3 & 4 & 5 & 0 & 1 & 2 & 3 & 4 & 5 & 0 & 1 & 2 & 3 & 4 & 5 \\
\hline \multicolumn{19}{|l|}{ Duração do Parto (Horas) } \\
\hline \multicolumn{19}{|l|}{ Extração Manual (Sim/Não) } \\
\hline \multicolumn{19}{|l|}{$\begin{array}{l}\text { Temperatura da Femea } 1 / 2 \\
\text { Hora Após Alimentação }\end{array}$} \\
\hline \multicolumn{19}{|l|}{ Corrimento Purulento } \\
\hline \multirow{2}{*}{\multicolumn{19}{|c|}{ Apetite : Pouco }} \\
\hline & & & & & & & & & & & & & & & & & & \\
\hline \multicolumn{19}{|l|}{ Mamite e/ou Agalaxia } \\
\hline \multicolumn{19}{|l|}{ Ocitocina } \\
\hline Antibiótico & & & & & & & & & & & & & & & & & & \\
\hline
\end{tabular}

\begin{tabular}{|c|c|c|c|c|c|c|c|c|c|c|c|c|c|c|c|c|c|c|}
\hline \multirow[b]{2}{*}{ Dia de Acompanhamento } & \multicolumn{6}{|c|}{ PORCA 1: } & \multicolumn{6}{|c|}{ PORCA 2 : } & \multicolumn{6}{|c|}{ PORCA 3:: } \\
\hline & 0 & 1 & 2 & 3 & 4 & 5 & 0 & 1 & 2 & 3 & 4 & 5 & 0 & 1 & 2 & 3 & & 5 \\
\hline \multicolumn{19}{|l|}{ Duração do Parto (Horas) } \\
\hline \multicolumn{19}{|l|}{ Extração Manual (Sim/Não) } \\
\hline \multicolumn{19}{|l|}{$\begin{array}{l}\text { Temperatura da Femea } 1 / 2 \\
\text { Hora Após Alimentação }\end{array}$} \\
\hline \multicolumn{19}{|l|}{ Corrimento Purulento } \\
\hline \multirow{2}{*}{\multicolumn{19}{|c|}{ Apetite : $\quad$ Pouco }} \\
\hline & & & & & & & & & & & & & & & & & & \\
\hline \multicolumn{19}{|l|}{ Mamite e/ou Agalaxia } \\
\hline \multicolumn{19}{|l|}{ Ocitocina } \\
\hline Antibiótico & & & & & & & & & & & & & & & & & & \\
\hline
\end{tabular}

Devem ser acompanhada no mínimo 4 fêmeas por grupo, desde o momento da transferência até cinco dias após o parto. 


\section{A VALIACC̃̃ O DA D I ARRÉ IA}

DIARRÉIA DOS LEITÕES.

Assinale com positivo $(+)$ para presença e com negativo ( - ) para ausência de diarréia em cada dia da primeira, segunda, ..., e quinta semana de idade.

\begin{tabular}{|l|l|l|l|l|l|l|l|l|l|l|l|l|l|l|l|l|l|l|l|l|l|}
\hline & \multicolumn{10}{|c|}{ Porca 1: } \\
\hline Dia & $\mathbf{1}$ & $\mathbf{2}$ & $\mathbf{3}$ & $\mathbf{4}$ & $\mathbf{5}$ & $\mathbf{6}$ & $\mathbf{7}$ & $\mathbf{1}$ & $\mathbf{2}$ & $\mathbf{3}$ & $\mathbf{4}$ & $\mathbf{5}$ & $\mathbf{6}$ & $\mathbf{7}$ & $\mathbf{1}$ & $\mathbf{2}$ & $\mathbf{3}$ & $\mathbf{4}$ & $\mathbf{5}$ & $\mathbf{6}$ & $\mathbf{7}$ \\
\hline Semana 1 & & & & & & & & & & & & & & & & & & & & & \\
\hline Semana 2 & & & & & & & & & & & & & & & & & & & & & \\
\hline Semana 3 & & & & & & & & & & & & & & & & & & & & & \\
\hline Semana 4 & & & & & & & & & & & & & & & & & & & & & \\
\hline Semana 5 & & & & & & & & & & & & & & & & & & & & & \\
\hline
\end{tabular}

\begin{tabular}{|l|l|l|l|l|l|l|l|l|l|l|l|l|l|l|l|l|l|l|l|l|l|}
\hline \multicolumn{10}{|l|}{ Porca 1: } & \multicolumn{10}{|c|}{ Porca 2: } & \multicolumn{10}{|c|}{ Porca 3: } \\
\hline Dia & $\mathbf{1}$ & $\mathbf{2}$ & $\mathbf{3}$ & $\mathbf{4}$ & $\mathbf{5}$ & $\mathbf{6}$ & $\mathbf{7}$ & $\mathbf{1}$ & $\mathbf{2}$ & $\mathbf{3}$ & $\mathbf{4}$ & $\mathbf{5}$ & $\mathbf{6}$ & $\mathbf{7}$ & $\mathbf{1}$ & $\mathbf{2}$ & $\mathbf{3}$ & $\mathbf{4}$ & $\mathbf{5}$ & $\mathbf{6}$ & $\mathbf{7}$ \\
\hline Semana 1 & & & & & & & & & & & & & & & & & & & & & \\
\hline Semana 2 & & & & & & & & & & & & & & & & & & & & & \\
\hline Semana 3 & & & & & & & & & & & & & & & & & & & & & \\
\hline Semana 4 & & & & & & & & & & & & & & & & & & & & & \\
\hline Semana 5 & & & & & & & & & & & & & & & & & & & & & \\
\hline
\end{tabular}

\begin{tabular}{|l|l|l|}
\hline MICRO AMBIENTE DOS LEITÕES & SIM & NÃO \\
\hline Presença de Escamoteador & & \\
\hline Fonte Suplementar de Calor & & \\
\hline Presença de Tampa no Escamoteador & & \\
\hline Uso de Cama & & \\
\hline
\end{tabular}

\begin{tabular}{|l|c|c|}
\hline \multicolumn{3}{|c|}{ DADOS REFERENTES À CONDIÇÃO NUTRICIONAL DAS FÊMEAS. } \\
\hline ESCORE & & NÚMERO DE FÊMEAS \\
\hline Estado Satisfatório & 5 & \\
\hline Razoável & 4 & \\
\hline Insuficiente & 3 & \\
\hline Magra & 2 & \\
\hline Muito Magra & 1 & \\
\hline
\end{tabular}




\section{ACOMPANHAMENTO DO PARTO}

\begin{tabular}{|l|l|l|}
\hline M A N E O SA N I T R I O DA MA T E R I DADE & Sim & Não \\
\hline Sistema Contínuo & & \\
\hline Vazio Sanitário (Até 5 dias) & & \\
\hline Vazio Sanitário (Maior que 5 dias) & & \\
\hline Aleitamento em Grupo & & \\
\hline
\end{tabular}

Parecer Sobre higiene da Maternidade

\begin{tabular}{|l|l|l|}
\hline Bom & Regular & Ruim \\
\hline & & \\
\hline
\end{tabular}

Assistência ao leitão com corte e desinfecção do umbigo e orientação das mamadas

Presente

Ausente

\section{A VALIACÃO CLÍNICA DOS LEITÓES}

\section{( Examinar no mínimo 30 leitões)}

1. Aspecto do umbigo (realizar o exame entre 10 a 15 dias de idade)

\begin{tabular}{|l|l|}
\hline Número de leitões com umbigo normal & \\
\hline Número de leitões com onfalite & \\
\hline Total de leitões examinados & \\
\hline
\end{tabular}

\section{Aspecto das Articulacões (No Desmame)}

\begin{tabular}{|l|l|}
\hline Número de leitões com articulações normais & \\
\hline Número de leitões com inflamações articulares & \\
\hline Total de leitões examinados & \\
\hline
\end{tabular}

3. Avaliação de tosse e espirros nos leitões: Realizar 3 contagens de dois minutos cada, com os animais em atividade (no desmame).

\begin{tabular}{|l|l|l|l|l|}
\hline \multicolumn{1}{|c|}{ CONTAGEM } & PRIMEIRA & SEGUNDA & TERCEIRA & MÉDIA \\
\hline Número de Tosse & & & & \\
\hline Número de Espirros & & & & \\
\hline
\end{tabular}

Total de leitões no lote observado 


\section{AVALIACÃO DAS INSTALACÓES}

\section{MATER NIDADE}

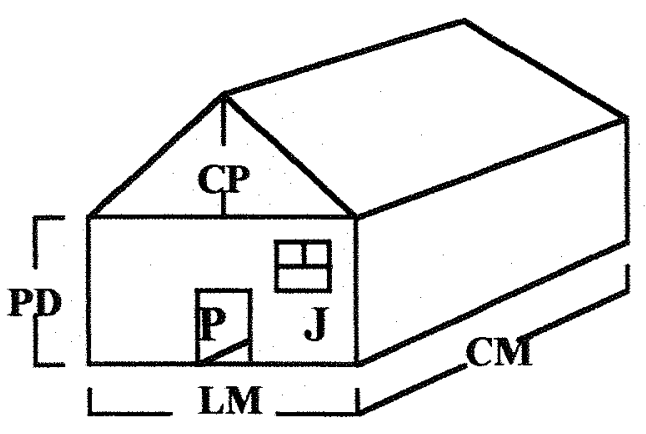

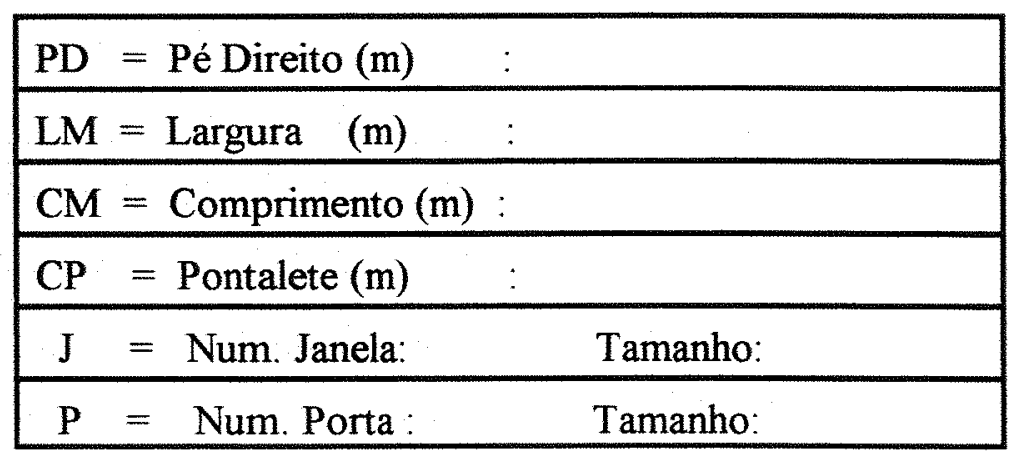

CELA PARIDEIRA

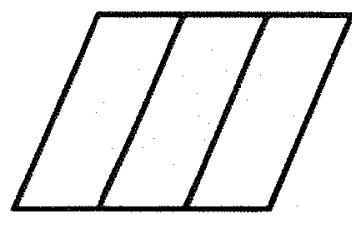

\begin{tabular}{|l|l|l|}
\hline Número de leitegadas Presentes: & & \\
\hline N. de Cela Parideira: & & Tamanho: \\
\hline Escamoteador Tamanho: & & Altura: \\
\hline
\end{tabular}

\begin{tabular}{|l|l|}
\hline Tipo de Piso: & Compacto \\
\hline
\end{tabular}

Semi - Ripado

Totalmente Ripado

\begin{tabular}{|l|l|l|}
\hline & Sim & Não \\
\hline Presença de Forro & & \\
\hline Presença de Lanternim & & \\
\hline Tipo de Cobertura: & & \\
\hline
\end{tabular}

Observações: 
TEMPERATURA AMBIENTAL Local

\begin{tabular}{|c|c|c|c|c|c|}
\hline & \multicolumn{2}{|c|}{ TEMPERATURA } & & \multicolumn{2}{|c|}{ TEMPERATURA } \\
\hline DATA & MÍNIMA & MÁXIMA & DATA & MÍNIMA & MÁXIMA \\
\hline & & & & & \\
\hline & & & & & \\
\hline & & & & & \\
\hline & & & & & \\
\hline & & & & & \\
\hline & & & & & \\
\hline & & & & & \\
\hline & & & & & \\
\hline & & & & & \\
\hline & & & & & \\
\hline & & & & & \\
\hline & & & & & \\
\hline & & & & & \\
\hline & & & & & \\
\hline & & & & & \\
\hline & & & & & \\
\hline
\end{tabular}




\section{PROGRAMA DE ANÁLISE DE CORRESPONDÊNCIA PARA “DIARREIA"}

\section{Sistema SAS}

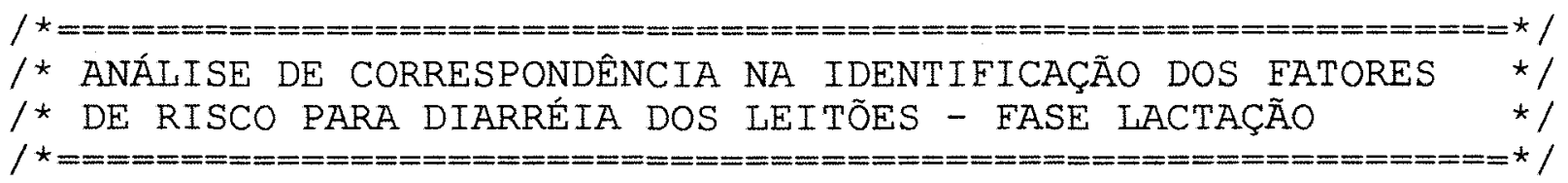

Options ps $=500 \quad 1 s=100$

Libname in'.';

titlel $\mathrm{h}=.6 \mathrm{~cm}$ 'Ecopatologia de Suínos';

title $2 \mathrm{~h}=.4 \mathrm{~cm}$ 'Aplicação Análise de Correspondência';

title $3 \mathrm{~h}=.4 \mathrm{~cm}$ 'Fatores de risco versus DIARREIA';

DATA DIARREIA;

SET IN.ECO;

IF $T P=' t p o 3 '$ OR TP='tpo2' THEN TP='tpo2';

PROC CORRESP data=DIARREIA outc=saida observed short all;

TABLES VC VS TP PF PE ARE NCP NLP CV35 TMORTE GPM35, DIARREIA;

SUPPLEMENTARY CV35 TMORTE GPM35;

/* Arquivo de saída da Análise de Correspondência */

DATA saida; set saida;

IF type ='VAR' then type ='DIAR.';

else IF_type_='OBS' then _type_='Risco'; else type ='Suple';

IABEL

$$
\begin{aligned}
& \text { type }=\text { 'Variável' } \\
& \text { Mass }=\text { 'Massa' } \\
& \text { dim1 } 1=\text { 'Coord. } 1^{a} \text { dim' } \\
& \text { contr1 }=\text { 'Contr. } 1^{a} \text { dim' } \\
& \text { sqcos1 }=\text { ' } \cos ^{2} 1^{a} \text { dim' } \\
& \text { run; }
\end{aligned}
$$

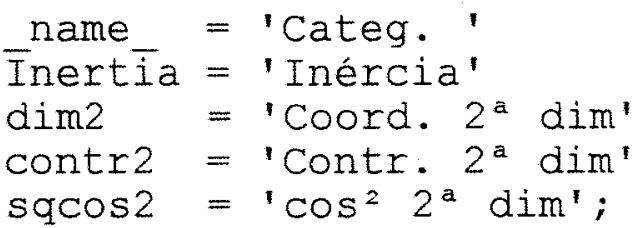

PROC PRINT data = saida label; VAR type ${ }_{\text {sqcos } 2 ;}^{\text {name_- mass inertia dim1 dim2 contr1 contr2 sqcos1 }}$

/* Criando o Arquivo Annotate para o GPLOT */

DATA saida;

Length style $\$ 8$;

SET saida;

if name__ $_{\text {narl }}$ 'diarl' or _name_ = 'diar2' or _name_ = 'diar3' then do;

size=1.0;

end;

style $=$ 'centx'; 
95.

else do;

size $=0.5$;

style $=$ ' duplex' ;

end;

$\mathrm{X}=\mathrm{DIM} 2$;

/* variável no eixo horizontal */

$\mathrm{Y}=\mathrm{DIM1}$;

/* variável no eixo vertical */

XSYS $=12 ' ;$

YSYS $=12^{\prime} ;$

TEXT = NAME $; /$ * texto que irá posicionado no lugar do ponto */

KEEP $X^{-} Y$ TEX $\bar{X} T$ XSYS YSYS SIZE STYLE;

GOPTIONS DEVICE = egal hsize $=12 \mathrm{~cm}$ vsize $=15 \mathrm{~cm}$;

axisl $\mathrm{v}=(\mathrm{f}=$ centx $\mathrm{h}=.2 \mathrm{~cm})$

label $=(f=$ centx $h=1.5$ cells 'DIMI (52\%)')

order $=(-0.4$ to 0.4 by 0.1$) ; /$ vertical */

axis $2 \mathrm{v}=(\mathrm{f}=$ centx $\mathrm{h}=.2 \mathrm{~cm})$

label $=(f=$ centx $h=1.5$ cells 'DIM2 (48\%)')

order $=(-0.3$ to 0.4 by 0.1$) ; /$ horizontal*/

/* Resultado gráfico da análise de correspondência */

PROC GPLOT data=saida;

title $4 \mathrm{~h}=.3 \mathrm{~cm}$ 'Mapa dos Fatores de Risco';

symboll $\mathrm{v}=$ none;

PLOT $Y * X=1 /$ annotate $=$ saida frame $V R E F=0$ HREF $=0$

RUN;

vaxis=axis1 haxis=axis 2 ; 


\section{PROGRAMA DE ANÁLISE DE CORRESPONDÊNCIA PARA "GPM35"}

\section{Sistema SAS}

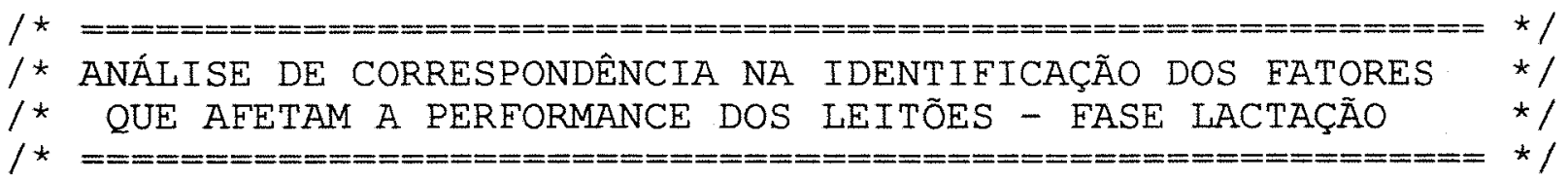

Options ps=500 $1 \mathrm{~s}=100$;

Libname in'.';

titlel $\mathrm{h}=.6 \mathrm{~cm}$ 'Ecopatologia de Suinos';

title2 $h=.4 \mathrm{~cm}$ 'Aplicação da Análise de Correspondência';

title $3 \mathrm{~h}=.4 \mathrm{~cm}$ 'Eatores de risco vs. GPM35';

DATA GPM;

SET IN.ECO;

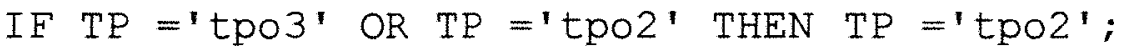

IF DIARREIA='diar3' OR DIARREIA='diar2' THEN DIARREIA='DIAR+';

ELSE DIARREIA=' DIAR-';

PROC CORRESP data $=G P M$ outC=saida observed short all;

TABLES Ale VS AG PE ARE NLV NLD TP NCP

NLP DTMAX28 MTMAX DIARREIA CV35, GPM35;

SUPPLEMENTARY DIARREIA CV35;

/* Arquivo de saída da Análise de Correspondência */

DATA saida; set saida;

IE type = 'VAR' then type $=$ 'GPM35';

else IF _type_='OBS' then _type_='Risco'; else type_='Suple';

LABEL type_ = 'Variável' name_ = 'Categ. '

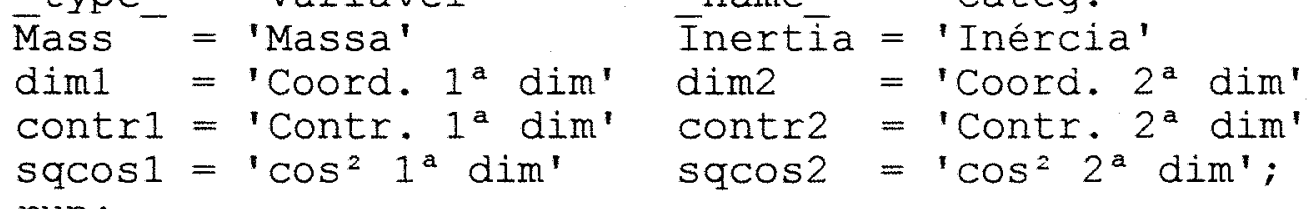

run;

PROC PRINT data = saida label;

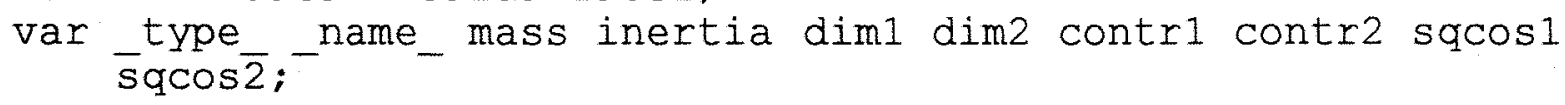

/* Criando o Arquivo Annotate para o GPLOT */

DATA saida;

Length style \$8; 


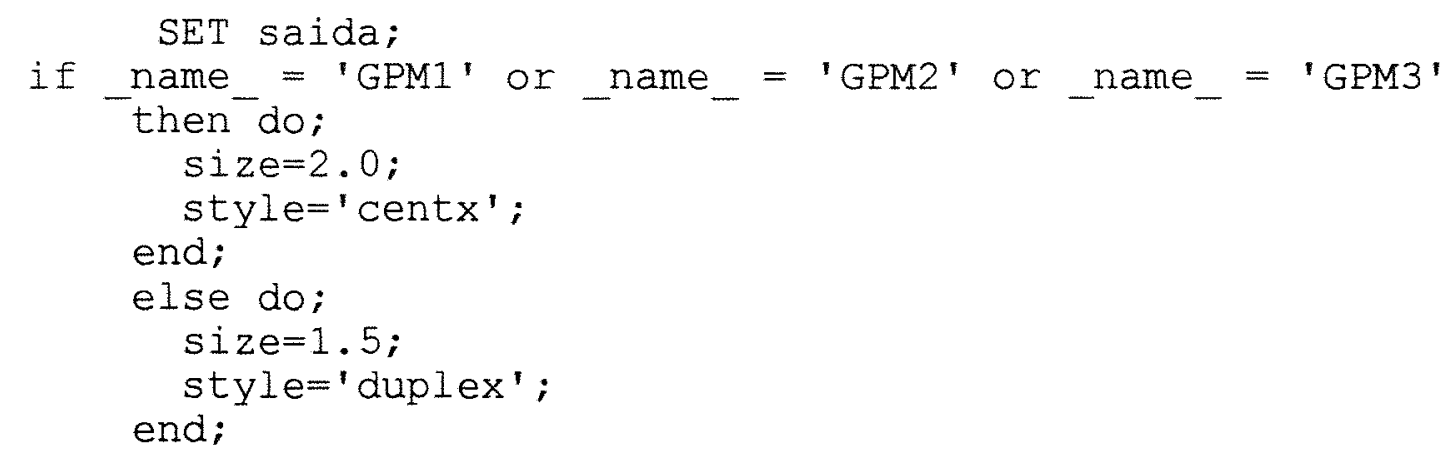

$\mathrm{X}=\mathrm{DIM} 1$

$Y=D I M 2$;

$\mathrm{XSYS}=12$ ';

YSYS $=12 '$;

$\mathrm{TEXT}=$ NAME_; $\quad /$ texto que irá posicionado no lugar do ponto $\bar{\star} /$

KEEP X Y TEXT XSYS YSYS SIZE STYLE;

GOPTIONS DEVICE = egal hsize=18 $\mathrm{cm}$ vsize=12 $\mathrm{cm}$;

axis $1 \mathrm{~V}=(\mathrm{f}=$ centx $\mathrm{h}=.2 \mathrm{~cm})$ label=(f=centx $\mathrm{h}=1.5$. cells 'DIMI (95\%)')

order $=(-0.5$ to 0.4 by 0.1$) ; /$ horizontal * $/$

axis2 $\mathrm{v}=(\mathrm{f}=$ centx $\mathrm{h}=.2 \mathrm{~cm})$ label=( $\mathrm{f}=$ centx $\mathrm{h}=1.5$ cells 'DIM2 $\left.(5 \%)^{\prime}\right)$

$$
\text { order }=(-0.2 \text { to } 0.2 \text { by } 0.1) ; / \text { vertical */ }
$$

/* Resultado gráfico da análise de correspondência */

PROC GPLOT data=saida;

title $4 \mathrm{~h}=.3 \mathrm{~cm}$ 'Mapa dos Eatores de Risco'; symbol1: $\mathrm{v}=$ none;

PLOT $Y * X=1 /$ annotate $=$ saida frame $V R E F=0$ HREF $=0$

RUN ; 